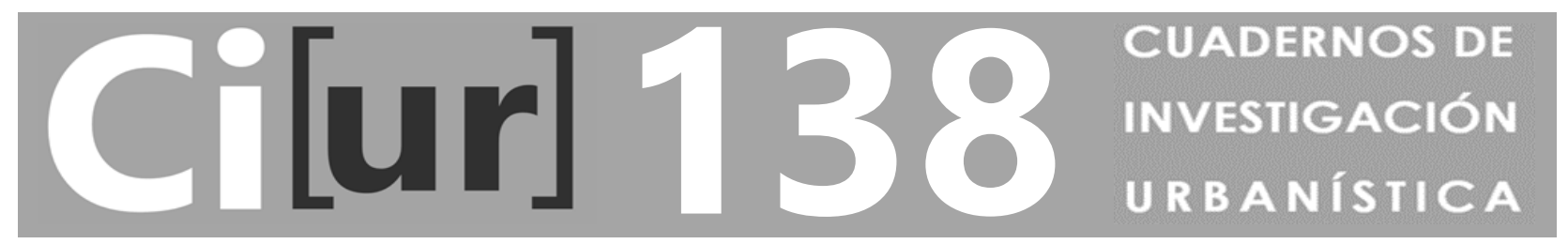

\title{
PLANEAMIENTO URBANÍSTICO DURANTE LA BURBUJA Y LA POSTERIOR RESACA INMOBILIARIA: DE LOS EXCESOS DEL NEODESARROLLISMO A LAS DIFICULTADES DE UN URBANISMO CORRECTOR. EL CASO DEL ÁREA URBANA DE LEÓN
}

EDUARDO DE SANTIAGO RODRÍGUEZ Doctor Arquitecto

ISABEL GONZÁLEZ GARCÍA

Doctora Arquitecta

septiembre / octubre 2021 


\begin{tabular}{|c|c|}
\hline Directores: & José Fariña Tojo - Ester Higueras García \\
\hline Editora: & María Cristina García González \\
\hline \multicolumn{2}{|c|}{ Consejo de Redacción: } \\
\hline Directora: & María Emilia Román López \\
\hline Comisión ejecutiva: & $\begin{array}{l}\text { Agustín Hernández Aja, José Antonio Corraliza Rodríguez, María Cristina García González, } \\
\text { María Emilia Román López, Eva Álvarez de Andrés. }\end{array}$ \\
\hline Vocales: & $\begin{array}{l}\text { Isabel Aguirre de Urcola (Escola Galega da Paisaxe Juana de Vega, A Coruña), Pilar Chías } \\
\text { Navarro (Univ. Alcalá de Henares, Madrid), José Antonio Corraliza Rodríguez (Univ. } \\
\text { Autónoma de Madrid), Alberto Cuchí Burgos (Univ. Politécnica de Cataluña), José Fariña Tojo } \\
\text { (Univ. Politécnica de Madrid), Agustín Hernández Aja (Univ. Politécnica de Madrid), Francisco } \\
\text { Lamíquiz Daudén (Univ. Politécnica de Madrid), María Asunción Leboreiro Amaro (Univ. } \\
\text { Politécnica de Madrid), Rafael Mata Olmo (Univ. Autónoma de Madrid), Luis Andrés Orive } \\
\text { (Centro de Estudios Ambientales, Vitoria-Gasteiz), Javier Ruiz Sánchez (Univ. Politécnica de } \\
\text { Madrid), Carlos Manuel Valdés (Univ. Carlos III de Madrid) }\end{array}$ \\
\hline Consejo Asesor: & $\begin{array}{l}\text { José Manuel Atienza Riera (Vicerrector de Estrategia Académica e Internacionalización, Univ. } \\
\text { Politécnica de Madrid), Manuel Blanco Lage (Director de la Escuela Superior de Arquitectura, } \\
\text { Univ. Politécnica de Madrid), José Miguel Fernández Güell (Director del Departamento de } \\
\text { Urbanística y Ordenación del Territorio, Univ. Politécnica de Madrid), Antonio Elizalde Hevia, } \\
\text { Julio García Lanza, Josefina Gómez de Mendoza, José Manuel Naredo, Julián Salas Serrano, } \\
\text { Fernando de Terán Troyano, María Ángeles Querol. }\end{array}$ \\
\hline Comité Científico: & $\begin{array}{l}\text { Antonio Acierno (Univ. Federico II di Napoli, Nápoles, ITALIA), Miguel Ángel Barreto (Univ. } \\
\text { Nacional del Nordeste, Resistencia, ARGENTINA), José Luis Carrillo (Univ. Veracruzana, } \\
\text { Xalapa, MÉXICO), Luz Alicia Cárdenas Jirón (Univ. de Chile, Santiago de Chile, CHILE), Marta } \\
\text { Casares (Univ. Nacional de Tucumán, Tucumán, ARGENTINA), María Castrillo (Univ. de } \\
\text { Valladolid, ESPAÑA), Dania Chavarría (Univ. de Costa Rica, COSTA RICA), Mercedes Ferrer } \\
\text { (Univ. del Zulia, Maracaibo, VENEZUELA), Fernando Gaja (Univ. Politécnica de Valencia, } \\
\text { ESPAÑA), Alberto Gurovich (Univ. de Chile, Santiago de Chile, CHILE), Josué Llanque (Univ. } \\
\text { Nacional de S. Agustín, Arequipa, PERÚ), Angelo Mazza (Univ. degli Studi di Napoli, Nápoles, } \\
\text { ITALIA), Luis Moya (Univ. Politécnica de Madrid, ESPAÑA), Joan Olmos (Univ. Politécnica de } \\
\text { Valencia, ESPAÑA), Ignazia Pinzello (Univ. degli Studi di Palermo, Palermo, ITALIA), Julio } \\
\text { Pozueta (Univ. Politécnica de Madrid, ESPAÑA), Alfonso Rivas (Univ. A. Metropolitana } \\
\text { Azcapotzalco, Ciudad de México, MÉXICO), Silvia Rossi (Univ. Nacional de Tucumán, } \\
\text { ARGENTINA), Adalberto da Silva (Univ. Estadual Paulista, Sao Paulo, BRASIL), Carlos } \\
\text { Soberanis (Univ. Francisco Marroquín, Guatemala, GUATEMALA), Carlos A. Torres (Univ. } \\
\text { Nacional de Colombia, Bogotá, COLOMBIA), Graziella Trovato (Univ. Politécnica de Madrid, } \\
\text { ESPAÑA), Carlos F. Valverde (Univ. Iberoamericana de Puebla, MÉXICO), Fernando N. } \\
\text { Winfield (Univ. Veracruzana, Xalapa, MÉXICO), Ana Zazo (Univ. del Bio-Bio, Concepción, } \\
\text { CHILE) }\end{array}$ \\
\hline
\end{tabular}

Realización y maquetación:

Maquetación: ciur.urbanismo.arquitectura@upm.es

\section{(C) COPYRIGHT 2021}

\section{EDUARDO DE SANTIAGO RODRÍGUEZ}

\section{ISABEL GONZÁLEZ GARCÍA}

Fecha de recepción: 28/06/2021

Fecha de aceptación: 15/09/2021

I.S.S.N. (edición digital): 2174-5099

DOI: $10.20868 /$ ciur.2021.138.4730

Año XIII, Núm. 138, septiembre-octubre 2021, 102 págs.

Edita: Instituto Juan de Herrera 


\section{Planeamiento urbanístico durante la burbuja y la posterior resaca inmobiliaria: de los excesos del neodesarrollismo a las dificultades de un urbanismo corrector. El caso del área urbana de León Urban planning during the Spanish housing bubble and after its outbrake: the difficulties of a corrective urbanism. Leon city urban area as a case-study}

DOI: $10.20868 /$ ciur.2021.138.4730

\section{DESCRIPTORES:}

Planeamiento urbanístico / Burbuja inmobiliaria / León / Desclasificación de suelo.

\section{KEY WORDS:}

Urban Planning / Housing bubble / León / Land Declassification.

\section{RESUMEN:}

En este artículo se presenta el planeamiento urbanístico del área urbana de León como ejemplo paradigmático del enfoque neodesarrollista que fue característico del pasado boom inmobiliario español, combinando liberalización del suelo y apuesta por el crecimiento residencial como motor económico. Se analizan también sus efectos territoriales, en particular el exceso y la sobredimensión del suelo clasificado, y la situación urbanística una vez producido el estallido de la burbuja. Para ello, el trabajo examina en detalle los planes vigentes en varios municipios (León, San Andrés, Villaquilambre, Garrafe, Villaturiel), tanto desde el punto de vista cualitativo como cuantitativo. Se repasan también los escasos instrumentos existentes en la actualidad para la reconducción y corrección de estos efectos negativos, destacando como conclusión la necesidad de diseñar herramientas específicas, de activar la ordenación del territorio a escala supramunicipal y de repensar el planeamiento a escala municipal.

\section{ABSTRACT:}

This article presents the urban planning of the urban area of León as a paradigmatic example of the expansive approach characteristic of the recent Spanish housing bubble. Its territorial effects are also analysed, in particular the excess and oversize of land classification, and the situation after the bubble outbreak. For this, the paper examines the plans in various municipalities, both from a qualitative and quantitative point of view. The few instruments currently in existence for the correction of these negative effects are also reviewed, highlighting as a conclusion the need to design specific tools, and to activate spatial planning at the supramunicipal scale and to rethink planning at the municipal level. 
* Eduardo de Santiago Rodríguez es Arquitecto por la Escuela Técnica Superior de Arquitectura de Madrid, y Doctor Arquitecto con premio extraordinario por la Universidad Politécnica de Madrid. edesantiago@fomento.es

ORCID: https://orcid.org/0000-0002-1867-7867 (Eduardo de Santiago Rodríguez)

** Isabel González García es Arquitecta por la Escuela Técnica Superior de Arquitectura de Madrid, y Doctora Arquitecta por la Universidad Politécnica de Madrid. Profesora Contratada Doctora en la ETSAM, Universidad Politécnica de Madrid. isabel.gonzalez@upm.es

ORCID: https://orcid.org/0000-0002-6790-0252 (Isabel González García)

CONSULTA DE NÚMEROS ANTERIORES/ACCESS TO PREVIOUS WORKS:

La presente publicación se puede consultar en formato pdf en la dirección:

This document is available in pdf format in the following web page:

https: / / duyot.aq.upm.es/publicaciones 


\section{ÍNDICE}

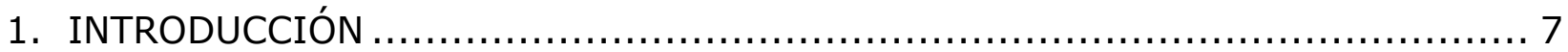

1.1. Antecedentes: el urbanismo de la burbuja y la posterior resaca inmobiliaria en

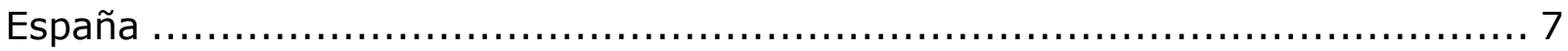

1.2. Ámbito de estudio y metodología. .......................................... 9

1.3. Breves pinceladas sobre los procesos y dinámicas poblacionales en el área urbana de León..........................................................................

2. EL CONTEXTO DE LAS DINÁMICAS INMOBILIARIAS RECIENTES: DEL BOOM AL ESTALLIDO DE LA BURBUJA EN EL ÁREA URBANA DE LEÓN. .........................15

3. LA LIBERALIZACIÓN DEL SUELO EN LA LEGISLACIÓN ESTATAL Y SU TRADUCCIÓN

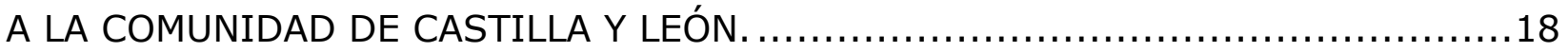

3.1. Los vericuetos de la liberalización del suelo en la legislación estatal. ..........18

3.2. La traducción de la liberalización del suelo en el marco normativo de Castilla y León 25

4. EL FRACASO DE LOS INSTRUMENTOS DE ORDENACIÓN TERRITORIAL EN EL ALFOZ LEONÉS. 27

5. EL MOSAICO DEL PLANEAMIENTO URBANÍSTICO MUNICIPAL EN EL ÁREA URBANA DE LEÓN: UN ANÁLISIS CUANTITATIVO. 34

5.1. El mosaico del planeamiento municipal: cuantificación de la desmesura en la clasificación de suelo. .34

5.2. Las piezas del puzle resultante: análisis detallado del suelo para el desarrollo urbano previsto por el planeamiento en el alfoz de León. 38

6. UNA LECTURA CUALITATIVA: LAS VARIADAS FACETAS DEL NEODESARROLLISMO EN EL PLANEAMIENTO MUNICIPAL DEL ÁREA URBANA DE LEÓN.

6.1. El Plan General del León como resultado del marco normativo neodesarrollista: el planeamiento "al límite de la capacidad" y el carácter residual del Suelo Urbanizable.

6.2. Los expansivos planes de San Andrés del Rabanedo y Villaquilambre como ejemplos de la idea del crecimiento "curativo".

6.3. Las modificaciones de planeamiento como mecanismo para la reclasificación de suelo: el caso de Villatoldanos en Villaturiel.

6.4. La supervivencia de un viejo proyecto del desarrollismo y su reconversión: el sector Venta de la Tuerta en Garrafe de Torío. 
7. EL PANORAMA DESPUÉS DE LA BATALLA: EL MERCADO INMOBILIARIO TRAS EL ESTALLIDO DE LA BURBUJA Y SU IMPACTO SOBRE EL TERRITORIO.

8. EL URBANISMO POSTERIOR A LA BURBUJA: DEL CAMBIO DE PARADIGMA AL

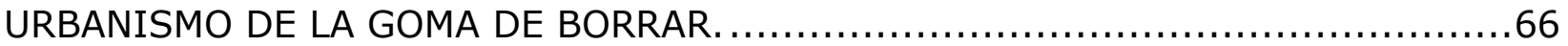

8.1. El cambio de paradigma urbanístico en la legislación estatal de suelo. ........66

8.2. Las novedades en la normativa urbanística de Castilla y León: el urbanismo de la "goma de borrar". 70

8.3. Las rondas autonómicas de desclasificación de Suelo Urbanizable de 2016 y 2018: sus efectos en el área urbana de León.... .72

9. ANÁLISIS DEL EXCESO DE SUELO CLASIFICADO PARA EL DESARROLLO URBANO EN EL ÁREA URBANA DE LEÓN Y ESTRATEGIAS A FUTURO PARA SU POSIBLE DIGESTIÓN: LAS DIFICULTADES DE UN URBANISMO CORRECTOR $\ldots \ldots \ldots \ldots \ldots \ldots . . . \ldots 79$

9.1. Una primera aproximación a la cuantificación del suelo sin desarrollar.... .79

9.2. Análisis del grado de consolidación de las piezas con más de 1.000 viviendas previstas: identificación de situaciones tipo.

9.3. Posibilidades de actuación en cada una de las situaciones identificadas: estrategias para un urbanismo corrector y reparador. .85

9.4. Conclusiones: las dificultades de un urbanismo corrector de los excesos de la burbuja inmobiliaria... .90

10. AGRADECIMIENTOS 94

11. BIBLIOGRAFIA 95 


\title{
1 INTRODUCCIÓN
}

\subsection{Antecedentes: el urbanismo de la burbuja y la posterior resaca inmobiliaria en España}

\author{
«Las realidades físicas creadas por el boom inmobiliario están aquí para \\ quedarse. Constituirán una herencia con la que nosotros y las generaciones \\ venideras deberemos inevitablemente lidiar durante largas décadas. Toda \\ pretensión de negar esta realidad, de desconocerla o erradicarla no puede ser \\ otra cosa que escapismo o quimera». (Nel.lo, 2012, p. 29)
}

Entre 1997 y 2007 tuvo lugar la que se ha conocido como la "década prodigiosa del urbanismo español" (Burriel, 2008), la versión nacional de una burbuja inmobiliaria que también se produjo en otros países desarrollados. La dimensión económica de esta burbuja en España ha sido analizada por numerosos autores (Naredo, 1998, 2006, 2011; García Montalvo, 2008), que han destacado entre sus causas una coyuntura internacional en la que gracias a la expansión del crédito se canalizó el ahorro familiar y la inversión - nacional e internacional- hacia el sector inmobiliario como mecanismo de capitalización, todo ello favorecido por la incorporación de nuestro país al euro, los bajos tipos de interés, una fiscalidad favorable a la adquisición de vivienda en propiedad y una reforma propicia del mercado hipotecario. Estos trabajos también han analizado los efectos de la resaca posterior al estallido de la burbuja, destacando no sólo el hundimiento del sector de la construcción, sino también el efecto de arrastre que tuvo la crisis hipotecaria sobre el sistema financiero español -induciendo su profunda reestructuración-, el impacto social de los desahucios, etc.

Además de los aspectos económicos y financieros, interesa destacar los enfoques que se han centrado en la dimensión territorial del ciclo inmobiliario, denominado de diferentes formas, como por ejemplo "tsunami urbanizador", "burbuja especulativa", "neodesarrollismo", "urbanismo expansivo", "urbanismo salvaje", "hipertrofia del planeamiento urbanístico", etc. En este sentido, cabe destacar la bulimia inmobiliaria como el resultado de la acción de unas dinámicas y unos agentes sobre el territorio ante el fracaso de la legislación, de la ordenación del territorio a escala supramunicipal, del planeamiento urbanístico, y de los mecanismos de regulación de los mercados de suelo y vivienda ( $y$, en particular, de la vivienda protegida).

También se han realizado numerosos estudios de caso que analizan las particularidades de la burbuja inmobiliaria, el planeamiento urbanístico y sus efectos territoriales en ámbitos espaciales concretos. Fundamentalmente estos trabajos se han centrado en los lugares donde la urbanización, la ocupación de suelo y la construcción de viviendas fueron más intensas: las grandes áreas metropolitanas españolas y el litoral mediterráneo. Son menos frecuentes los trabajos sobre las regiones del interior, donde, aparentemente, el boom no fue tan espectacular, concretamente sobre Castilla y León sólo se han realizado algunos análisis desde la perspectiva económica del boom, pero apenas hay trabajos sobre el impacto 
territorial o que propongan una lectura urbanística (García Argüello, 2016; Calderón y García Cuesta, 2017; Marinero, 2018).

En cuanto al enfoque, la mayoría de los estudios sobre el impacto de la burbuja suele centrarse en cuantificar de forma agregada la sobredimensión del suelo clasificado y la capacidad residual de viviendas en el planeamiento urbanístico o en la dimensión del stock de viviendas nuevas vacías ${ }^{1}$. Una primera novedad del enfoque que se presenta en este artículo es el análisis tanto en la escala agregada del ámbito de estudio, como a nivel municipal y de las piezas que componen el mosaico de planeamiento.

Además, este trabajo se centra en la disciplina urbanística, analizando los discursos e ideas que subyacen en los documentos de los planes, examinando el modo en que la ideología "neodesarrollista" imperante en los años de la burbuja permearon y se asumieron por los Ayuntamientos y los técnicos redactores de los documentos de planeamiento. Como veremos, en esta ideología confluyen aspectos característicos de la doctrina económica neoliberal (en especial, la insistencia en la necesidad de liberalizar el suelo $)^{2}$ de amplia difusión a nivel internacional durante estos años, con aspectos propiamente españoles (algunos heredados del franquismo) como la apuesta por el sector inmobiliario como elemento motor del crecimiento económico a nivel local, abriendo el juego a todo tipo de prácticas en el tablero de agentes implicados (políticos, promotores, propietarios de suelo).

Finalmente, más allá del enfoque descriptivo de los efectos territoriales del estallido de la burbuja, se intenta avanzar en un enfoque propositivo, teniendo en cuenta lo que en la línea teórica se han denominado "teorías del decrecimiento" Latouche (2008, 2009), que, en el plano urbanístico, han comenzado a desbrozar Fariña y Naredo (2010), Gaja (2015) o Górgolas (2019), con términos como "urbanismo reparador", "estrategias de decrecimiento" o "urbanismo regenerativo".

En última instancia, esta reflexión implica reconocer el fracaso de las lógicas del mercado por sí solo: en un contexto como el experimentado en el alfoz leonés durante el boom inmobiliario -en el que apenas existían restricciones para el desarrollo del suelo por parte de los promotores-, el mercado se ha mostrado incapaz de racionalizar u optimizar su desarrollo. Frente a la fe ciega en la liberalización del suelo, es manifiesta la existencia de fallos de mercado, market failures, que requieren mecanismos de intervención pública para su corrección: como veremos, uno de estos mecanismos debería ser un planeamiento supramunicipal capaz de programar y secuenciar las actuaciones, pero también algún nuevo instrumento para reconducir

\footnotetext{
${ }^{1}$ Al avanzar la crisis, además del enfoque sobre el impacto en el territorio (sobredimensión de suelo y viviendas), otros trabajos comenzaron a centrarse en los efectos directos de la crisis sobre las personas (desahucios, desposesión, etc).

${ }^{2}$ En este texto se utiliza "neoliberal" referido a esta conocida doctrina económica, y el término "liberalización del suelo" (que forma parte del ideario neoliberal) en lo referido al suelo. Este último es un término de uso común en los discursos políticos y además fue acuñado como tal en el Decreto 4/2020, que después se comenta. Sobre las importantes diferencias entre liberalismo y neoliberalismo, véase Jáuregui (1997) y sobre la perspectiva "neoliberal" en el urbanismo, Rullán (1998).
} 
territorialmente la demanda inmobiliaria y reajustar la ordenación urbanística existente.

\section{2 Ámbito de estudio y metodología}

El ámbito de estudio de este trabajo es el área urbana de León ${ }^{3}$. Se ha elegido la Comunidad de Castilla y León por dos motivos fundamentales: el primero, para completar el vacío en los estudios de caso a nivel nacional, en los que se echaba en falta el análisis del impacto de la burbuja en una ciudad media del interior, ajena a las dinámicas de las grandes áreas metropolitanas del país y del litoral mediterráneo, y, por tanto, fundamentalmente sometida a sus propias dinámicas internas. El segundo es que, dado nuestro interés en completar el enfoque descriptivo con el propositivo, Castilla y León ha sido la comunidad autónoma pionera en proponer un programa de desclasificación de suelo a nivel regional ${ }^{4}$, cuyos efectos pueden ser evaluados en un área urbana concreta. Finalmente, se ha elegido el área urbana particular de León por ser la segunda en población de esta región, y por haber tenido en ella especial intensidad los procesos de urbanización y edificación ligados a la burbuja inmobiliaria, de forma que esta provincia supone por sí misma nada menos que la cuarta parte del stock de vivienda sin vender en toda esta comunidad autónoma (MITMA, 2020).

El caso cuenta también con interesantes antecedentes de estudios relacionados, entre los que destacan los trabajos de Reguera Fernández (1987 a, b y c), López Trigal y Relea Fernández (2010) y, especialmente la Tesis doctoral de García Argüello (2016), dedicada a la evolución de la planificación urbanística en los municipios del área urbana de León.

El ámbito de estudio ${ }^{5}$ concreto está compuesto por León capital y los municipios limítrofes de San Andrés del Rabanedo, Sariegos, Villaquilambre, Valdefresno, Villaturiel, Onzonilla, Santovenia de la Valdoncina y Valverde de la Virgen, que forman lo que se denomina propiamente el "área urbana" (MITMA, 2020b); a los que se han añadido 6 los municipios de Cuadros, Chozas de Abajo, Garrafe de Torío, Villaturiel y Villadangos del Páramo, situados en una segunda corona (que denominamos "área ampliada"), pero que también han experimentado, como veremos, intensos procesos

\footnotetext{
${ }^{3}$ Se emplea el concepto de "área urbana" del Atlas Digital de las Áreas Urbanas, del Ministerio de Fomento (2020b), del cual también se parte para una primera aproximación a su delimitación, matizada más adelante (véase la nota 6).

4 Otras Comunidades han optado por poner nuevos instrumentos para la desclasificación en manos de los Ayuntamientos: es el caso de Baleares (Ley 12/2017) o de Castilla La Mancha y la Comunitat Valenciana, que han introducido el procedimiento de reparcelación inversa (Decreto 86/2018 y Ley 1/2019, respectivamente).

${ }^{5}$ A lo largo del texto, a veces se usa de forma genérica el término "alfoz" para referirse al ámbito de estudio. Es un término de uso muy arraigado en la zona, pero de definición espacial imprecisa. El alfoz de León surgió en el año 1017, cuando el rey Alfonso $\mathrm{V}$ otorgó a la ciudad de León su Fuero propio, definiéndose como los territorios que dependían fiscal y judicialmente del Rey de forma directa.

${ }^{6}$ Para la definición del ámbito se ha partido de las oficiales del Área Funcional Estable y de la Mancomunidad de Interés General Urbana de León y su Alfoz (Véase apartado 9.3), de las que se han seleccionado los municipios limítrofes con la capital y, una segunda corona con los de dinámicas inmobiliarias más activas. No se han tomado directamente los del Área Funcional Estable (AFE) de León porque no todos ellos han experimentado estas dinámicas.
} 
de clasificación de suelo y/o urbanización durante el período de la burbuja inmobiliaria.

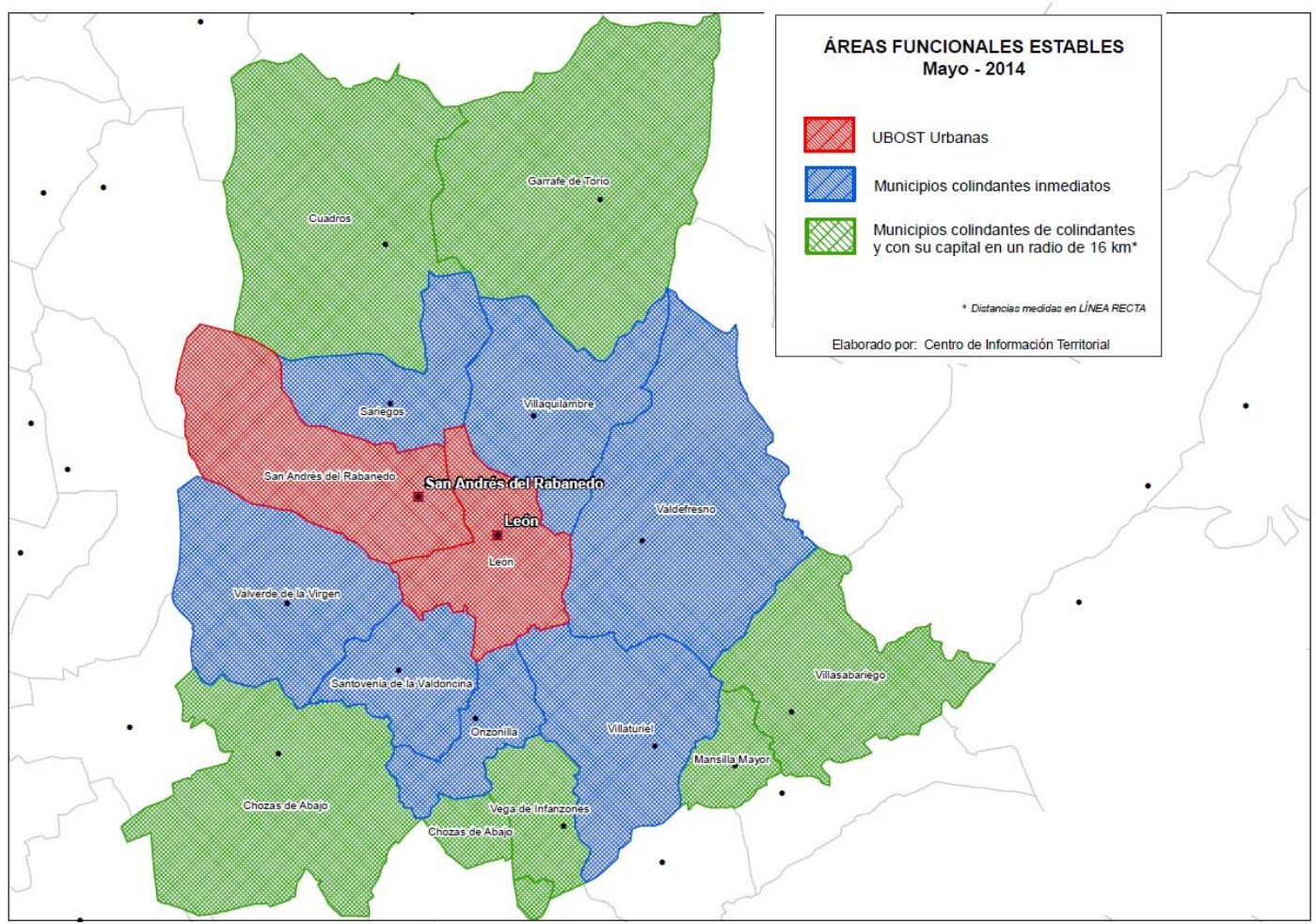

Figura 1. Delimitación del Área Funcional Estable (AFE) de León (2014).

Fuente: Centro de Información Territorial de Castilla y León.

Este trabajo se organiza en dos grandes bloques: en el primero se analiza el período del boom inmobiliario, y en el segundo, los años transcurridos desde el estallido de la burbuja hasta la actualidad.

En la primera parte, se comienzan contextualizando las dinámicas del boom en el área urbana de León, mediante el clásico análisis de las series estadísticas del precio y del volumen de viviendas terminadas, del Ministerio de Transportes, Movilidad y Agenda Urbana (en adelante, MITMA). A continuación, se examina la influencia de una serie de aspectos relacionados con el urbanismo que han actuado como catalizadores de la burbuja: la liberalización del suelo (a través del análisis de la legislación estatal y su traducción a la Comunidad de Castilla y León), el fracaso de los instrumentos de ordenación territorial en el alfoz leonés, y, finalmente, el mosaico del planeamiento urbanístico municipal en el área urbana de León. Este punto se aborda primero desde un análisis cuantitativo, basándose en los datos del Sistema de Información Urbana del MITMA contrastados con los documentos de planeamiento municipal accesibles en el Archivo de Planeamiento de Castilla y León, en el que se cuantifica la desmesura de la clasificación de suelo de forma agregada y después se detallan las principales características de las piezas previstas. Posteriormente, se realiza una lectura cualitativa de los documentos de planeamiento, identificando los 
discursos y objetivos propuestos sobre los casos de León, San Andrés, Villaquilambre, Villaturiel y Garrafe.

En la segunda parte del trabajo, se examina la situación desde el estallido de la burbuja hasta la fecha de redacción de este texto (principios de 2021), comenzando por las principales cifras descriptivas de la crisis (desplome de los precios y las viviendas construidas, stock de vivienda sin vender, etc.) para pasar después al análisis detallado del suelo clasificado y urbanizado sin desarrollar en el área urbana de León. Para esta tarea se trabaja partiendo de los datos del Sistema de Información Urbana (SIU) y del Estudio de Sectores Residenciales en España del MITMA (2014), igualmente contrastados con los documentos de planeamiento municipal.

Por último, se concluye con la revisión de las propuestas urbanísticas que se han hecho tanto a nivel estatal (repasando la evolución de la legislación sobre suelo y Catastro, y la jurisprudencia) como en la normativa autonómica de Castilla y León, en la que destaca la propuesta de desclasificación de los suelos urbanizables que no hayan aprobado su correspondiente planeamiento de desarrollo en unos determinados plazos, partiendo de los datos de la propia Junta y del trabajo previo de Marinero (2018). Más allá de este "urbanismo de la goma de borrar", se termina con una reflexión sobre las dificultades de un urbanismo corrector de los excesos de la burbuja inmobiliaria con un enfoque más amplio.

\subsection{Breves pinceladas sobre los procesos y dinámicas poblacionales en el área urbana de León}

En este apartado se presentan unas pinceladas sobre los procesos urbanos y dinámicas poblacionales en el ámbito de estudio, con el objeto de introducirlo ante el lector no familiarizado con el área urbana de León. Para un análisis más detallado nos remitimos a los trabajos clásicos de Reguera (1987), González González (2000) 0 García Argüello (2016).

Durante la primera mitad del siglo $X X$, la ciudad de León experimentó un importante crecimiento demográfico, impulsada por la llegada del ferrocarril y su papel como de nudo de comunicaciones en el noroeste peninsular, así como por la industria y las actividades mineras del carbón en la provincia. De este modo, pasó de 17.022 habitantes en 1900 a 59.403 en 1950. Su expansión se produjo primero en el casco histórico y el ensanche burgués de principios de siglo, para saltar al exterior en los años 50, cuando se levantaron los barrios obreros periféricos de San Esteban, San Mamés y Las Ventas, y de El Crucero-Pinilla y La Vega de la Sal, junto al ferrocarril (González González, 2000).

Dada la pequeña extensión del término leonés, posteriormente el crecimiento se desbordó hacia los municipios limítrofes, aprovechando como directrices de crecimiento las carreteras y caminos existentes, así como los numerosos núcleos rurales de los municipios del alfoz. Este crecimiento llevó a la anexión del municipio de la Armunia en 1970. También en esta década comenzaron a promoverse las primeras urbanizaciones residenciales de tipo suburbano, en localizaciones aisladas, o a levantarse viviendas unifamiliares generando -por acumulación- tejidos dispersos de baja densidad. Entre las primeras urbanizaciones cabe destacar El Montico en 
Sariegos, La Atalaya en San Andrés, El Caminón en Villaquilambre, Janodembra en Valverde o Las Lomas en Valdefresno. Todos estos procesos de relocalización de la población y dispersión residencial coincidieron con la crisis de las estructuras productivas agrarias tradicionales, de forma que el desarrollo urbanístico comenzó a ser la alternativa más rentable para los propietarios del suelo ${ }^{7}$.

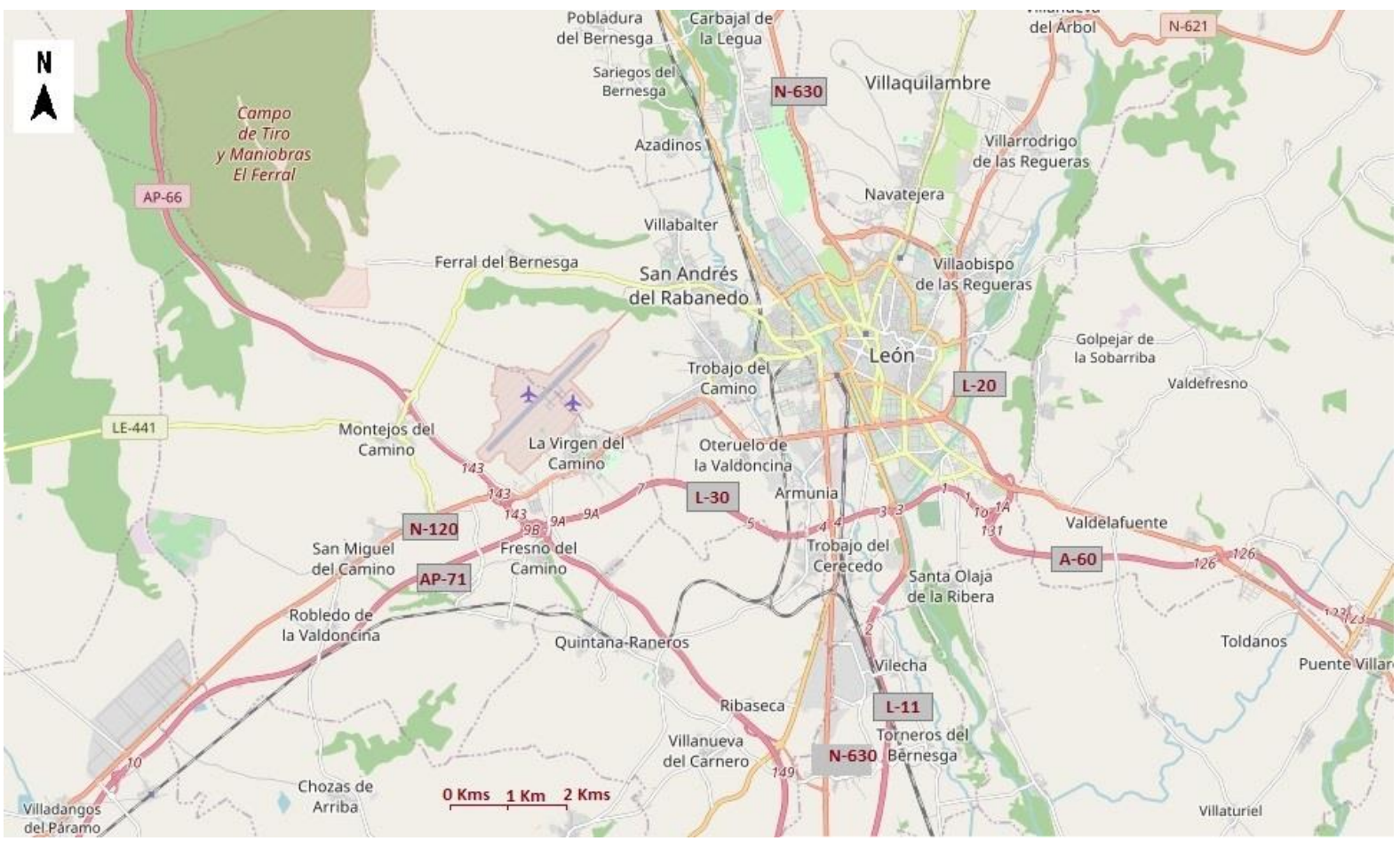

Figura 2. Mapa de la parte central del Área Urbana de León.

Fuente: Elaboración propia sobre OpenMaps.

Sobre este tablero de dinámicas micro-metropolitanas incipientes va a tener lugar en los años 90 y primeros 2000 un proceso de intensa urbanización ligado al boom inmobiliario, muy condicionado por dos nuevos factores: por un lado, la reorganización de la movilidad en el área urbana de León, gracias a la construcción de una serie de infraestructuras viarias de alta capacidad, entre ellas el anillo de circunvalación exterior L-20 (incompleto, por el noroeste), la L-30, A-60, AP-71, etc. que han mejorado notablemente las accesibilidad de determinados municipios del alfoz, despertando las expectativas de su desarrollo urbanístico.

Por otro, la reorganización de la centralidad, y la descentralización del comercio y determinados servicios por el área urbana. Los primeros formatos comerciales innovadores se implantaron en León en los años 90 y fueron El Corte Inglés, como

\footnotetext{
${ }^{7}$ Como recogen las Directrices de Ordenación del Área Urbana de León (2008, p. 159-160): "El proceso de abandono del terrazgo agrícola durante toda la segunda mitad del siglo XX en la periferia de León (L. López Trigal, Dir., 1996) ha dejado tras sí extensas zonas de erial y de "barbecho social" (terrenos de anterior uso agrario a la espera de una reutilización derivada del crecimiento periférico de la ciudad), hasta el punto que en los páramos e interfluvios la dominante es el espacio no cultivado que se transforma en erial con el paso del tiempo y en el territorio del alfoz interior viene a ser cada vez más extenso el tipo de barbecho social con vocación de "solar"."
} 
Gran Almacén, ubicado en el barrio de La Chantría (al sur del casco), y el hipermercado Carrefour, junto al nudo de la N-630 con la L-20. Posteriormente se construirían el Centro Comercial Espacio León (en San Andrés, junto al río) con 37.000 $\mathrm{m}^{2}$ y 110 locales, y el Centro Comercial León Plaza, en el nuevo barrio de Eras de Renueva (al norte de San Marcos), con $40.000 \mathrm{~m}^{2}$ (18.000 $\mathrm{m}^{2}$ de locales) y 70 tiendas. En la actualidad se está construyendo el Centro Comercial Reino de León, junto a la LE-20, con la tipología de Parque de Grandes Superficies (Decathlon, Leroy Merlin, Conforama, etc.). En la tabla adjunta se presentan las cifras de las dinámicas demográficas e inmobiliarias recientes desde 1991 hasta la actualidad, que se comentan a continuación:

\begin{tabular}{|c|c|c|c|c|c|c|c|}
\hline MUNICIPIO/ÁREA & $\begin{array}{c}2019 \\
\text { Población }\end{array}$ & $\begin{array}{c}2011 \\
\text { Población }\end{array}$ & $\begin{array}{c}2001 \\
\text { Población }\end{array}$ & $\begin{array}{c}1991 \\
\text { Población }\end{array}$ & $\begin{array}{c}2011 \\
\text { Viviendas } \\
\text { totales }\end{array}$ & $\begin{array}{c}2001 \\
\text { Viviendas } \\
\text { totales }\end{array}$ & \begin{tabular}{|c|}
1991 \\
Viviendas \\
totales
\end{tabular} \\
\hline TOTAL León & 124.303 & 131.411 & 130.916 & 144.021 & 78.725 & 66.362 & 54.325 \\
\hline 24105 Onzonilla & 1.835 & 1.749 & 1.508 & 1.402 & 1.030 & 609 & 697 \\
\hline 24142 San Andrés del Rabanedo & 30.615 & 31.675 & 26.054 & 20.504 & 17.545 & 12.241 & 8.510 \\
\hline 24162 Santovenia de la Valdoncina & 2.126 & 1.975 & 1.706 & 1.312 & 1.050 & 679 & 653 \\
\hline 24163 Sariegos & 5.050 & 4.658 & 3.011 & 1.688 & 2.320 & 1.533 & 795 \\
\hline 24175 Valdefresno & 2.187 & 2.037 & 1.854 & 1.558 & 1.505 & 1.203 & 989 \\
\hline 24189 Valverde de la Virgen & 7.328 & 7.021 & 4.400 & 3.559 & 4.285 & 2.319 & 1.717 \\
\hline 24222 Villaquilambre & 18.638 & 18.054 & 9.772 & 5.298 & 10.585 & 5.829 & 2.690 \\
\hline TOTAL Área Urbana & 67.779 & 67.169 & 48.305 & 35.321 & 38.320 & 24.413 & 16.051 \\
\hline 24061 Cuadros & 2.001 & 1.999 & 1.730 & 1.680 & 1.465 & 1.296 & 1.045 \\
\hline 24065 Chozas de Abajo & 2.581 & 2.411 & 2.189 & 2.258 & 1.850 & 996 & 1.200 \\
\hline 24076 Garrafe de Torío & 1.504 & 1.354 & 1.188 & 1.107 & 1.060 & 1.109 & 881 \\
\hline 24205 Villadangos del Páramo & 1.132 & 1.123 & 1.017 & 1.029 & 735 & 599 & 692 \\
\hline 24227 Villaturiel & 1.852 & 1.955 & 1.797 & 1.770 & 1.210 & 955 & 820 \\
\hline TOTAL Área Ampliada & 9.070 & 8.842 & 7.921 & 7.844 & 6.320 & 4.955 & 4.638 \\
\hline TOTAL Área Urbana +Ampliada & 76.849 & 76.011 & 56.226 & 43.165 & 44.640 & 29.368 & 20.689 \\
\hline TOTAL León+Area Urbana+Ampliada & 201.152 & 207.422 & 187.142 & 187.186 & 123.365 & 95.730 & 75.014 \\
\hline TOTAL Municipios provincia menores de 2.000 habitantes & 88.935 & 101.286 & 118.169 & 145.666 & 90.805 & 84.997 & 86.042 \\
\hline TOTAL Municipios provincia mayores de 2.000 habitantes & 89.429 & 99.712 & 106.650 & 118.559 & 64.550 & 56.682 & 54.849 \\
\hline TOTAL Área Urbana de Ponferrada & 80.485 & 84.890 & 76.790 & 74.485 & 46.370 & 38.248 & 32.065 \\
\hline TOTAL Provincia de León & 460.001 & 493.310 & 488.751 & 525.896 & 325.090 & 275.657 & 247.970 \\
\hline
\end{tabular}

Figura 3. Cuadro resumen de las dinámicas demográficas (1991-2019) y de vivienda (1991-2011). Fuente: Elaboración propia a partir de Padrón (2019) y Censos (1991, 2001 y 2011) del INE.

A la vista de la tabla, lo primero que cabe destacar son dos procesos de reajuste demográfico - a escala nacional y provincial- que son muy importantes, pero que exceden el enfoque de este artículo: en el contexto nacional, la provincia de León viene perdiendo peso relativo y población (-65.895 habitantes, un 12,5\%) entre 1991 y 2019, lo que es indicativo de una situación de estancamiento económico que se enmarca en un contexto mucho más amplio (crisis de la España interior, frente al dinamismo de Madrid y la costa mediterránea, etc.). Además, este saldo negativo esconde también una reorganización interna de la población -y, en paralelo, en un proceso de influencias cruzadas, del empleo y los servicios- a nivel provincial: las áreas urbanas de León y Ponferrada ganan población, frente a la pérdida del resto de los municipios, sobre todo de los menores de 2.000 habitantes, donde el descenso demográfico desde 1991 alcanza casi el 40\%.

En cuanto al ritmo temporal, se observa cómo el declive ha sido constante en las décadas 1991-2001 y 2011-2019 y sólo ha habido un pequeño saldo positivo en las 
áreas urbanas (pues en el resto de los municipios rurales ha continuado el saldo negativo) durante década 2001-2011, coincidente con la etapa de mayor crecimiento económico, el boom inmobiliario, y la llegada de población inmigrante.

En cuanto al área urbana de León (incluyendo a la capital), la población total se mantuvo prácticamente estable entre 1991 y 2001, creció algo más del 10\% entre 2001 y 2011 y ha decrecido de nuevo entre 2011 y 2019. En la primera de estas tres etapas, el saldo final estable fue el resultado de la pérdida de población de la capital (-13.105 habitantes), frente a un incremento demográfico casi paralelo en los municipios del área urbana, sobre todo en San Andrés y Villaquilambre, los dos más próximos a León y donde primero comenzó a extenderse la ciudad al desbordar el estricto término municipal (barrio de Pinilla y núcleos de Trobajo, Villaobispo y Navatejera). En la segunda etapa 2001-2011, coincidente con la época de mayor bonanza económica, el crecimiento demográfico (con un total de +20.280 habitantes) fue generalizado en todos los municipios del área urbana, incluso en la capital, aunque nuevamente el $93 \%$ del mismo se concentró fuera de ésta. Finalmente, en la etapa más reciente hasta 2019, León y San Andrés - los municipios más maduros- han perdido población mientras el resto la ha seguido ganando, aunque a menor velocidad.

Estas dinámicas demográficas son características de los procesos de tipo micro metropolitano clásico ${ }^{8}$, en los que se produce un desbordamiento o descentralización desde la ciudad central hacia el resto de núcleos, de acuerdo con los condicionantes de la estructura territorial existente (medio físico, calidad ambiental, dotación de infraestructuras, etc.). Se caracterizan por vaciamiento progresivo del centro urbano y un desplazamiento de los nuevos hogares (en particular, los formados por emancipación de jóvenes y familias) hacia los núcleos periféricos, atraídos por una mayor oferta de vivienda a precios competitivos y una calidad de vida más acorde con sus expectativas (vivienda unifamiliar, baja densidad, etc.). En el caso del área urbana de León, esta estructura ha dado lugar a una especialización territorial en la que la descentralización residencial y el crecimiento demográfico se dirige fundamentalmente hacia San Andrés y Villaquilambre, seguidos de Sariegos y Valverde ${ }^{9}$, mientras que las pautas de localización industrial se dirigen hacia Onzonilla y Trobajo del Camino (en el término municipal de San Andrés). De este modo, el peso poblacional de la capital frente al resto del área urbana ha bajado del $76,9 \%$ al $61,8 \%$ entre 1991 y 2019.

Estos procesos de descentralización coexisten con unas dinámicas de declive urbano, que -en palabras de S. Tomé, 2019- convierten a León en el más claro ejemplo nacional de shrinking city. Como el autor señala ello es consecuencia de un círculo vicioso retroalimentado por diversos factores: el envejecimiento (segunda

\footnotetext{
${ }^{8}$ Entendiendo por tales las dinámicas de interrelación y dependencia entre una ciudad central y otros núcleos satélite, entre los cuales se va conformando una red de relaciones funcionales (mercado laboral y de servicios integrado, redes de transporte público compartidas, mercado inmobiliario relacionado, etc.).

9 Entre 1991 y 2019, los municipios del área urbana de León incrementaron su población en 32.458 habitantes, de los cuales 13.340 correspondieron a San Andrés, 10.111 a Villaquilambre, 3.769 a Sariegos y 3.362 a Valverde. El resto no superó incrementos mayores de 1.000 habitantes. La capital perdió 19.718 vecinos.
} 
ciudad española - tras Ferrol- más envejecida, con una edad media de 49 años), la tasa de actividad (la más baja de las capitales, con un 50,8\%), el cierre de numerosas actividades económicas (por ejemplo: la minería en la provincia, o el recorte de la plantilla de la emblemática empresa de Antibióticos de León desde los 1.472 empleos de 2009 a 240), la desidia administrativa, la escasa movilización social, etc.

Frente al declive demográfico y económico, el parque residencial ha tenido un incremento notable, fiel reflejo del reciente boom inmobiliario: en el área urbana de León, el parque creció 48.351 viviendas entre 1991 y 2011, cuando la población sólo tuvo un incremento de 20.236 habitantes; y, de forma aún más significativa, en la provincia, el número de viviendas se incrementó en 77.120 unidades, a pesar de la reducción de la población en 28.750 personas. En este caso, las viviendas se repartieron casi a partes iguales entre la capital (+24.400 nuevas viviendas) y los municipios del área urbana (+22.269), apreciándose también un cierto crecimiento en algunos pequeños municipios exteriores del área urbana ampliada.

\section{EL CONTEXTO DE LAS DINÁMICAS INMOBILIARIAS RECIENTES: DEL BOOM AL ESTALLIDO DE LA BURBUJA EN EL ÁREA URBANA DE LEÓN}

La evolución del precio unitario de la vivienda en la ciudad de León que puede verse en el gráfico adjunto muestra su paralelismo con el ciclo inmobiliario a nivel nacional: un crecimiento en la parte alcista del ciclo hasta los máximos absolutos alcanzados en torno a 2007-2008, para después descender casi un 40\% (del entorno de los 1.800 $€ / \mathrm{m}^{2}$ en 2007 al de los $1.100 € / \mathrm{m}^{2}$ en 2017) y volver a subir ligeramente desde entonces hasta el inicio de la pandemia en 2020. Por su parte, y como ilustración de la evolución del precio en el área urbana puede tomarse el caso de San Andrés del Rabanedo, que resulta sensiblemente paralelo al de la capital (así como también a Ponferrada, el otro municipio leonés del cual existen datos), si bien a una conveniente distancia (el rango de precios es 1,3 veces más caro en la capital) que es indicativa del diferente espectro social al que se dirige el mercado inmobiliario en el área urbana. En efecto, esta diferencia de precios explica el alimento de la demanda de vivienda en los municipios del alfoz leonés, donde por un precio total equivalente al de la capital pueden conseguirse viviendas de mayor superficie y/o determinados productos inmobiliarios como viviendas unifamiliares inexistentes o más escasos en la capital, o simplemente, a igualdad de superficie y producto, precios más baratos.

Además de la subida de los precios, el otro componente que permite describir el boom inmobiliario es el notable incremento de la producción de viviendas. En efecto, como puede verse en la imagen adjunta, y a falta de datos más desagregados territorialmente ${ }^{10}$, el volumen de viviendas terminadas en la provincia de León pasó del entorno de las 2.000 unidades en la primera mitad de los años 90 a superar las

\footnotetext{
${ }^{10}$ Los datos de transacciones de vivienda nueva sí están disponibles para cada uno de los municipios del área urbana de León -pueden verse más adelante en la figura 28-, y permiten corroborar estas afirmaciones: el volumen de transacciones en la provincia ha pasado de 5.822 en 2007 a sólo 170 en 2020, y en el área urbana de León, de 2.982 a 128.
} 
7.000 en el momento álgido del boom (años 2006-2008). El estallido de la burbuja en el año 2007 supuso la parálisis de la demanda de vivienda nueva, como puede verse en el desplome del número de viviendas terminadas anualmente, que llegó a reducirse a un mínimo de 233 unidades en 2017 y que, aunque después se ha recuperado ligeramente, apenas alcanzó las 399 en 2019.

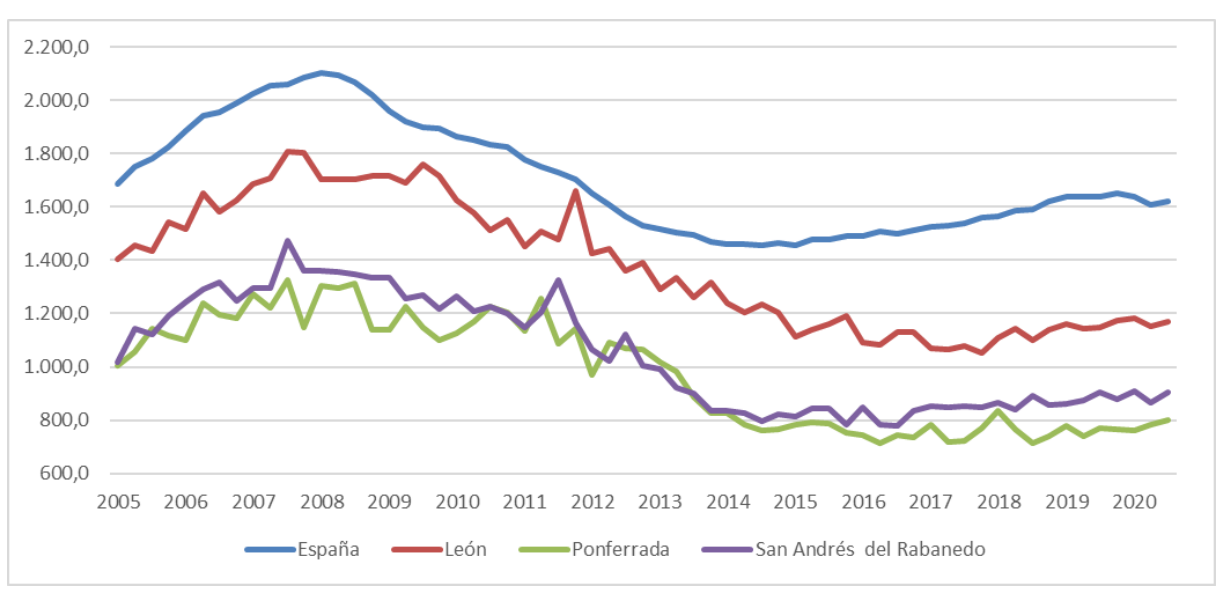

Figura 4. Evolución del precio medio del metro cuadrado construido (vivienda libre) $\left(€ / \mathrm{m}^{2}\right)$ en los municipios leoneses de más de 25.000 habitantes (León, Ponferrada y San Andrés del Rabanedo).

Fuente: Elaboración propia sobre Serie Estadística del valor tasado medio de vivienda libre de los municipios mayores de 25.000 habitantes (trimestral). MITMA.

En definitiva, tanto en precios como en producción de viviendas, el ciclo inmobiliario leonés es perfectamente paralelo al experimentado en España, con una primera fase alcista o boom entre 1997 y 2007 , seguido del estallido de la burbuja a partir de 2008, con un largo período de atonía posterior en el que se comenzaba a atisbar una cierta recuperación en los últimos años, súbitamente interrumpida por la pandemia de 2020.

Por otra parte, la distribución entre vivienda libre y vivienda protegida del total de viviendas terminadas y/o calificadas anualmente es también claramente indicativa de la desaparición o del fracaso -ya a nivel estatal, pues es en el que se diseña- de la política de vivienda en régimen de protección pública ${ }^{11}$. Si durante la primera parte de la década de los 90 , la vivienda protegida supuso casi un tercio del total en León, rozando incluso casi el $40 \%$ en el año 1997, su peso durante el boom inmobiliario se redujo hasta cifras medias del $7 \%$, y desde el año $2013^{12}$ puede decirse que ha desaparecido en la práctica, pues en 7 años sólo se han calificado 72 viviendas protegidas en toda la provincia. Esta distribución también caracteriza bien el último ciclo inmobiliario: en ausencia de mecanismos efectivos de intervención u orientación pública del mercado de vivienda, se trata de un ciclo simplemente dirigido a la producción inmobiliaria para las clases sociales que pueden permitirse acceder con

\footnotetext{
11 No es este el lugar de abordar este complejo debate.

12 Fecha de arranque del Plan Estatal de Fomento del Alquiler de Viviendas, la Rehabilitación Edificatoria, y la Regeneración y Renovación Urbanas 2013-2016, que supuso en la práctica la sentencia final de la vivienda protegida en España.
} 
cierta holgura a la vivienda libre mediante los mecanismos que ofrece el mercado inmobiliario convencional: básicamente, el acceso a un producto de crédito hipotecario, aligerada -en algunos casos - la cuantía del préstamo mediante el ahorro familiar o la venta de una vivienda previa en el mercado de segunda mano.

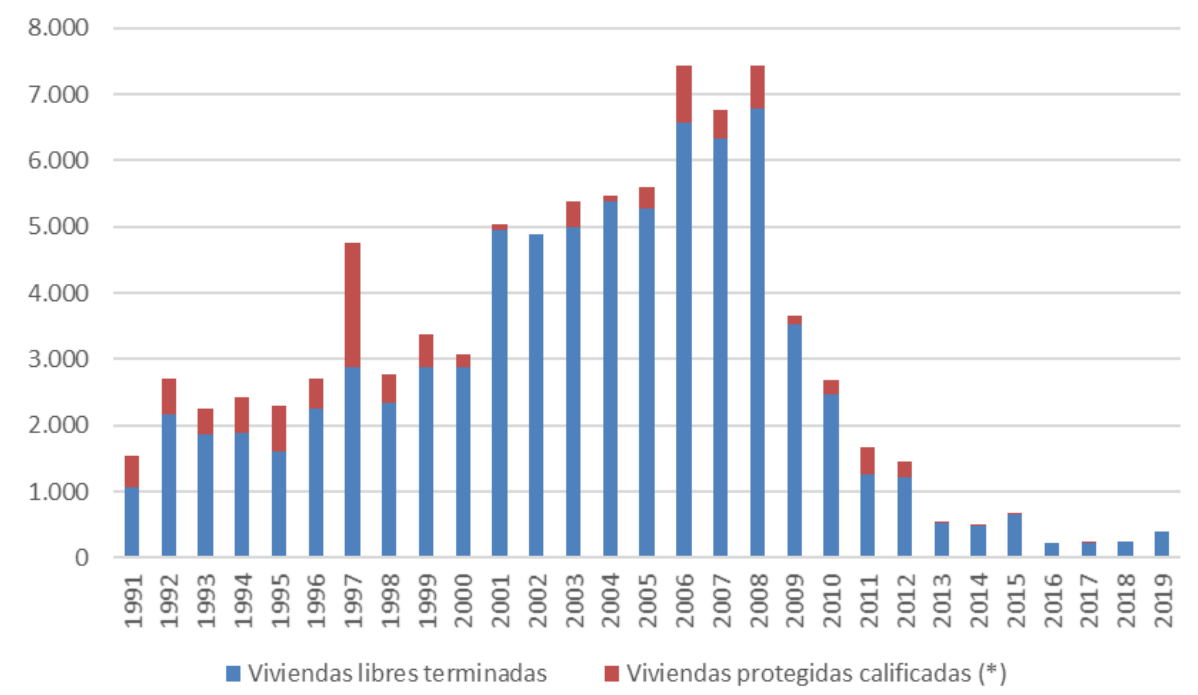

Figura 5. Número de viviendas libres terminadas y protegidas calificadas en la provincia de León.

(*) Número de calificaciones definitivas. Planes estatales y planes autonómicos.

Fuente: Elaboración propia sobre Series Estadísticas de Número de viviendas libres terminadas y Número de calificaciones definitivas. MITMA.

Desde una interpretación típicamente economicista, como la que fue habitual durante los años del boom (y que permeó a la cultura urbanística española, inspirando tanto la liberalización del suelo de la Ley 6/1998 como muchos planes urbanísticos de aquellos años), el incremento de los precios debía venir motivado por la escasez de viviendas, como típico desajuste entre las leyes de la oferta y la demanda ${ }^{13}$. Sin embargo, el gráfico de evolución tomando como Base 100 el año 1995 -justo antes del inicio del ciclo- muestra el paralelismo entre el incremento de los precios y los volúmenes de vivienda construidos. Esto, que resulta una paradoja desde el punto de vista estrictamente economicista, en realidad encuentra su explicación en la existencia de la consabida burbuja en la que la demanda crece precisamente porque crecen los precios, y en el momento en que estalla la burbuja, todo el sistema se desploma como un castillo de naipes, descendiendo tanto los precios como las viviendas construidas anualmente ${ }^{14}$.

\footnotetext{
13 Como veremos, el colofón de esta interpretación era que, si el precio sube es porque la escasez en oferta de vivienda es incapaz de satisfacer la alta demanda existente, de modo que la solución es simplemente ampliar la oferta de vivienda, para lo cual es imprescindible ampliar primero la oferta de suelo, clasificando generosamente suelo residencial.

${ }^{14}$ Como puede verse, en realidad el desplome es mucho más acusado en la construcción de viviendas que en los precios, que muestran una notable inercia.
} 


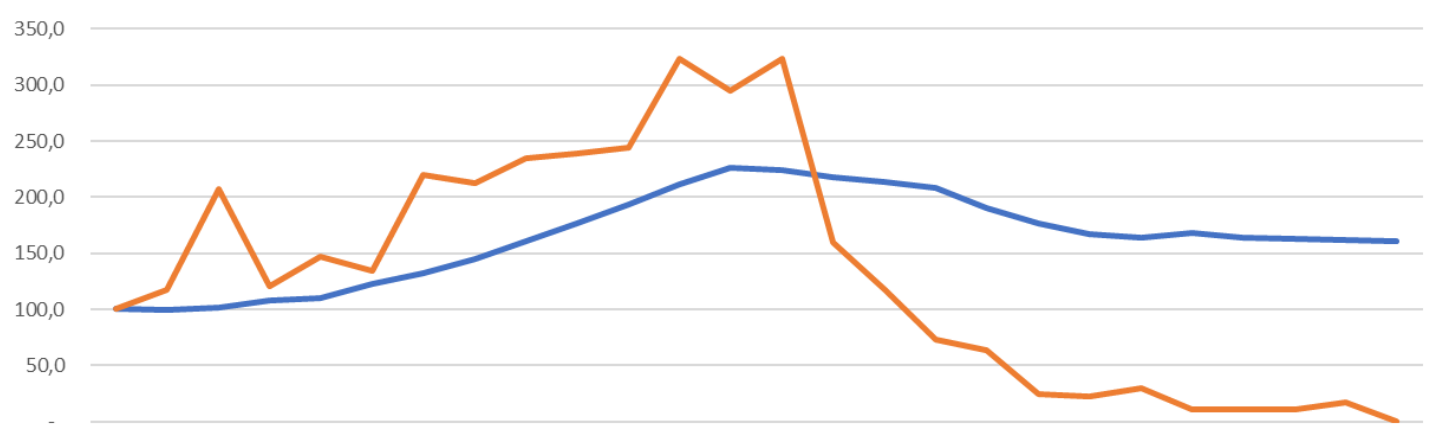

19951996199719981999200020012002200320042005200620072008200920102011201220132014201520162017201820192020

Precio Vivienda Viviendas Terminadas

Figura 6. Evolución del Precio de la vivienda y del Volumen de viviendas terminadas en la provincia de León. Base 100 en 1995.

Fuente: Elaboración propia a partir de MITMA.

\section{LA LIBERALIZACIÓN DEL SUELO EN LA LEGISLACIÓN ESTATAL Y SU TRADUCCIÓN A LA COMUNIDAD DE CASTILLA Y LEÓN}

\subsection{Los vericuetos de la liberalización del suelo en la legislación estatal}

El recorrido -con sus vericuetos, sus idas y venidas- por la senda de liberalización del suelo en España se remonta -en su fase más reciente- hasta mediados de los años 1990. La breve pero intensa crisis económica experimentada por el país entre 1992 y 1993 tuvo, entre otros, el efecto de provocar el agotamiento y final súbito del primer boom inmobiliario del período democrático que se había desarrollado entre 1985 y 1992. Este momento catártico fue especialmente propicio para realizar un diagnóstico del boom precedente, analizando las causas del incremento desmesurado que habían alcanzado los precios de la vivienda durante esos años. En 1993, el Tribunal de Defensa de la Competencia realizó un primer Informe, donde se propuso la creación de una Comisión de Expertos que analizara el problema del suelo con relación al incremento del precio de la vivienda experimentado durante el boom inmobiliario 1985-1992 y presentara sus conclusiones al respecto.

Atendiendo a ello se creó la Comisión de Expertos sobre Urbanismo, dependiente del Ministerio de Obras Públicas, Transportes y Medio Ambiente, que elaboró sus trabajos a lo largo de 1994 y elevó sus conclusiones al Gobierno a finales de ese mismo año. El diagnóstico de la Comisión era prácticamente unánime sobre el hecho de que el incremento del precio de la vivienda se debía un desequilibrio entre la oferta y la demanda ${ }^{15}$ : en un contexto de alta demanda como el experimentado durante el boom, era la escasez en la oferta la que había impulsado el ascenso de los precios. Y detrás de esta escasez en la oferta de viviendas estaban las restricciones en la oferta

\footnotetext{
15 Otros diagnósticos e interpretaciones, en los cuales se afirma justo lo contrario - que es precisamente el precio del suelo el que se deriva del precio de la vivienda, y no al revés- y donde se explican las peculiaridades de los mercados de suelo y de la conformación del precio de la vivienda pueden encontrarse en Naredo (1996), Naredo y Montiel (2011), etc.
} 
de suelo urbanizado disponible, que se terminaban traduciendo en el incremento del precio del suelo, trasladado posteriormente al precio final de la vivienda. A partir de aquí se proponían dos formas de solucionar el problema, siempre desde el lado de la oferta de suelo:

La mayor parte de los miembros de la Comisión estimaba que en aquel momento los problemas no se derivaban de la escasez de Suelo Urbanizable sino de la escasez de Suelo Urbanizado y, por tanto, centraban el problema en la gestión. De este modo, no se cuestionaban las técnicas de clasificación de suelo vigentes, sino que se focalizaba el problema en el desarrollo y la urbanización del suelo una vez ya clasificado, proponiendo como solución la liberalización/agilización de la gestión/ejecución y la separación del derecho de la propiedad del suelo del derecho a su desarrollo urbanístico, en línea con la figura del agente urbanizador que se estaba gestando también en aquellas mismas fechas y que muy poco después recogería de modo pionero la Ley 6/1994 Reguladora de la Actividad Urbanística (LRAU) en la Comunidad Valenciana.

Otra parte minoritaria de la Comisión, sostenía que, además de existir problemas instrumentales de gestión, el problema central eran las restricciones que el planeamiento urbanístico introducía en el mercado del suelo (a través del estricto dimensionado del Suelo Urbanizable realizado en los planes municipales), pues éstas se terminaban traduciendo en un estrangulamiento de la oferta de Suelo Urbanizado disponible, lo cual elevaba su precio y finalmente repercutía también en el alza del precio de las viviendas. Desde este punto de vista, se sostenía que el problema estaba en la legislación urbanística sobre suelo entonces vigente (la Ley del Suelo estatal de 1990 y su Texto Refundido de 1992), y se hacía necesario reformarla a fondo para acometer una liberalización del suelo, dejar "al mercado que funcione" y "así poner fin a la restricción de su oferta, a la especulación sobre el mismo, a la carestía de la vivienda y a las arbitrariedades administrativas" (Tribunal de Defensa de la Competencia, 1993, p. 41).

Como se verá, si bien ambas fórmulas (liberalización de la gestión-ejecución a través del agente urbanizador, liberalización del suelo) ${ }^{16}$ fueron finalmente

\footnotetext{
${ }^{16}$ En un primer momento cada fórmula se identificó con una postura política diferente: la liberalización del suelo fue la fórmula liberal/conservadora y el agente urbanizador la fórmula progresista/socialista, pero posteriormente ambas fueron puestas al servicio del boom inmobiliario. Como señala F. Gaja, "la LRAU [...] fue una de las últimas leyes aprobadas por el gobierno autonómico del PSPV-PSOE antes de que la derecha ganara las elecciones en 1995. Presentada como una norma que pretendía liquidar una estructura fundiaria urbana pre-moderna (feudal se llegó a decir), fue, quizás por eso mismo, duramente atacada por la derecha desde la oposición. Pero los ataques, bien pronto se verían, eran en realidad fuegos artificiales, retórica electoral. Ganados los comicios, la derecha gobernante se convirtió en su más acérrima defensora. ¿A qué se debe esta metamorfosis? ¿̇regeneración social, centrismo político? Nada de eso, pura identidad y convergencia de intereses" (2003, pp. 56-57). En efecto, según fue avanzando el ciclo inmobiliario ambas fórmulas fueron desvelando sus posibilidades de convergencia, como en el caso valenciano, o la pertinencia de una u otra según el contexto de la estructura de la propiedad local. Como señala el Observatorio Metropolitano, finalmente, "ambos tipos de legislación coexistieron pacíficamente, funcionando como un menú estratégico a elección de las élites autonómicas. Por ejemplo, Valencia, bajo la dirección del Partido Popular, siguió utilizando la LRAU del PSOE, en tanto ariete para eliminar las barreras a la acumulación de capital que supone una estructura de propiedad rústica atomizada. Sin embargo, en el caso de Castilla y León, ese mismo partido optó por un modelo de liberalización de suelo con clara intención de rehabilitar la figura del propietario de suelo agrícola, que constituye una de sus bases tradicionales" (2010, p. 310).
} 
introducidas en la legislación estatal ${ }^{17}$, su desarrollo (especialmente de la figura del agente urbanizador) tuvo muy distinta intensidad en las diferentes Comunidades Autónomas ${ }^{18}$. Además de estas dos vías de flexibilización de la actividad urbanística de raíz típicamente liberal, conviene destacar también que ambas coexistieron en la práctica diaria municipal con un neodesarrollismo propiamente hispano basado en el ladrillo, generalizado en casi todos los Ayuntamientos del país, con independencia de su color político. En este neodesarrollismo confluyeron factores estructurales heredados (la cultura de la vivienda en propiedad) con otros característicos del ciclo económico 1997-2007 (la disponibilidad de crédito y financiación abundante y barata, el papel asignado a la vivienda como instrumento de acumulación del ahorro cuando no de especulación), así como la elevación a axioma unánimemente compartido de las virtudes de la sobreclasificación de suelo y del planeamiento al límite de la capacidad (pues supuestamente la sobreoferta - primero de suelo, y después de vivienda - haría disminuir los precios), el recurso a la financiación municipal a través del urbanismo, etc. (Naredo, 1996; García Montalvo, 2004; Rodríguez López, 2006; Naredo y Montiel, 2011; Fernández y Roch, 2012).

Regresando al hilo histórico, el Consejo de Ministros, con fecha 13 de enero de 1995, aprobó un documento titulado Reformas legislativas para atajar el problema de la escasez de suelo, que había sido elaborado por el MOPTMA tomando como base las recomendaciones de la parte mayoritaria de la Comisión de Expertos. En él se trazaban las líneas generales de actuación para solventar el problema del suelo, partiendo de la base de que lo que escaseaba era el Suelo Urbanizado y que la cantidad de Suelo Urbanizable disponible entonces en España era más que suficiente para atender a la demanda de vivienda prevista en los quince años siguientes ${ }^{19}$. Por ello, las actuaciones que se planteaban pretendían favorecer el proceso de transformación del suelo simplemente clasificado como urbanizable en suelo efectivamente urbanizado, consistiendo en pequeños retoques legislativos de la Ley del Suelo estatal entonces vigente para favorecer la acción urbanizadora, planteando mecanismos similares al del "agente urbanizador" recién introducido en aquel entonces y de forma pionera por la Ley Reguladora de la Actividad Urbanística (LRAU) valenciana, con el objeto de que "los promotores y constructores que deseen urbanizar y edificar sustituyan a los propietarios de suelo que no puedan o no deseen

\footnotetext{
17 Como se ha comentado, el agente urbanizador se introdujo primero en la escala autonómica, de modo pionero en la Comunidad Valenciana - gobernada entonces por el PSOE- mediante la LRAU de 1994, y posteriormente en otras CCAA, con independencia de su signo político - entre ellas, en la de Madrid, mediante la Ley de 2001-. En la escala estatal la figura fue incorporada y desarrollada en la Ley 8/2007 de Suelo, aprobada por el PSOE. Respecto a la liberalización del suelo fue introducida por el PP primero en la escala estatal (1998 y 2000), y posteriormente se trasladó a las CCAA cuando estas aprobaron su primera legislación urbanística propia, de acuerdo con la Sentencia del Tribunal Constitucional de 1997.

18 En la Comunidad Valenciana y en Castilla La Mancha, la fórmula del agente urbanizador se convirtió en el sistema exclusivo de ejecución del planeamiento, pero en el resto de Comunidades convivió con los sistemas tradicionales (compensación, expropiación, etc.).

${ }^{19}$ Apoyándose en un Informe interno del propio MOPTMA de diciembre de 1995 "Disponibilidad de Suelo Urbanizable en los municipios de más de 20.000 habitantes. Previsiones de planeamiento urbanístico y relación con las necesidades de suelo urbanizado".
} 
hacerlo (...) tras el consiguiente trámite de concurrencia pública (subasta)" (Tribunal de Defensa de la Competencia, 1993, p. 42) ${ }^{20}$.

Sin embargo, estas propuestas - fieles a la opinión mayoritaria de la Comisión de Expertos- fueron duramente criticadas por el nuevo Informe del Tribunal de la Competencia de 1995, según el cual "España padece agudamente los efectos derivados de la escasez de suelo pese a que este factor es relativamente abundante en términos físicos. Ello se debe a la existencia de una legislación sobre la materia sumamente intervencionista que restringe artificialmente la oferta de suelo hasta el punto de conseguir que haya una gran falta del mismo y que, por consiguiente, su precio sea muy elevado. Esta carestía del suelo es origen de graves distorsiones. Al ser el coste del suelo un componente fundamental del precio de la vivienda, los altos precios de suelo se traducen en precios de la vivienda muy elevados, lo que dificulta el acceso a este bien esencial." (op. cit, p. 35)

Abundando en la culpabilidad del suelo, se le convertía en el chivo expiatorio de todos los males urbanísticos conocidos: "por otra parte, la escasez de suelo afecta a la calidad de vida de los ciudadanos al condicionar la configuración urbanística de las ciudades, donde la falta de espacio propicia que la densidad de población sea mayor, que sea menor el tamaño de las viviendas, que haya menos espacios libres, que el tráfico sea más difícil, etc." (op. cit., p. 37). De modo que el Informe terminaba concluyendo: "[S]i se quiere acabar con la carestía del suelo y de la vivienda es necesario abandonar el espíritu intervencionista y planificador con que la Administración regula y actúa en la actualidad y optar por la liberalización de la legislación del suelo, recurriendo a unas reglas objetivas y transparentes que conjuguen el respeto a los objetivos públicos con el funcionamiento eficiente del mercado" (op. cit., p. 43).

Estas declaraciones del Tribunal de Defensa de la Competencia y los reclamos en el mismo sentido del bloque inmobiliario ${ }^{21}$ encontraron un contexto especialmente propicio con la llegada del Partido Popular (PP) al gobierno central tras las elecciones generales de 1996. Comenzó entonces una senda progresiva hacia la liberalización del suelo, primero de forma tímida mediante el paquete de Medidas Urgentes Liberalizadoras en materia de Suelo y Colegios Profesionales introducido en el Real Decreto 5/1996, que culminó en la aprobación de la Ley 6/1998 sobre Régimen de Suelo y Valoraciones y, sobre todo (tras la obtención de la mayoría absoluta

\footnotetext{
20 La concepción original del agente urbanizador -impulsada intelectualmente en buena medida por Javier García Bellido, Gerardo Roger Fernández y Luciano Parejo- fue posteriormente desvirtuándose, sobre todo en la práctica real, contribuyendo a la turbo-urbanización del territorio. Analizando la LRAU, F. Gaja (2003, p. 57) señala: "La LRAU se construye a partir de dos hipótesis explícitas: la primera es que los propietarios son el principal obstáculo que se opone a la modernización del sector inmobiliario [...]; y la segunda, que el suelo es el principal factor de carestía de los productos inmobiliarios. Amunicionados con estas dos hipótesis por todo bagaje conceptual, la conclusión es clara: se impone acabar con los terratenientes clásicos, devenidos capa parasitaria. Y a ello se dedica con denuedo la LRAU, a anular la posición hegemónica de los propietarios del suelo y a auspiciar una política de fomento a toda costa de la producción de suelo urbanizado".

21 La cantidad de Suelo Urbanizable clasificado siempre parecía sistemáticamente insuficiente a las empresas inmobiliarias, a no ser que éstas fuesen a su vez grandes propietarias de suelo $-y$ por tanto beneficiarias también de su monopolio-, lo cual no ha sido habitual hasta muy recientemente. Véanse al respecto las notas 16 y 27.
} 
parlamentaria en las elecciones del año 2000) en el Real Decreto 4/2000 de Medidas Urgentes de Liberalización en el Sector Inmobiliario y de Transportes.

Así, la Ley 6/1998, dentro de las importantes restricciones competenciales en materia de urbanismo que dibujó la Sentencia del Tribunal Constitucional de 1997 recogía la idea de que todo el territorio - salvo aquellas zonas que debieran ser justificadamente protegidas - era susceptible de ser urbanizado. En el Preámbulo podía leerse que su pretensión era "facilitar el aumento de la oferta de suelo, haciendo posible que todo el suelo que todavía no ha sido incorporado al proceso urbano, en el que no concurran razones para su preservación, pueda considerarse como susceptible de ser urbanizado".

No obstante, $y$, a pesar de estas declaraciones explícitas a favor de la liberalización del suelo, la falta de una mayoría absoluta parlamentaria hizo que Ley se limitase en la práctica a atribuir al Suelo No Urbanizable un carácter residual, lo cual sin duda resultó conceptualmente importante, pero no alteró sustancialmente la metodología tradicional de clasificación del suelo 22 .

En realidad, el cambio trascendental se produjo tras la rotunda victoria del PP en las elecciones de marzo de 2000, con las medidas urgentes de liberalización del RD 4/2000, mediante el cual, según se comentaba en su Preámbulo: "[Se] pretenden corregir las rigideces advertidas en el mercado como consecuencia del fuerte crecimiento de la demanda y la incidencia en los productos inmobiliarios del precio del suelo, condicionada a su vez por la escasez de suelo urbanizable. En consecuencia, la reforma [...] habrá de incrementar la oferta del suelo al eliminar aquellas previsiones normativas en vigor que por su falta de flexibilidad pudieran limitarla, trasladando este efecto positivo al precio final de los bienes inmobiliarios" 23 .

Desarrollando al máximo estas intenciones, el RD 4/2000 consiguió la liberalización efectiva del suelo -mediante un sutilísimo retoque del régimen urbanístico de la propiedad del suelo que había establecido la Ley de 1998- y con ella alteró de forma radical el modelo canónico de planeamiento que había estado vigente en España durante 40 años (Rullán, 1999; Menéndez Rexach, 2006; Cardoso Delso, 2020).

La liberalización se realizó a través de la nueva definición de Suelo No Urbanizable, derivada de la supresión de la famosa "coletilla" 24 de la Ley de 1998 mediante la cual

\footnotetext{
22 Véase al respecto Rullán (1999).

23 Real Decreto-ley 4/2000, de 23 de junio, de Medidas Urgentes de Liberalización en el Sector Inmobiliario y Transportes (Boletín Oficial del Estado, no. 151 de 24 de junio de 2000, páginas 22436 a 22438).

${ }^{24}$ La definición del Suelo No Urbanizable que se establecía en el artículo 9 de la Ley 6/1998 era la siguiente: "Tendrán la condición de Suelo No Urbanizable, a los efectos de esta Ley, los terrenos en que concurran alguna de las circunstancias siguientes:

1. Que deban incluirse en esta clase por estar sometidos a algún régimen especial de protección incompatible con su transformación de acuerdo con los planes de ordenación territorial o la legislación sectorial, en razón de sus valores paisajísticos, históricos, arqueológicos, científicos, ambientales o culturales, de riesgos naturales acreditados en el planeamiento sectorial, o en función de su sujeción a limitaciones o servidumbres para la protección del dominio público.
} 
todavía se había permitido que el planeamiento general incluyera como No Urbanizables los terrenos que se considerasen inadecuados para el desarrollo urbano. De modo que a partir del RD 4/2000 sólo quedaban excluidos de la posibilidad de ser urbanizables los terrenos que fuera necesario proteger por sus valores (paisajísticos, históricos, arqueológicos, científicos, ambientales, culturales, agrícolas, forestales, ganaderos o por sus riquezas naturales), los inadecuados por presentar riesgos naturales acreditados o los sujetos a limitaciones o servidumbres para la protección del dominio público. En la práctica esto implicaba la máxima liberalización del suelo posible ${ }^{25}$ y también que, de un plumazo, los Suelos No Urbanizables de tipo común, que constituían la mayor parte de la superficie en casi todos los términos municipales españoles, perdieran la razón por la que se clasificaron como tales y que, por tanto, en caso de revisarse el planeamiento de acuerdo con la nueva legislación, pasasen a ser potencialmente urbanizables ${ }^{26}$.

De este modo, el RD 4/2000 abrió la posibilidad de que, una vez delimitada la ciudad consolidada y preservados ciertos fragmentos del medio natural merecedores de protección o afectados por las infraestructuras, se entendiera que el resto del suelo era potencialmente urbanizable y por tanto susceptible de ser desarrollado por sus propietarios, a quienes - desde esa nueva perspectiva- no puede sustraerse este derecho ${ }^{27}$.

La liberalización introducida por esta reforma era conceptualmente tan profunda (al invertir la tradicional sujeción de los derechos de la propiedad a la función social de la misma, que había caracterizado toda la legislación urbanística española desde 1956), que no pudo sostenerse mucho tiempo, de modo que se rectificó al cabo de 3

2. Que el planeamiento general considere necesario preservar por los valores a que se ha hecho referencia en el punto anterior, por su valor agrícola, forestal, ganadero o por sus riquezas naturales, así como aquellos otros que considere inadecuados para un desarrollo urbano" (el subrayado es nuestro).

La modificación introducida por el RD 4/2000 consistió simplemente en eliminar la parte subrayada. Eliminando sólo esta frase se transformaron radicalmente las bases conceptuales del planeamiento en España, pues se suprimió la potestad ordenadora del planeamiento general que hasta entonces - desde la primera Ley de Suelo de 1956- había incluido la posibilidad de establecer un determinado modelo urbano, en base al cual determinados suelos podían ser considerados como "inadecuados para el desarrollo urbano", limitando por tanto el ius aedificandi y regulando el suelo conforme a la función social de la propiedad. Esta capacidad regulatoria y ordenadora del planeamiento, basada en la función social de la propiedad, fue por tanto desplazada por los derechos de los propietarios de suelo.

${ }^{25}$ A pesar de ello, desde la máquina inmobiliaria se ha seguido reclamando interesadamente -al menos hasta el cambio de ciclo a mediados de 2007- más liberalización ... ¿̇de qué?, ¿de los suelos protegidos?

${ }^{26}$ Aunque en el caso de la ciudad de León esto pudo no resultar especialmente problemático (por la escasa superficie de su término municipal), en otros municipios sí supuso un grave problema de dispersión urbana.

27 Por el contrario, según la perspectiva que había sido tradicional desde la Ley de 1956, "la propiedad sería por naturaleza rústica. Su conversión en urbana (y la plusvalía correspondiente) no entraría dentro de las facultades de goce y disposición del propietario, sino que le sería otorgada (en las condiciones marcadas por la ley) por los poderes públicos competentes" (Menéndez Rexach, 2006, p. 260). Como se ha apuntado, la perspectiva de la opción del "agente urbanizador" es también diferente: en este caso el propietario de suelo clásico es visto como un obstáculo para la apertura del proceso de urbanización a la iniciativa empresarial de los agentes profesionales (promotores) no propietarios de suelo. Véase a este respecto la nota 16 y Gaja (2003). En realidad, el debate central subyacente en las reformas legislativas de todo el período analizado se resume en estas tres perspectivas y finalmente en determinar cuál es el papel que deben jugar los propietarios de suelo en la actividad urbanística. De modo que cada una de las perspectivas expresa determinados intereses. En función de cada contexto concreto, los intereses del bloque local hegemónico (en unos casos pequeños propietarios; en otros, pequeñas empresas promotoras no propietarias de suelo; en otros, grandes promotoras que también son propietarias, etc.) presionan para imponer una u otra perspectiva. 
años mediante la Ley $10 / 2003$, de 20 de mayo, donde se volvió a reintroducir nuevamente la famosa "coletilla"28, devolviendo así al planeamiento su capacidad de ordenar el territorio y de delimitar socialmente los derechos de la propiedad privada. No obstante $-y$ en pleno fragor del boom inmobiliario-, la liberalización había ganado ideológicamente la batalla, al imponerse culturalmente junto a las ideas neodesarrollistas de crecimiento hasta la saturación, las bondades de la sobreclasificación, etc.

Más allá de estas idas y vueltas, a nuestro juicio, el verdadero significado de todo este proceso a medio camino entre el neodesarrollismo y el neoliberalismo ha sido la puesta en carga, o el establecimiento de las bases para que fuese posible hacerlo- de la mayor parte del suelo con expectativas de desarrollo urbanístico de los municipios. De este modo, esa oferta cuasi-ubicua de suelo permitiría romper los posibles monopolios parasitarios que sobre otros suelos pudieran ejercerse, manteniendo al mismo tiempo los privilegios de las operaciones mejor situadas en la parrilla de salida. De este modo se evitaba la capacidad de interferir en la toma de nuevas posiciones a futuro por parte de los principales agentes, pues cualquier posición monopolística indeseada estrangularía no sólo su negocio, sino también esa turbo-urbanización pretendida que supuestamente habría de hacer descender los precios.

En el caso del área urbana de León, Rafael Santamaría, presidente del Colegio de Arquitectos durante aquellos años, expresaba esta idea afirmando que "la iniciativa privada es la que ha decidido que la ciudad fuera por un sitio o por otro. Eso, amparado luego por los políticos, ha hecho que la ciudad sea tan caótica. Nos encontramos con una ciudad que no tiene una visión clara de cómo quiere ser. Quien quiso especular con su terreno, especuló. La ciudad va saltando de lado a lado sin un concierto, sin un orden, sin una partitura que seguir" (VV.AA., 2007).

En la misma línea, Gago (2005, p. 6) señalaba también que entre los conceptos manejados: "[E]I principal sin duda es la confianza prácticamente ilimitada no tanto en la "economía de mercado" como en la capacidad del negocio inmobiliario para -a través del mercado- organizar del modo más eficiente la ocupación y el uso del territorio. La antigua visión de la ciudad como lugar de los negocios abre así el paso a un nuevo entendimiento -el negocio de hacer ciudad-, en donde ésta se concibe directamente no ya como lugar, sino como objeto propio de negocio [...]".

En este sentido, no hay que olvidar que una coordenada fundamental del modelo de acumulación de la burbuja inmobiliaria fue la conversión de la vivienda - por encima de su valor de uso o superponiéndose a él- en un simple instrumento de capitalización hacia el cual se canalizó el ahorro y los excedentes de capital de los particulares (nacionales o extranjeros) y de las empresas del sector, para posteriormente convertirla junto al suelo en el objeto más rentable de las prácticas especulativas; de modo que la urbanización se entendía no sólo o prioritariamente al servicio de las necesidades de alojamiento, sino como simple soporte de la

\footnotetext{
28 Quedando con la siguiente redacción: "así como aquellos otros que considere inadecuados para el desarrollo urbano, bien por imperativo del principio de utilización racional de los recursos naturales, bien de acuerdo con criterios objetivos de carácter territorial o urbanístico establecidos por la normativa urbanística".
} 
construcción de viviendas devenidas en instrumentos de capitalización o especulación. Todo lo cual no es sino un reflejo del cambio producido en el modelo de acumulación español, y del papel protagonista que jugó en el mismo el sector inmobiliario hasta el estallido de la burbuja en 2007: en efecto, del urbanismo puesto al servicio del despliegue prioritario de la "modernización industrial" desarrollista se pasó al urbanismo al "servicio de la economía monetaria" (González García y Hernández Aja, 2007), a la mera disposición de suelo para la construcción de un armatoste inmobiliario de acumulación familiar y empresarial cuando no de mera especulación.

\subsection{La traducción de la liberalización del suelo en el marco normativo de Castilla y León}

Como se ha apuntado, en 1997, la Sentencia 61/1997 del Tribunal Constitucional había sentado las bases de la descentralización competencial plena y efectiva en materia de urbanismo en España, estableciendo que ésta era una competencia exclusiva de las CCAA y que al Estado sólo le correspondía una regulación básica que permitiera la igualdad en el ejercicio de derechos y deberes, que fue la Ley de Suelo de 1998. De este modo, cada Comunidad Autónoma redactó su propia normativa en materia de suelo y urbanismo, posicionándose -dentro de las posibilidades del marco estatal- de una u otra forma con respecto al tema del suelo y su liberalización, conformando el menú final de flexibilización de la actividad urbanística mediante la selección y la combinación de las opciones disponibles según resultase más apropiado para cada contexto autonómico ${ }^{29}$.

Aprobada justo entre la Ley de Suelo de 1998 y el RD 4/2000 -y por tanto, antes de completarse plenamente la liberalización del suelo-, la primera legislación urbanística castellanoleonesa, la Ley 5/1999, siguió el mandato estatal de trasladar el carácter residual del suelo al Urbanizable ${ }^{30}$, si bien todavía permitía incluir dentro

\footnotetext{
29 Por ejemplo, tomando posición sobre la conveniencia de la figura del agente urbanizador en cada territorio, dependiendo de la estructura de la propiedad del suelo y de los intereses asociados a ésta. Así, en la Comunidad de Madrid, a pesar de su incorporación en la Ley autonómica de suelo del año 2001, esta figura casi no se ha usado en la práctica y terminó suprimiéndose en la reforma de la legislación de 2007. Esto puede explicarse porque (según indican los datos del Atlas Estadístico de las Áreas Urbanas en España del Ministerio de Fomento (2009), siendo un este mercado con fuertes expectativas, hace ya mucho tiempo que una parte considerable del suelo del área metropolitana de Madrid se encuentra en manos de empresas y promotoras, así en 2009 el 40,3\% del suelo urbano no edificado ya era propiedad de personas jurídicas - frente al 18,9\% de personas físicas- y en el suelo rústico éstas disponían del 25,1\%. Por el contrario, en la Comunidad Valenciana - paradigma de la liberalización de la gestión del suelo en España a través del agente urbanizador, a costa de los pequeños y medianos propietarios- la atomización de la estructura de la propiedad era mucho mayor, como muestra el hecho que personas físicas fueran titulares del $37,8 \%$ del suelo urbano no construido y del $72,4 \%$ del rústico. Por tanto, es lógico que en esta Comunidad interesase a los promotores profesionales romper los pequeños monopolios sobre el suelo de los propietarios locales.

${ }^{30}$ Según el tenor literal de su artículo 13 "tendrán la condición de Suelo Urbanizable los terrenos que no puedan ser considerados como Suelo Urbano o como Suelo Rústico". Y, según el artículo 14, éste se podía dividir en dos categorías: el Suelo Urbanizable Delimitado, "constituido por los terrenos cuya transformación en Suelo Urbano se considere adecuada a las previsiones del planeamiento urbanístico, y que a tal efecto se agruparán en ámbitos denominados sectores", y el No Delimitado, "constituido por los demás terrenos que se clasifiquen como Suelo Urbanizable". Poco tiempo después se reformó este último artículo, para introducir la idea de que la naturaleza del suelo depende del cumplimiento de unos derechos y deberes dentro de unos plazos. La Ley 13/2003, 23 diciembre, de Medidas Económicas, Fiscales y Administrativas modificó el artículo 14, estableciendo que la ordenación detallada de los sectores podría ser realizada por el planeamiento general o remitirse a un Plan Parcial, y que, en éste debe
} 
del Rústico -además de los terrenos "sometidos a algún régimen especial de protección incompatible con su urbanización", con valores manifiestos "que justifiquen la necesidad de protección o de limitaciones de aprovechamiento", o los "amenazados por riesgos naturales o tecnológicos incompatibles con su urbanización" - inadecuados para su urbanización, conservando la categoría del Suelo Rústico Común.

Por tanto, la Ley 5/1999 dejaba un cierto margen para que el planeamiento urbanístico, aun dentro de la consideración del Suelo Urbanizable como residual, pudiese justificar la inadecuación de determinados terrenos para su urbanización. No obstante, en el área urbana de León, y como veremos en el caso del PGOU de la capital, apenas se utilizó esta potestad, optándose por planes de tipo expansivo al límite de la capacidad.

A escala autonómica es posible hacer una primera aproximación general sobre el número de municipios afectados por la sobredimensión en la clasificación de suelo a partir de los datos del Sistema de Información Urbana analizados por De Santiago y González (2019), según los cuales en el año 2018 de 2.248 municipios castellanoleoneses, el $57,1 \%$ no tenía planeamiento o contaba sólo con un Proyecto de Delimitación del Suelo Urbano, frente al 42,8\% que tenía Normas Subsidiarias, Normas Urbanísticas Municipales o Plan General. De estos 963 municipios con planeamiento (que, aunque sólo suponían el 56\% del territorio, albergaban el $91 \%$ de la población), 196 contaban con figuras anteriores a la Ley 5/1999, 459 con figuras aprobadas en el marco de esta Ley y hasta 2008, y 308 con figuras posteriores a la Ley estatal de 2008 y la inmediata modificación del marco autonómico. De manera que el porcentaje de ayuntamientos con planeamiento aprobado en el marco de la liberalización del suelo a nivel estatal sería del 20,4\% sobre el total y del $47,6 \%$ sobre los que cuentan con algún instrumento de ordenación. Respecto al peso del sobredimensionado de suelo, puede aproximarse a partir del número de municipios afectados por las 2 rondas de desclasificación que más adelante se analizarán con detalle. La primera, del año 2016, afectó a 153 municipios (521 sectores, con una superficie de $11.389 \mathrm{ha}$ ), lo que supone casi el $80 \%$ de los que tenían figuras anteriores a 1999. Mientras, la segunda ronda de desclasificación (270 sectores, con 28.131 ha) de 2018 , sólo afectó a 95 municipios, lo que supone aproximadamente el $20 \%$ de los que tenían figuras aprobadas entre 1999 y 2008.

Una lectura superficial de estos datos indicaría que paradójicamente habría habido más municipios con sobreclasificación entre los de planeamiento anterior a la liberalización de suelo de finales de los 90. En realidad, un análisis más detallado de estos municipios afectados por la primera ronda de desclasificación de 2016 (Marinero 2018) indica que muchos de ellos arrastraban sectores clasificados durante el desarrollismo salvaje de los años 70, que habían permanecido sin desarrollar hasta entonces. Respecto a la segunda ronda, y dado que ésta sólo se circunscribió al Suelo Urbanizable No Delimitado, lo que indican los datos disponibles es que no todos los municipios castellanoleoneses que aprobaron su planeamiento entre 1999 y 2008

señalar un plazo - como un máximo de 8 años- para su aprobación, transcurrido el cual los terrenos se considerarán como Suelo Urbanizable No Delimitado. 
incluyeron esta categoría como clase residual ni recurrieron a planes al límite de la capacidad, lo que no es óbice, como veremos también en los ejemplos del alfoz leonés, para que clasificasen suelo de manera expansiva y muy por encima de las necesidades reales. Como ha analizado Marinero (2018), a pesar de la desmesura rayana en el absurdo de la sobreclasificación de suelo en estos municipios afectados por la segunda ronda de desclasificación, lo cierto es que el margen de maniobra que dejó la normativa autonómica permitió a los que optaron por ello realizar clasificaciones de suelo mucho más contenidas ${ }^{31}$, o incluso expansivas pero sin llegar a agotar el límite de la capacidad residual. En este sentido, habrá que esperar a los resultados en 2022 de la tercera ronda de desclasificación prevista para aclarar de forma agregada la intensidad de los excesos en la clasificación del Suelo Urbanizable Delimitado en la región.

\section{EL FRACASO DE LOS INSTRUMENTOS DE ORDENACIÓN TERRITORIAL EN EL ALFOZ LEONÉS}

A continuación, se presenta un repaso de los intentos de redacción de algún instrumento de ordenación territorial a escala supramunicipal en el Área Urbana de León, aunque, como veremos, finalmente ninguno de ellos ha llegado a aplicarse en la práctica.

El primero fue el Plan Comarcal de Ordenación Urbana de León, cuyos trabajos comenzaron en 1969 a iniciativa del ayuntamiento de la capital, incluyendo los municipios de León, Onzonilla, San Andrés, Santovenia, Sariegos, Valverde y Villaquilambre. Su objetivo declarado era la creación de una gran comarca urbana, con una ordenación urbanística común, teniendo como centro administrativo y principal la ciudad de León (García Argüello, p. 78). El Plan se basaba en unas hipótesis muy optimistas de crecimiento demográfico y económico -fundamentadas en una industrialización intensiva-, estimando que la comarca pasaría de 140.000 habitantes en 1973 a 235.000 en 1988. Según Reguera (p. 338): "Bajo los supuestos de desarrollo señalados e incuestionables las tendencias a la concentración de las fuerzas productivas, el espacio comarcal delimitado queda definido como una unidad espacial base de recepción-expansión de elementos productivos, infraestructuras y servicios". Como puede verse en el plano, esta unidad espacial donde se concentra el desarrollo urbano tiene forma de una gran " $Y$ ", estructurada en dos áreas: un Área Urbana, que incluía la ciudad y una pequeña zona de expansión inmediata ${ }^{32}$; y otra, llamada Área Rural-Suburbana, que comprendía el resto del espacio comarcal, incluyendo los núcleos de población predominantemente rural, así como las llamadas zonas de "expectativas de suburbanización" (Reguera, 1987a, p. 338).

\footnotetext{
31 "Quizá porque ese modelo de clasificación total generaba cierto vértigo en la administración, quizá porque su desmesura y falta de lógica eran más evidentes de lo que puede pensarse, fue mucho más frecuente el camino de clasificar paquetes de suelo amplios, de dimensión relevante en comparación con el suelo urbano, pero no tanto en comparación con el conjunto del territorio municipal" (Marinero, 2018).

32 Que quedaba agotada en el propio límite municipal de la ciudad, por lo que las posibilidades reales de oferta de suelo eran muy escasas. (Reguera, 1987a, p. 338).
} 
La mencionada "Y" se configuraba como un eje direccional de crecimiento nortesur de unos $3 \mathrm{Km}$ de anchura media, centrado en la ciudad de León, con una pata central (hacia el sur) de carácter industrial, y dos brazos hacia el norte (siguiendo los ríos Bernesga y Torio) donde se concentraban las "expectativas de suburbanización", traducidas en grandes crecimientos de tipo suburbano en torno a los pequeños núcleos rurales existentes con viviendas unifamiliares para primera y segunda residencia. El modelo resultante, en palabras de Reguera (1987a, p. 338) suponía en realidad "la difusión del modelo de ciudad en el espacio por agregación, expansión y dominio".

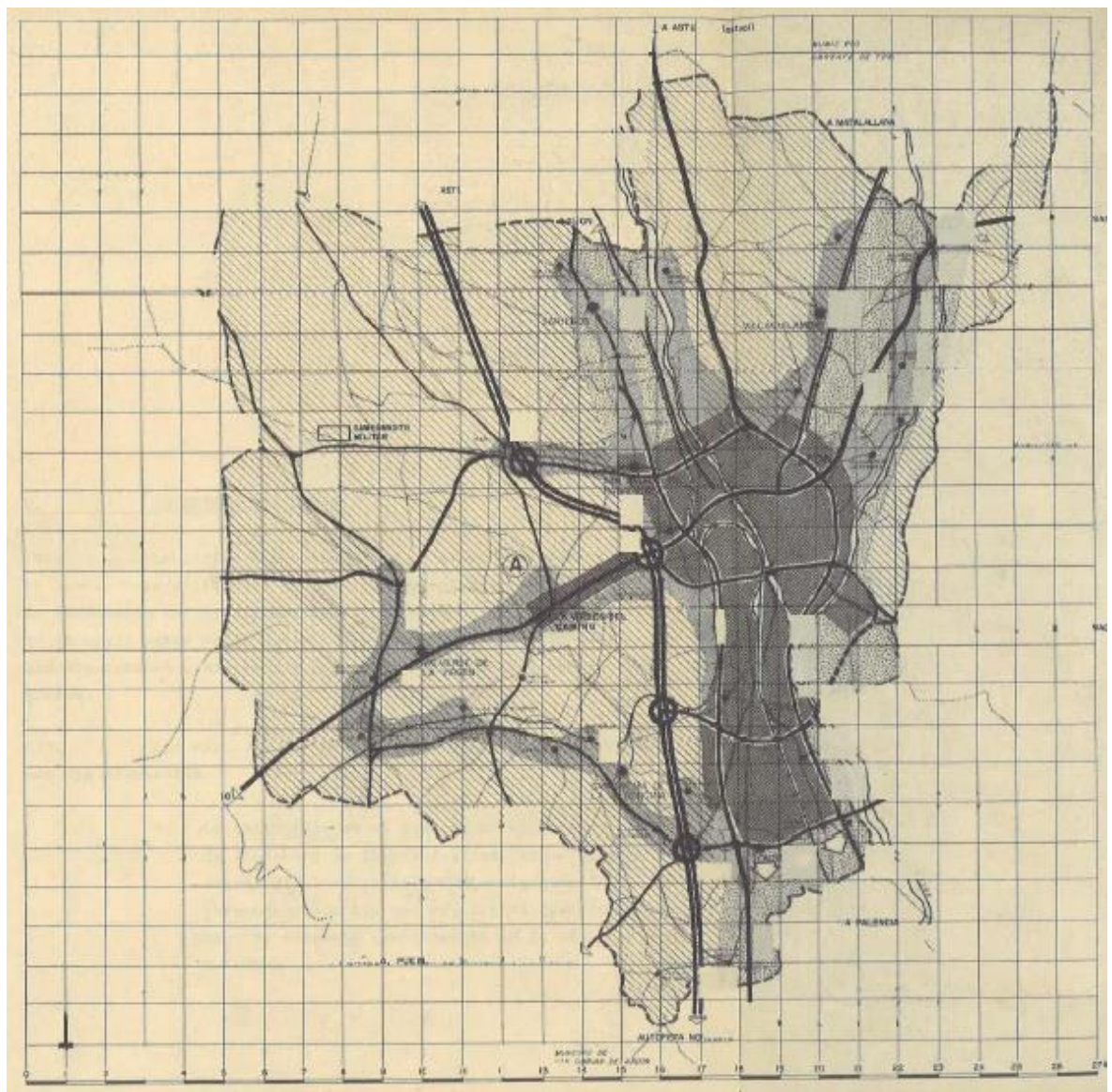

Figura 7. Modelo de desarrollo para el área urbana de León según el Plan Comarcal de Ordenación Urbana de 1971.

Fuente: García Argüello, 2016, p. 80 recogido del Archivo Municipal de León.

Aunque el Plan Comarcal fue aprobado por el Pleno municipal del Ayuntamiento de León celebrado el 17 de septiembre de 1971 (García Argüello, 2016, p.78), no fue asumido por ningún otro municipio del alfoz. Fue tal su desinterés que éstos ni tan siquiera se preocuparon de recoger los ejemplares que les correspondían del Plan (García Argüello, 2016, p.84).

Así pues, un primer motivo del fracaso del Plan Comarcal fue la ausencia de un órgano administrativo de coordinación supramunicipal que se pudiera encargarse de gestionar su aplicación, incluyendo el desarrollo de las determinaciones pertinentes 
para todos los núcleos de población (García Argüello, 2016, p.84). Pero es que, además de esta ausencia, hubo un absoluto desinterés y falta de participación de "las administraciones municipales de los territorios que había que ordenar, puesto que la idea partió directamente desde el Ayuntamiento de León para crear una gran área urbana de expansión, idea no compartida por el resto de municipios limítrofes y que no les interesaba para nada [...]" (García Argüello, 2016, p.84).

También se opusieron al Plan Comarcal los propietarios de los terrenos, que "con él veían frenados sus deseos especulativos y con ellos las plusvalías correspondientes al no poder recalificar o simplemente edificar parcelas de suelo rústico como si fueran urbanas a su antojo, tal y como habían estado haciendo hasta entonces" (García Argüello, 2016, p.84).

En realidad, y como señalaba Reguera (1987a, p. 339) el Plan Comarcal ocultaba una lucha de intereses conflictivos entre municipios, que se pretendía orientar unilateralmente desde la capital: "el Plan Comarcal, formalmente diseñado como instrumento de planificación supramunicipal, se instrumentaliza en realidad como un mecanismo de apropiación, gestión y dominio del suelo que la ciudad de León necesita, pero que se encuentra fuera de su ámbito administrativo. Formalmente el Plan se presentaría como un esfuerzo de coordinación intermunicipal, pero a nadie se le oculta que el elemento dominante es el Ayuntamiento de León [...]" que, ante la falta de suelo disponible en su término municipal ${ }^{33}$, pretendía utilizar el Plan Comarcal para materializar (como ya había hecho de forma más brutal en 1970 al incorporar directamente en un primer asalto el término limítrofe de la Armunia34) "sus expectativas de anexionar los terrenos de las Juntas Vecinales para la ubicación en

\footnotetext{
33 La cantidad de suelo de que disponía el Ayuntamiento de León en 1968 - un año antes de empezarse a redactar el Plan Comarcal- era cuantitativamente muy reducida: 173 ha (Reguera, p. 340). Frente a ello, "las 2.600 ha de propiedad municipal que suman todos los Ayuntamientos incluidos en la «Comarca» formaban una potencial oferta de suelo sobre las que sin duda ejercería opciones prioritarias el presunto Ente Gestor del Plan". (Reguera, p. 341).

${ }^{34}$ La anexión forzada del término municipal de la Armunia en 1970 fue interpretada por los demás ayuntamientos del alfoz como "un primer asalto a los patrimonios públicos de suelo de los municipios vecinos" (Reguera, 1987a, p.340). Según Reguera (1987a, p. 341): "La dotación de terrenos públicos que las Juntas Vecinales de los núcleos del Municipio de Armunia poseían parece ser en principio que tendría algo que ver con la «expansión administrativa» de León hacia el sur al anexionar dicho Municipio. Cabe indicar que este suelo sería tanto más cotizado cuanto que ya se estaban observando tendencias prioritarias de crecimiento de la ciudad hacia el sur. Tan sólo unos años más tarde varias actuaciones urbanísticas de importancia sancionarán estas tendencias direccionales: varias promociones inmobiliarias, ampliación de las instalaciones de RENFE, Mercado Nacional de Ganados, Polígono Industrial y otras en proyecto". Y según García Argüello (2016, pp. 78-79): "La anexión del municipio de Armunia al de León, en 1970, hizo saltar la voz de alarma para que se viera en la aprobación y posterior desarrollo de un Plan Comarcal de Ordenación Urbana el pretexto para incorporar posiblemente otros municipios aledaños, siendo muy codiciadas las propiedades que poseían las Juntas Vecinales, que eran muy extensas y podrían servir para ubicar en ellas algunos de los equipamientos de los que carecía la ciudad o trasladar otros a estos terrenos más baratos y poner en venta los que ocupaban en el casco urbano, con las consiguientes plusvalías y beneficios para el Ayuntamiento de León. Ejemplo muy claro de estas intenciones fue el traslado de las instalaciones del Mercado Nacional de Ganado desde la Avenida José Aguado en el Barrio de La Chantría hasta la localidad de Trobajo del Cerecedo, en donde concretamente la revalorización de los terrenos no fue directamente para los del antiguo Mercado, que sirvió para crear zonas verdes y equipamientos, sino todos los aledaños al mismo que vieron aumentar de forma automática el valor de sus inmuebles".
} 
ellas de infraestructuras o equipamientos, o simplemente para su venta como zonas residenciales para viviendas unifamiliares" (García Argüello, 2016, p. 45).

Desde una posición más humilde, el Plan General de León de 1980 tenía programados para el Segundo Cuatrienio los Ilamados Planes Especiales de Áreas de Contacto con los municipios limítrofes, mediante los cuales pretendía coordinar la ordenación de los bordes (García Argüello,2016, p. 494). Tampoco se desarrollaron.

A finales de los años 90 se produjo la formalización de los instrumentos de ordenación territorial en Castilla y León mediante la Ley 10/1998, de 5 de diciembre, de Ordenación del Territorio, que establece los principios y objetivos de ésta en el ámbito de la Comunidad Autónoma, y regula los instrumentos para que la Junta ejerza sus competencias en la materia. Entre estos instrumentos destacan las Directrices de Ordenación del Territorio (DOT) de Castilla y León, cuyo objetivo es "la ordenación conjunta de la Comunidad mediante la definición de un modelo territorial que pueda utilizarse tanto como marco de referencia para los demás instrumentos de ordenación del territorio, como de orientación general para la política territorial de la Junta". Conforme a su artículo 11, las DOT se formalizan en dos documentos independientes: en primer lugar y con rango legal, el de las Directrices Esenciales, que deben definir el modelo territorial de toda Castilla y León y los principios que guíen el conjunto de las políticas con incidencia territorial; y en segundo lugar y con rango reglamentario, el de las Directrices Complementarias. Transcurridos más de 20 años, sólo han sido aprobadas las Directrices Esenciales, mediante la Ley 3/2008, de 17 de junio.

En realidad, el instrumento que interesa destacar aquí es el de las Directrices de Ordenación de Ámbito Subregional, definidas en el Capítulo III (arts. 14-19) de la Ley 10/1998, pues su objetivo (art. 14) es "la planificación de las áreas de la Comunidad que precisen una consideración conjunta y coordinada de sus problemas territoriales. [...]". Entre sus funciones se encuentran (art. 14.2): "proponer un modelo flexible para la utilización racional del territorio", [...], "definir un marco de referencia, orientación y compatibilización para los planes, programas de actuación y proyectos, tanto sectoriales como locales, con incidencia sobre su ámbito, en especial para los planes de ordenación urbanística [...]", para lo cual deben contener "criterios y normas para el desarrollo urbanístico y para la implantación de nuevos usos y actividades sobre el territorio $[\ldots]^{\prime \prime}$.

Según la Disposición Adicional Tercera, la Junta debía elaborar, en el plazo de 5 años, la documentación necesaria para iniciar el procedimiento de aprobación de Directrices de Ordenación de Ámbito Subregional sobre todo el territorio de la Comunidad, entendiendo como "como ámbitos prioritarios la provincia y en especial los entornos de sus capitales, de forma que se asegure la existencia de una ordenación territorial de nivel subregional que oriente a la planificación sectorial y urbanística, así como a los instrumentos de ordenación del territorio más detallados que fueran necesarios para resolver problemas específicos". En cumplimiento de esta previsión, en los primeros años 2000 se iniciaron las Directrices de Ordenación del Territorio de Ámbito Subregional de varias capitales de provincia, entre ellas las del Área Urbana de León. Sin embargo, sólo se llegaron a aprobar las de Burgos, Segovia 
y Valladolid; de forma que finalmente se terminó por derogar ${ }^{35}$ también la Disposición Adicional Tercera.

Las Directrices de Ordenación del Área Urbana de León (DOAUL) comprendían los municipios de León, Onzonilla, San Andrés de Rabanedo, Santovenia de Valdoncina, Sariegos, Valdefresno, Valverde de la Virgen, Villaquilambre, Villaturiel, Chozas de Abajo, Cuadros, Garrafe de Torío, Vega de Infanzones y Villadangos del Páramo (de manera parcial). Según el Documento de la Fase 2 de Propuesta (de fecha diciembre de 2008) de las DOAUL, el resumen de su contenido es el siguiente:

a) Salvaguarda ambiental y protección patrimonial: Las DOAUL entendían el medio y el paisaje rurales como recursos valiosos y escasos, que deben ser objeto de protección para asegurar su conservación en condiciones adecuadas. En este sentido, identificaban y delimitaban una serie de áreas de interés natural, agropecuario y cultural, con objeto de preservarlas y mejorarlas, clasificándolas como Suelo Rústico. Entre ellas, destacaba la protección de las áreas más sensibles y el control de los usos en los valles del Bernesga y el Torío, como ejes vertebradores del área urbana en materia ambiental, así como la articulación de una red de corredores verdes y la integración paisajística de los crecimientos residenciales en los valles.

En materia ambiental, también consideraban la importancia del riesgo de inundaciones, acentuado además por el cambio climático, y, en consecuencia, establecían afecciones y limitaciones para el desarrollo urbano en las zonas con riesgo.

b) Infraestructuras viarias: Se planteaba un mallado estructurante de la red urbana de carácter supramunicipal, que incluía el cierre por el arco noroeste de la ronda de circunvalación de León LE- $30^{36}$ configurada como viario de alta capacidad con accesos limitados, y la realización de dos bulevares estructurantes en la orilla occidental del Bernesga: un Bulevar Este-Oeste, para asegurar una adecuada conexión del aeropuerto con el conjunto del área urbana (enlazando el final de la variante de la Virgen del Camino y conexión del aeropuerto con la Universidad de León en el límite León-Villaquilambre), y un Bulevar Norte-Sur entre Villabalter y la autovía LE-30, que vertebrase una nueva malla viaria estructurante del crecimiento en esta zona.

c) Ferrocarril: Por un lado, se planteaba la integración funcional de las redes de ferrocarril convencional y de alta velocidad que atraviesan la orilla occidental del Bernesga, en particular en el entorno de la Estación intermodal. Por otro, se proponía la utilización de las redes de RENFE y FEVE para ofrecer un servicio de cercanías a los valles del Torío y del Bernesga.

d) Usos residenciales: Como criterio general se daba prioridad a las formas compactas en continuidad con los núcleos existentes y a la optimización de los sistemas de transporte. En relación con los usos residenciales (artículo 40 de la Normativa de las

\footnotetext{
35 Derogada mediante la Disposición Derogatoria Única de la Ley $7 / 2013$, de 27 septiembre, de Ordenación, Servicios y Gobierno del Territorio de la Comunidad de Castilla y León.

${ }^{36}$ El trazado propuesto enlazaba el actual final norte de la circunvalación dirigiéndose hacia el sur, bordeando por el norte el núcleo de El Ferral (San Andrés del Rabanedo), para enlazar con la N-120 a la altura de la A-66, permitiendo un enlace con la nueva salida prevista para la Ronda Sur.
} 
DOAUL), por un lado se proponía la concentración preferente del crecimiento residencial en el interior del recinto de la ronda de León LE-30, reforzando así su papel de centralidad en el conjunto del área urbana y aprovechando la concentración de empleos y grandes equipamientos, especialmente en torno a la nueva área de oportunidad propuesta en la orilla derecha del Bernesga (Bulevares de articulación y mallado urbano, integración ferroviaria, etc.). Por otra parte, se proponía orientar preferentemente el resto del crecimiento residencial hacia las cabeceras y los núcleos urbanos ya consolidados de los diferentes municipios, planteando un desarrollo por continuidad en torno a los núcleos existentes que evitase la conformación de corredores residenciales lineales parasitando el viario. Para ello, se establecía que, mientras estuviesen vigentes las DOAUL, el crecimiento por continuidad no podría superar el necesario para que el núcleo incrementase su población inicial un $25 \%$, considerando a efectos de cálculo una densidad de 70 hab/ha.

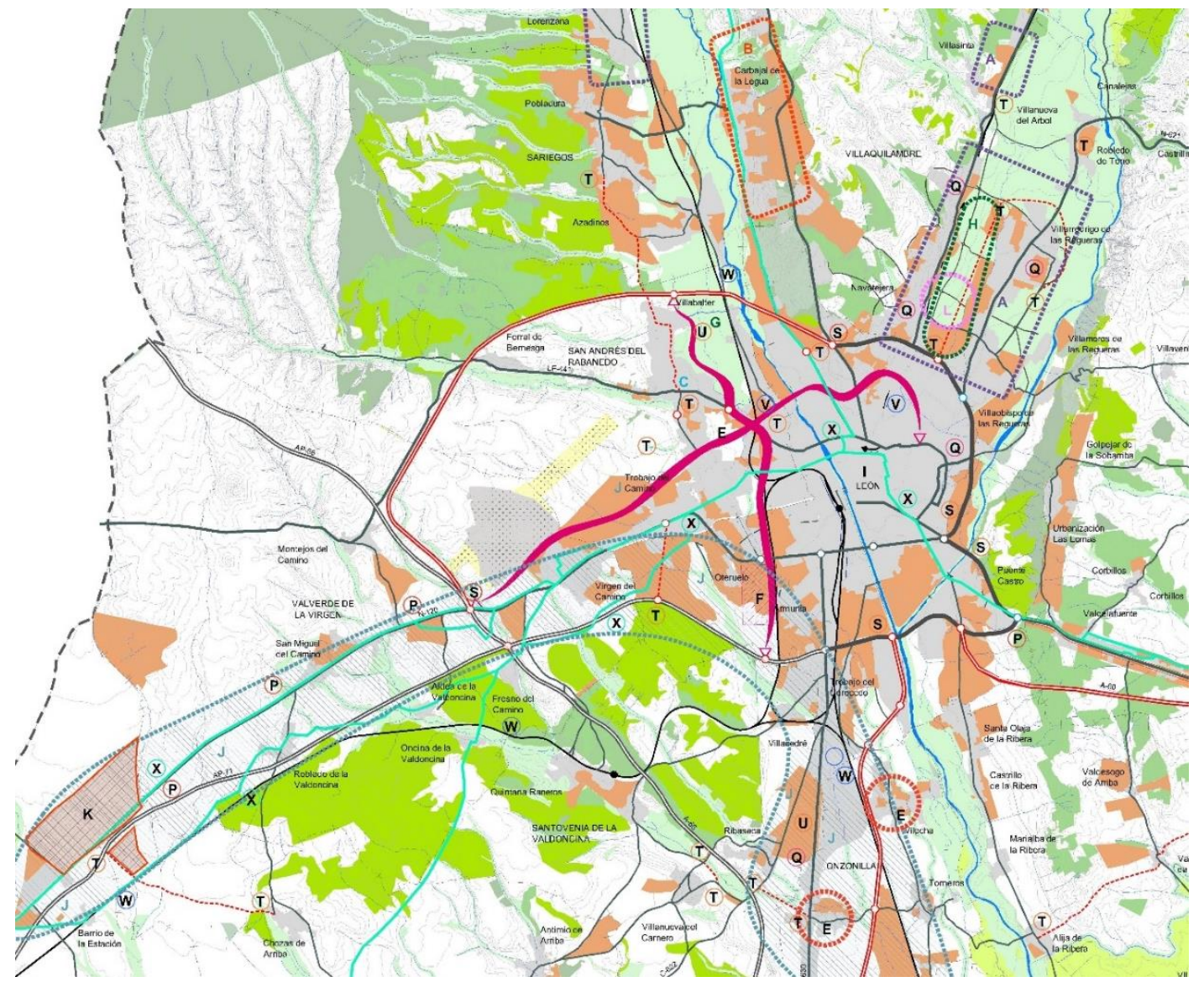

Figura 8. Modelo territorial y propuestas estructurantes de las DOAUL. (Diciembre de 2008). Fuente: OMICRON AMEPRO Ezquiaga Arquitectura Sociedad y Territorio SL.

e) Usos del suelo para actividades económicas. En el artículo 41 de las DOAUL se planteaba que las grandes actuaciones en materia industrial y logística deberían localizarse preferentemente en torno al arco viario definido por las autovías AP-71 León-Astorga, A-66 León-Benavente y A-231 León-Burgos, en torno al cual habrían de desarrollarse nuevas áreas de oportunidad para estas actividades. 
Por su parte, las actividades de carácter terciario administrativo deberían localizarse en el centro urbano de León, junto al área de la estación intermodal o en el entorno de la Universidad y el Parque Tecnológico. Finalmente, para las de carácter terciario de gran superficie comercial se planteaba su ubicación en el entorno de la LE-30.

f) Planeamiento urbanístico. Las DOAUL contenían sólo unas determinaciones muy genéricas sobre planeamiento, pues no entraban en la cuantificación de la capacidad de viviendas o suelo propuestas por los planes municipales. Sí incluían - con carácter de aplicación plena- unos criterios básicos para la formulación del planeamiento municipal (artículo 45) y unos objetivos estratégicos para el planeamiento municipal (artículo 46), así como unas reglas mínimas acreditar la consistencia y coherencia territorial de los planes municipales. Sin duda, en este capítulo, lo más relevante era la Disposición Adicional Primera, por la que se pretendían modificar algunas disposiciones del planeamiento municipal vigente. En concreto, se proponía reclasificar como Suelo Rústico de protección de riberas y prados asociados algunos sectores clasificados como Suelo Urbanizable: en Garrafe de Torío, los emplazados a lo largo de la carretera LE-311 y en el área recreativa de las Manzanedas, por inadecuación al modelo de protección del paisaje propuesto en las Directrices; en Villaquilambre, los sectores emplazados a menos de 100 metros del cauce del río Torío; y, en Sariegos, los situados en la orilla occidental del Bernesga, entre su cauce y los trazados ferroviarios.

Nuevamente, el fracaso de las DOAUL se debió a su rechazo por parte de los municipios del alfoz en su competencia entre sí por atraer el crecimiento urbanístico hacia sus respectivos términos municipales ${ }^{37}$. A modo de ejemplo, en febrero de 2006 el Ayuntamiento de Villaquilambre - que entonces estaba redactando en paralelo su Plan General- manifestó su oposición a las Directrices presentando una serie de alegaciones en contra, pues éstas planeaban un gran parque entre Villaobispo, Navatejera, Villarrodrigo y Villaquilambre, precisamente allí donde el municipio quería plantear un gran área de crecimiento urbanístico entre todos estos núcleos, así como el proyecto de la "Ciudad del Estudiante" o una zona de expansión de la Universidad de León (García Argüello, 2016, p. 103). Igualmente presentó alegaciones el Ayuntamiento de Santovenia sobre el proyecto de un gran bulevar ajardinado a su paso por el núcleo de Villacedré, en dirección Norte-Sur que discurría a lo largo de 10 km hasta Villabalter para conectar con Azadinos. Para las Directrices, este trazado era un emplazamiento óptimo para ubicar a lo largo de él grandes equipamientos dando servicio al conjunto del área urbana y para la creación de un gran espacio libre en el cuadrante noroeste comprendido entre las rondas (García Argüello, 2016, p. 103). Para el Ayuntamiento, que ya tenía ya aprobadas sus NNSS desde 1995, esto implicaba anular el desarrollo urbano previsto en Villacedré.

\footnotetext{
37 En un debate sobre el urbanismo en León, celebrado en aquellos años, Rafael Santamaría, entonces presidente del Colegio de Arquitectos, (VVAA, 2007) decía sobre las Directrices: "No ha habido voluntad. Yo he oído hablar en el Consejo de Urbanismo a algún Director General decir: "Háganse los Planes Generales, que luego haremos las Directrices". También pesimista, pero con otro matiz, se mostraba Óscar García Luna (VVAA, 2007): "Yo sé que va a haber Directrices en León, pero también sé que van a ser la suma del actual Plan General de León, ligerísimamente retocado, el Plan de San Andrés y el Plan de Villaquilambre".
} 
Abortadas las Directrices, con posterioridad sólo ha habido algún documento de coordinación sectorial, como el Plan Regional de Ámbito Territorial (PRAT) para la Planificación de las Actuaciones Urbanísticas derivadas de la implantación de las nuevas infraestructuras ferroviarias en los municipios de León, San Andrés del Rabanedo, Santovenia de la Valdoncina, Onzonilla y Vega de Infanzones, aprobado en 2010 y cuyo desarrollo posterior ha sido un completo fracaso, en gran medida por el exceso de optimismo de sus cálculos de viabilidad basados en las plusvalías urbanísticas del suelo liberado como motor y mecanismo de financiación del urbanismo ${ }^{38}$.

\section{EL MOSAICO DEL PLANEAMIENTO URBANÍSTICO MUNICIPAL EN EL ÁREA URBANA DE LEÓN: UN ANÁLISIS CUANTITATIVO}

\subsection{El mosaico del planeamiento municipal: cuantificación de la desmesura en la clasificación de suelo}

En consecuencia, y ante la ausencia de instrumentos a escala supramunicipal, la ordenación urbanística del territorio del alfoz leonés no es más que el mosaico o la mera yuxtaposición de los distintos instrumentos de planeamiento municipal. Veamos su génesis y evolución.

Durante la época del desarrollismo tardío de los 70, y ante las expectativas de desarrollo despertadas en los municipios del alfoz urbanístico -que hemos visto en el Plan Comarcal-, algunos de ellos consiguieron aprobar un primer instrumento de planeamiento para canalizarlas: es el caso de Sariegos (NNSS de 1974) o Garrafe de Torío (NNSS de 1976). Durante los años 80, y, en el marco del nuevo urbanismo que caracterizó a los primeros ayuntamientos democráticos, hay que destacar la aprobación en 1982 del PG de León, revisando el de 1960, y las NNSS de San Andrés de 1986, que -aunque se habían comenzado en los 70- no habían conseguido sacarse adelante en la ronda anterior.

Hubo que esperar hasta los años 90 para que comenzase la redacción del planeamiento en el resto de los municipios del alfoz, aprobándose las primeras NNSS de Villaquilambre en 1993, y las de Santovenia en 1995, de manera que el planeamiento fue muy por detrás de la presión urbanística, lo que explica la aparición de numerosas urbanizaciones ilegales ${ }^{39}$. Ya en la segunda mitad de la década, y al calor del boom inmobiliario, todos los municipios del ámbito de estudio iniciaron la aprobación o la revisión de su planeamiento urbanístico (excepto Santovenia, que mantuvo las NNSS de 1995). Por su fecha de aprobación, también la práctica totalidad de estos instrumentos se aprobó durante el período de vigencia (1998-2007) de la

\footnotetext{
38 Para contribuir a la financiación del soterramiento del ferrocarril en 2002 se previeron inicialmente de 3.000 viviendas, que pasaron a ser 6.000 posteriormente, cifra que la crisis inmobiliaria ha dejado completamente fuera de la realidad. El Diario de León, 29 de noviembre de 2020: "La integración del tren deja flecos".

${ }^{39}$ Como recogen las DOAUL (2008, p.260) "esta actividad ilegal se ha apoyado no sólo en la ausencia de planeamiento, sino también en la falta de capacidad técnica (cuando no de voluntad política) para ejercer un control efectivo sobre los procesos urbanísticos, aún con recurso a la normativa subsidiaria de carácter provincial o a la legislación estatal".
} 
legislación de suelo estatal de 1998, que -como se ha comentado- impulsaba la liberalización del Suelo Urbanizable. A su vez, una gran mayoría de ellos se encuadra además en el marco normativo autonómico castellano leonés posterior a la Sentencia del Tribunal Constitucional de 1997, conformado por la Ley 5/1999, de 8 de abril, de Urbanismo de Castilla y León y su correspondiente Reglamento (Decreto 22/2004), que definió los contenidos de las figuras de planeamiento de las Normas Urbanísticas Municipales (NUM) ${ }^{40}$ y los Planes Generales de Ordenación, obligando también a adaptarse a este nuevo marco a los instrumentos aprobados con anterioridad ${ }^{41}$. Así en 1999 se aprobó la revisión de las NNSS de San Andrés; en 2000 las primeras NNSS de Valverde; en 2001 las NUM de Onzonilla, Villaturiel y Sariegos; en 2003 las de Villadangos; en 2004 las de Cuadros; y en 2005 las de Chozas.

Más allá del tortuoso cumplimiento de estas previsiones y plazos ${ }^{42}$, sin embargo, lo que nos interesa destacar aquí es la aprobación definitiva de varios instrumentos ya cambiado el ciclo inmobiliario, en plena fase recesiva: en 2010, el PG de San Andrés; en 2011, el PG de Villaquilambre y las NUM de Villaturiel; en 2013, las NUM de Onzonilla; y en 2015, las NUM de Garrafe de Torío. Siendo todos estos planes revisiones, ya en plena crisis económica e inmobiliaria, de otros instrumentos previos, lo significativo, es que - como queda reflejado en sus cifras de clasificación de suelo, en lugar de recortar previsiones, continúan con la inercia del crecimiento y siguen siendo de tipo claramente expansivo, sin hacer referencia alguna en su documentación a este profundo cambio de contexto.

\footnotetext{
40 Figura más o menos equivalente a las tradicionales Normas Subsidiarias de Planeamiento (NNSS).

41 La Disposición Transitoria Primera de la Ley 5/1999 establece que los municipios con población igual o superior a 20.000 habitantes deberían adaptarse a ella cuando procedieran a la Revisión de sus respectivos Planes Generales, y en cualquier caso antes de cuatro años (lo que obligaba a adaptar los PG de León y San Andrés, aunque también lo ha hecho Villaquilambre). Los municipios con población inferior a 20.000 habitantes deben adaptarse cuando procedan a la elaboración o revisión de su instrumento de planeamiento general. Dentro de estos, también se exigía a los municipios con población igual o superior a 5.000 habitantes sin planeamiento general vigente, contar con Normas Urbanísticas Municipales (NUM) antes de 2 años desde la entrada en vigor de la Ley. Para los menores de esta población no se exige ningún instrumento.

42 El caso de San Andrés del Rabanedo muestra estas dificultades. Tras intentar aprobar infructuosamente un Plan General durante los años 80, San Andrés consiguió sacar adelante unas primeras NNSS aprobadas definitivamente el 24 de julio de 1986, y que después fueron modificadas en numerosas ocasiones. Entre otras, el 16 de diciembre de 1999, para adaptarlas a la legislación aprobada con posterioridad (Ley estatal de Suelo de 1998). Sin embargo, esta modificación ya nació obsoleta, pues fue posterior a la aprobación de la Ley 5/1999, de 8 de abril, de Urbanismo de Castilla y León, que, según su Disposición Transitoria Primera, obligaba a los municipios mayores de 20.000 habitantes a adaptarse a la misma antes de 2 años. Expirado este plazo el 5 de mayo de 2003, las NNSS estuvieron vigentes una década, y aunque se modificaron en numerosas ocasiones ( 25 de octubre de 2001, 21 de enero de 2002,21 de marzo de 2003 y 6 de julio de 2004) en realidad nunca se adaptaron a la Ley ni al Reglamento de Urbanismo de Castilla y León. En lugar de proceder a la adaptación, se fue redactando en paralelo un nuevo Plan General, cuya aprobación definitiva se dilató hasta 2010, ya en un contexto completamente diferente al del boom en que se había gestado.
} 


\begin{tabular}{|c|c|c|c|c|c|c|c|c|c|c|c|c|}
\hline & $\begin{array}{l}\text { Figura de } \\
\text { planeamiento }\end{array}$ & $\begin{array}{c}\text { Año } \\
\text { aprobación } \\
\text { definitiva }\end{array}$ & Suelo Urbano & $\begin{array}{c}\text { Suelo } \\
\text { Urbano } \\
\text { Consolidado }\end{array}$ & $\begin{array}{c}\text { SUNC+SUZ } \\
\text { D+SUZND }\end{array}$ & $\begin{array}{c}\text { Suelo Urbano } \\
\text { No } \\
\text { Consolidado }\end{array}$ & \begin{tabular}{|c|} 
Edificabilidad \\
Suelo Urbano \\
No \\
Consolidado \\
\end{tabular} & $\begin{array}{c}\text { Suelo } \\
\text { Urbanizable } \\
\text { Delimitado }\end{array}$ & \begin{tabular}{|c|} 
Edificabilidad \\
Suelo \\
Urbanizable \\
Delimitado \\
\end{tabular} & $\begin{array}{c}\text { Suelo } \\
\text { Urbanizable } \\
\text { No } \\
\text { Delimitado }\end{array}$ & $\begin{array}{c}\text { Suelo No } \\
\text { Urbanizable }\end{array}$ & SG \\
\hline TOTAL León & PG adaptado & 2004 & $1.764,3$ & $1.312,1$ & $1.514,2$ & 452,2 & $2.796 .877,3$ & $1.062,0$ & $5.295 .922,4$ & - & $1.075,7$ & 27,6 \\
\hline Onzonilla & NUM & 2013 & 355,2 & 347,4 & 282,3 & 7,8 & $39.942,7$ & 274,5 & $1.511 .965,7$ & - & $1.548,4$ & - \\
\hline San Andrés del Rabanedo & PG adaptado & 2010 & 621,7 & 514,8 & 563,7 & 106,9 & $684.287,6$ & 456,8 & $2.109 .193,9$ & & $5.417,2$ & - \\
\hline Santovenia de la Valdoncina & NNSS & 1995 & 210,5 & 182,6 & 119,1 & 27,9 & - & 91,2 & - & - & $2.747,9$ & - \\
\hline Sariegos & NUM & 2001 & 286,3 & 181,6 & 640,8 & 104,7 & $73.774,0$ & 266,5 & $1.254 .106,1$ & 269,6 & $2.833,1$ & - \\
\hline Valdefresno & NUM & 2003 & 253,7 & 251,0 & 220,6 & 2,7 & - & 65,1 & $24.796,3$ & 152,8 & $9.802,6$ & - \\
\hline Valverde de la Virgen & NNSS & 2000 & 250,1 & 239,7 & 304,6 & 10,4 & $62.754,0$ & 155,4 & $325.650,5$ & 138,8 & $5.823,8$ & - \\
\hline Villaquilambre & PG adaptado & 2011 & 634,2 & 558,7 & 645,4 & 75,5 & $429.177,0$ & 569,9 & $2.419 .882,0$ & - & $4.066,6$ & - \\
\hline TOTAL Área Urbana de León & & & $2.611,7$ & $2.275,8$ & $2.776,5$ & 335,9 & $1.289 .935,4$ & $1.879,4$ & $7.645 .594,5$ & 561,2 & $32.239,6$ & - \\
\hline Cuadros & NUM & 2004 & 262,9 & 206,3 & 171,2 & 56,6 & $273.372,0$ & 23,4 & $66.097,0$ & 91,2 & $10.505,2$ & - \\
\hline Chozas de Abajo & NUM & 2005 & 353,0 & 293,4 & 426,2 & 59,6 & $55.881,0$ & 363,1 & $159.475,0$ & 3,5 & $9.339,3$ & - \\
\hline Garrafe de Torío & NUM & 2015 & 300,3 & 291,4 & 119,5 & 8,9 & $36.326,0$ & 110,6 & $522.812,8$ & - & $12.119,4$ & - \\
\hline Villadangos del Páramo & NNSS & 2003 & 109,3 & 107,3 & 235,1 & 2,0 & $9.550,0$ & 233,1 & $1.066 .662,5$ & - & $4.152,5$ & - \\
\hline Villaturiel & NUM & 2011 & 308,3 & 256,8 & 77,3 & 51,5 & $247.334,0$ & 25,8 & $128.893,5$ & - & $5.369,3$ & - \\
\hline \multicolumn{2}{|c|}{ TOTAL Ampliación Área Urbana de León } & & $1.333,8$ & $1.155,2$ & $1.029,3$ & 178,6 & $622.463,0$ & 756,0 & $1.943 .940,8$ & 94,7 & $41.485,7$ & - \\
\hline \multicolumn{2}{|c|}{ TOTAL Área Urbana de León+Ampliación } & & $3.945,5$ & $3.431,0$ & $3.805,8$ & 514,5 & $1.912 .398,4$ & $2.635,4$ & $9.589 .535,3$ & 655,9 & $73.725,3$ & - \\
\hline \multicolumn{2}{|c|}{ TOTAL León+Área Urbana de León+Ampliación } & & $5.709,8$ & $4.743,1$ & $5.320,0$ & 966,7 & $4.709 .275,6$ & $3.697,4$ & $14.885 .457,6$ & 655,9 & $74.801,0$ & 27,6 \\
\hline
\end{tabular}

Figura 9. Resumen del planeamiento urbanístico municipal en el alfoz de León. Suelo Clasificado. SUNC: Suelo Urbano No Consolidado, SUZD: Suelo Urbanizable Delimitado, SUZND: Suelo Urbanizable No Delimitado. (Unidades de Superficie: Hectáreas (ha). Unidades de Edificabilidad: $\mathrm{m}^{2} \mathrm{c} / \mathrm{m}^{2} \mathrm{~s}$ )

Fuente: Elaboración propia a partir del Sistema de Información Urbana (SIU) del MITMA (2020).

\begin{tabular}{|c|c|c|c|c|c|c|c|}
\hline & $\begin{array}{c}\text { Figura de } \\
\text { planeamiento }\end{array}$ & pob 2019 & $\%$ & $\begin{array}{l}\text { SU/1000 } \\
\text { hab }\end{array}$ & $\begin{array}{c}\text { SUNC+SUZD+SUZ } \\
\text { ND/1000 hab }\end{array}$ & $\begin{array}{c}\% S U N C+S U Z D+S U \\
Z N D / S U\end{array}$ & $\begin{array}{c}\% S U N C+S U Z D+S U \\
\text { ZND/SNU }\end{array}$ \\
\hline TOTAL León & PG adaptado & 124.303 & 61,8 & 10,6 & 12,2 & 115,4 & 140,8 \\
\hline Onzonilla & NUM & 1.835 & 0,9 & 189,3 & 153,8 & 81,3 & 18,2 \\
\hline San Andrés del Rabanedo & PG adaptado & 30.615 & 15,2 & 16,8 & 18,4 & 109,5 & 10,4 \\
\hline Santovenia de la Valdoncina & NNSS & 2.126 & 1,1 & 85,9 & 56,0 & 65,2 & 4,3 \\
\hline \begin{tabular}{|l|} 
Sariegos \\
\end{tabular} & NUM & 5.050 & 2,5 & 36,0 & 126,9 & 352,9 & 22,6 \\
\hline Valdefresno & NUM & 2.187 & 1,1 & 114,8 & 100,9 & 87,9 & 2,3 \\
\hline Valverde de la Virgen & NNSS & 7.328 & 3,6 & 32,7 & 41,6 & 127,1 & 5,2 \\
\hline Villaquilambre & PG adaptado & 18.638 & 9,3 & 30,0 & 34,6 & 115,5 & 15,9 \\
\hline TOTAL Área Urbana de León & & 67.779 & 33,7 & 33,6 & 41,0 & 122,0 & 8,6 \\
\hline Cuadros & NUM & 2.001 & 1,0 & 103,1 & 85,6 & 83,0 & 1,6 \\
\hline Chozas de Abajo & NUM & 2.581 & 1,3 & 113,7 & 165,1 & 145,3 & 4,6 \\
\hline Garrafe de Torío & NUM & 1.504 & 0,7 & 193,8 & 79,5 & 41,0 & 1,0 \\
\hline Villadangos del Páramo & NNSS & 1.132 & 0,6 & 94,8 & 207,7 & 219,1 & 5,7 \\
\hline Villaturiel & NUM & 1.852 & 0,9 & 138,7 & 41,7 & 30,1 & 1,4 \\
\hline \multicolumn{2}{|c|}{ TOTAL Ampliación Área Urbana de León } & 9.070 & 4,5 & 127,4 & 113,5 & 89,1 & 2,5 \\
\hline \multicolumn{2}{|c|}{ TOTALÁrea Urbana de León+Ampliación } & 76.849 & 38,2 & 44,6 & 49,5 & 110,9 & 5,2 \\
\hline \multicolumn{2}{|c|}{ TOTAL León+Área Urbana de León+Ampliación } & 201.152 & 100,0 & 23,6 & 26,4 & 112,2 & 7,1 \\
\hline
\end{tabular}

Figura 10. Indicadores de suelo clasificado por 1.000 habitantes en el planeamiento urbanístico municipal en el alfoz de León. (Unidades: Hectáreas (ha). SUNC: Suelo Urbano No Consolidado, SUZD: Suelo Urbanizable Delimitado, SUZND: Suelo Urbanizable No Delimitado.

Fuente: Elaboración propia a partir del Sistema de Información Urbana (SIU) del MITMA (2020).

El Suelo Urbano Consolidado en todo el territorio analizado ocupa 4.743,1 ha, de las cuales el $48 \%$ se ubica en los municipios Área Urbana, el $27,7 \%$ en la capital y el $24,4 \%$ en los pequeños municipios que hemos denominado Ampliación del Área Urbana, que, aunque en población y viviendas no eran muy relevantes, sí lo son en términos de planeamiento urbanístico, pues el suelo ocupado en ellos es casi equivalente al de la ciudad de León, cuya población es 14 veces superior ${ }^{43}$.

${ }^{43}$ La Ampliación del Área Urbana, con sólo el 4,5\% de la población, supone el 23,4\% del Suelo Urbano de todo el conjunto de municipios analizados. Ello es debido a su baja densidad, consecuencia de un modelo extensivo de ocupación de suelo: 127,4 ha por cada 1.000 habitantes, frente a las 10,6 ha/1.000 hab. ocupadas en la ciudad de 
El suelo previsto en el planeamiento para el desarrollo urbano (incluyendo el Urbano No Consolidado y el Urbanizable), que es el objeto central de nuestro análisis, asciende a 5.805,8 ha, lo que significa una previsión de superficie mayor que toda la consolidada hasta la actualidad; de forma gráfica, equivaldría a decir que el total de suelo previsto para la urbanización durante el boom inmobiliario fue igual o mayor al de la toda la superficie ocupada por la ciudad desde su fundación. Su reparto es muy similar al del Suelo Urbano Consolidado: un 52,2\% en el Área Urbana, un el $28,5 \%$ en la capital y el 19,3\% en la Ampliación. De estos suelos, la mayor parte corresponde a Suelo Urbanizable Delimitado (3.697,4 ha, con una edificabilidad de 14,8 millones de $\left.\mathrm{m}^{2}\right), 966,7 \mathrm{ha}$-con una edificabilidad de 4,7 millones de $\mathrm{m}^{2}-$ a Suelo Urbano No Consolidado, y 655 ha a Suelo Urbanizable No Delimitado ${ }^{44}$.

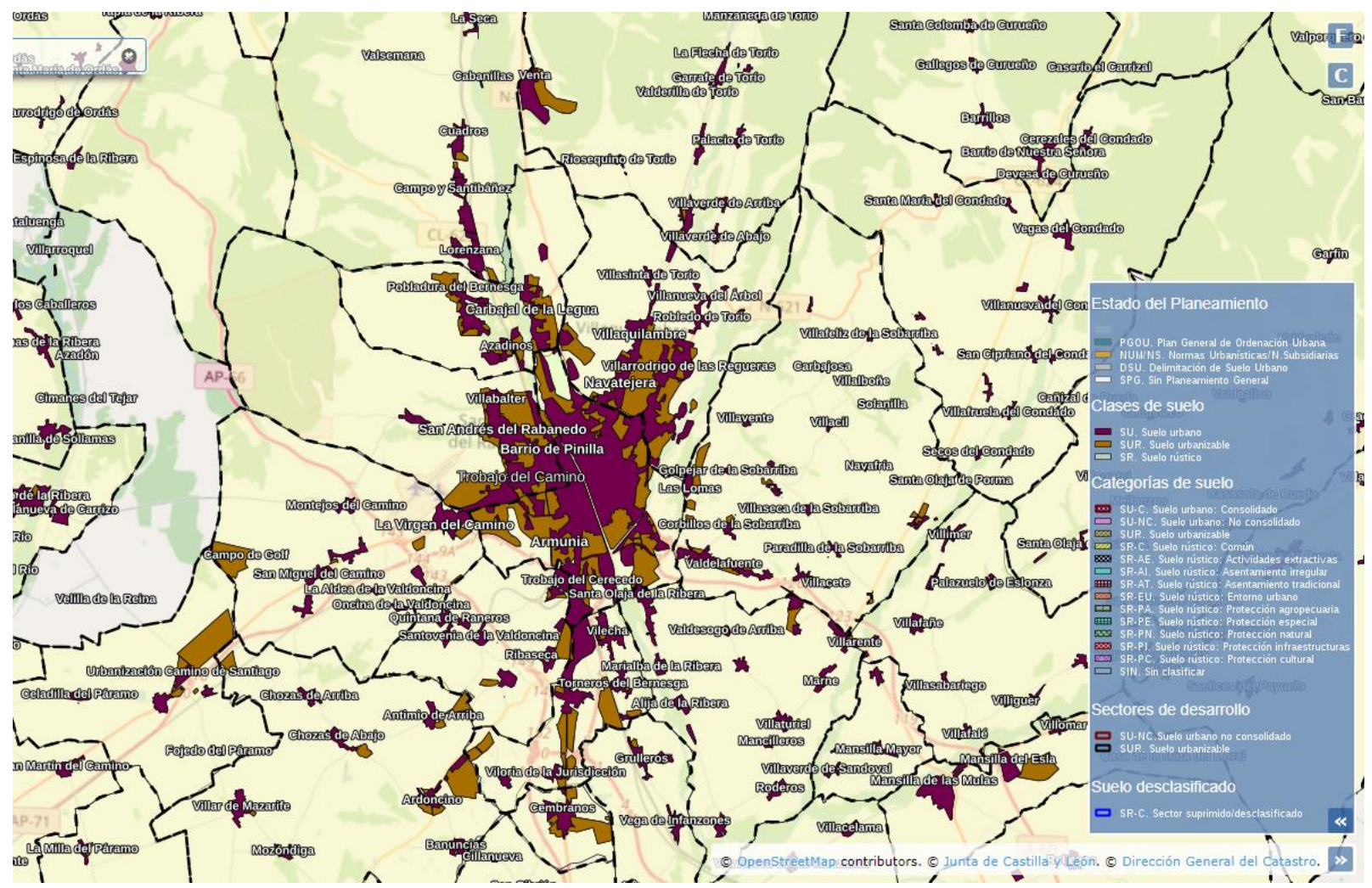

Figura. 11. Mosaico de planeamiento municipal en el área urbana de León y su entorno. (Suelo Urbano: morado. Suelo Urbanizable: ocre).

Fuente: Sistema de Información Urbanística de Castilla y León. https://idecyl.jcyl.es/siur/

Los mayores crecimientos en términos de suelo por habitante, con ratios superiores a las 100 ha por cada 1.000 habitantes - de 2019- se producen en

León, o las 33,6 ha en el Área Urbana. También hay que destacar que, en estos municipios, a pesar de su escasa población actual, es donde se prevén los crecimientos relativos más intensos: el suelo previsto para el desarrollo urbanístico (Suelo Urbano + Urbanizable) asciende a 113,5 ha por cada 1.000 habitantes, frente a las 41 ha previstas en el Área Urbana, y las 12,2 ha de la ciudad de León. Esta dinámica de mayor crecimiento previsto en la periferia es consecuente con la difusión de los procesos micro metropolitanos, en los que, en términos relativos, el dinamismo se va desplazando del centro a la periferia.

${ }^{44}$ Como se verá más adelante, este último suelo se ha terminado desclasificando entre 2016 y 2018. 
Villadangos (207,7 ha/1.000 hab), Chozas (165,1), Onzonilla $(153,8)$, Sariegos $(126,9)$ y Valdefresno $(100,9)$. Y los mayores incrementos de nuevo suelo en relación con el ya consolidado, por encima de su duplicación, se dan en Sariegos, donde la suma de Suelo Urbano No Consolidado y Suelo Urbanizable multiplica por 3,5 el Suelo Urbano Consolidado existente; en Villadangos, por 2,19; en Chozas, por 1,45; en Valverde, por 1,27; en Villaquilambre, por 1,15; y, en San Andrés, por 1,09. Además, Onzonilla, Valdefresno y Cuadros, también se acercan casi a la duplicación del suelo existente, pues en ellos este cociente supera el valor de 0,8.

En definitiva, desde el punto de vista cuantitativo, las distintas figuras de planeamiento urbanístico municipal vigente en el Área Urbana de León son claramente expansionistas en su dimensionado de suelo.

\subsection{Las piezas del puzle resultante: análisis detallado del suelo para el desarrollo urbano previsto por el planeamiento en el alfoz de León}

En este epígrafe se analizan las características de los ámbitos de Suelo Urbano No Consolidado y de los sectores de Suelo Urbanizable que constituyen las piezas previstas para el desarrollo urbano en el mosaico de los planes urbanísticos de los municipios del alfoz de León. Para ello se ha trabajado con los datos brutos disponibles del Sistema de Información Urbana (SIU) del MITMA, publicados en 2020.

\begin{tabular}{|c|c|c|c|c|c|c|}
\hline Urbano No Consolidado Residencial & № Ambitos & $\%$ & Superficie & $\%$ & Edificabilidad & $\%$ \\
\hline Total Menor $1 \mathrm{Ha}$ & 46 & 18,9 & $323.998,6$ & 3,7 & 151.462 & 3,5 \\
\hline Total 1-2,5 Has & 95 & 38,9 & $1.598 .707,7$ & 18,1 & 821.213 & 18,9 \\
\hline Total 2,5-5 Has & 69 & 28,3 & $2.351 .015,9$ & 26,6 & 1.326 .784 & 30,6 \\
\hline Total 5-10 Has & 21 & 8,6 & $1.490 .734,2$ & 16,9 & 880.774 & 20,3 \\
\hline Total $10-20$ Has & 8 & 3,3 & $1.117 .603,4$ & 12,7 & 582.522 & 13,4 \\
\hline Total Mas 20 Has & 5 & 2,0 & $1.948 .566,1$ & 22,1 & 573.871 & 13,2 \\
\hline Total general & 244 & 100,0 & $8.830 .625,9$ & 100,0 & 4.336 .627 & 100,0 \\
\hline
\end{tabular}

Figura.12. Distribución de los ámbitos de Suelo Urbano No Consolidado de uso global residencial por rangos de tamaño. Unidades de Superficie: $\mathrm{m}^{2}$. Unidades de Edificabilidad: $\mathrm{m}^{2} \mathrm{c} / \mathrm{m}^{2} \mathrm{~s}$.

Fuente: Elaboración propia a partir de explotación de datos del Sistema de Información Urbana (SIU), MITMA, 2020.

Comenzando por el Suelo Urbano No Consolidado, existen en total 257 ámbitos de que ocupan una superficie de 966,5 ha, con un techo edificable de 4,7 millones de $\mathrm{m}^{2}$, de los cuales 883 ha y 4,3 millones de $\mathrm{m}^{2}$ corresponden a 244 ámbitos de uso global residencial.

Según se observa en la tabla de la Figura 12, estos 244 ámbitos de uso residencial son, en general, de pequeño tamaño medio (3,6 ha), correspondiendo el $86,1 \%$ (concretamente 210 ) a superficies menores de 5 ha, aunque sólo suponen el $48,4 \%$ de la superficie (427,3 ha). El resto de los ámbitos se reparte del siguiente modo: 21 de entre 5 y 10 ha (que suponen en $16,9 \%$ de la superficie y el $20,3 \%$ de la edificabilidad); 8 de entre 10 y 20 ha (que suman 111,7 ha y suponen el $13,4 \%$ de la edificabilidad) y otros 5 sectores mayores de 20 ha (que ocupan 194,8 ha y acogen el $13,2 \%$ de la edificabilidad). De estos 5 ámbitos residenciales mayores de 20 ha, el más extenso corresponde al municipio de Sariegos, donde el planeamiento optó por incluir en un único ámbito todo el Suelo Urbano No Consolidado del término (SUNC- 
01 , con una superficie de 102,4 ha) y los otros 4 restantes son del municipio de León (NC03-02, NC01-01, NC10-02, NC14-01), donde también se ubican otros 6 de los 8 ámbitos comprendidos entre 10 y 20 ha (SOA 03-01, NC14-02, NC06-01, NC20-01, NC14-03, NC01-02).

Por su parte, el SUNC de uso global industrial se distribuye en 13 ámbitos de una superficie comprendida entre 0,7 y 14,9 ha, ocupando un total de 64,6 ha y con una edificabilidad máxima prevista de 0,28 millones de $\mathrm{m}^{2}$. Estos suelos se ubican exclusivamente en dos municipios: León y Villaturiel. En León se sitúan 9 sectores con una extensión de 54,7 ha, y los otros 4 en Villaturiel, con 9,8 ha.

Además, en la capital también se ubica el único ámbito de uso global terciario previsto, con una superficie de 18,8 ha y una edificabilidad de $84.519 \mathrm{~m}^{2}$.
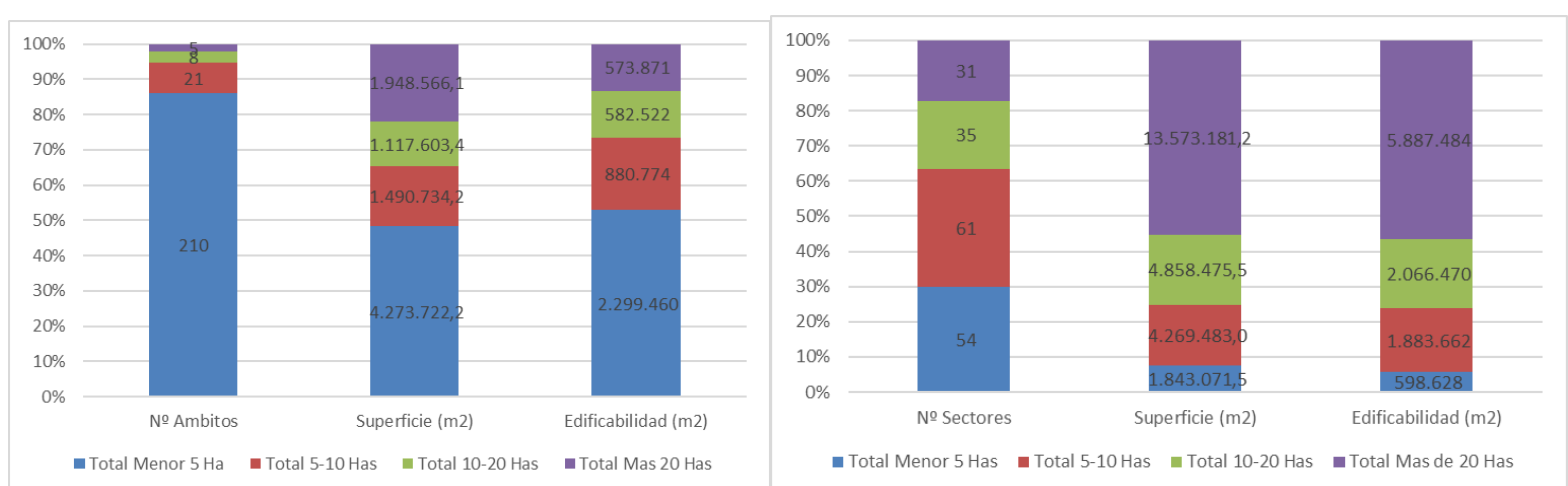

Figura13. Análisis por tamaños de los ámbitos de Suelo Urbano No Consolidado y de los Sectores de Suelo Urbanizable en el área urbana de León. Distribución por número, superficie y edificabilidad. Fuente: Elaboración propia a partir de explotación de datos del Sistema de Información Urbana, MITMA, 2020.

\begin{tabular}{|c|c|c|c|c|c|c|}
\hline Urbanizable Residencial & № Sectores & $\%$ & Superficie & $\%$ & Edificabilidad & $\%$ \\
\hline Total Menor 2,5 & 13 & 7,2 & 235.835 & 1,0 & 98.273 & 0,9 \\
\hline Total $2,5-5$ Has & 41 & 22,7 & 1.607 .236 & 6,5 & 500.355 & 4,8 \\
\hline Total 5-10 Has & 61 & 33,7 & 4.269 .483 & 17,4 & 1.883 .662 & 18,0 \\
\hline Total $10-20$ Has & 35 & 19,3 & 4.858 .476 & 19,8 & 2.066 .470 & 19,8 \\
\hline Total $20-40$ Has & 20 & 11,0 & 5.965 .863 & 24,3 & 2.680 .099 & 25,7 \\
\hline Total Mas de 40 Has & 11 & 6,1 & 7.607.318 & 31,0 & 3.207 .385 & 30,7 \\
\hline Total general & 181 & 100,0 & 24.544 .211 & 100,0 & 10.436 .244 & 100,0 \\
\hline
\end{tabular}

Figura 14. Distribución de los sectores de Suelo Urbanizable de uso global residencial por rangos de tamaño.

Fuente: Elaboración propia a partir de explotación de datos del Sistema de Información Urbana, MITMA, 2020.

El Suelo Urbanizable Delimitado en el área urbana de León ocupa una extensión de 3.697 ha, con 14,8 millones de $\mathrm{m}^{2}$ edificables, de los cuales $2.454,4$ ha son de uso global residencial, con una edificabilidad de 10,4 millones de $\mathrm{m}^{2}$.

Como puede verse en detalle en la tabla de la Figura 14, este suelo residencial se reparte en 181 sectores, de un tamaño muy superior al de los ámbitos de Suelo Urbano No Consolidado, pues su superficie media es de 14,3 ha. En este caso, sólo un $29,7 \%$ de los sectores (54, concretamente) son menores de 5 ha, ocupando una extensión de 184,3 ha (aproximadamente el 7,5\% sobre el total); mientras que los sectores de tamaño medio entre 5 y 10 ha (61 en total) suman 426,9 ha y los 
comprendidos entre 10 y 20 ha (35) otras 485,8 ha Destaca sobre todo el peso de los 31 sectores de tamaño superior a 20 ha, que suman nada menos que 1.357 ha (casi un $60 \%$ sobre la superficie total) y 5,8 millones de $\mathrm{m}^{2}$ edificables. Dentro de estos grandes sectores, hay incluso 11 mayores de 40 ha y 3 macrosectores que rondan o superan las 100 ha La mayoría de estos grandes sectores se sitúa en 3 municipios: 10 en León (con 417,9 ha), 8 en Villaquilambre (con 295,8 ha) y 6 en San Andrés (con 217, 7 ha). El resto se reparte del modo siguiente: 2 sectores en Sariegos (132,9 ha) y otros 2 en Chozas (101,7 ha), un sector en Valverde $(132,9$ ha), otro en Garrafe ( $91,3 \mathrm{ha})$ y otro en Villaturiel (22,6 ha). Los 3 macrosectores son: el sector SUR-01 en Garrafe de Torío, con 91,3 ha y $431.354 \mathrm{~m} 2$ edificables; el PP La Lastra en León, con 94,1 ha y 661.440 m2 edificables; y el sector Campo de Golf El Cueto, con 132,9 ha y $237.123 \mathrm{~m}^{2}$.

Muy diferente es la distribución del Suelo Urbanizable de uso global industrial, que totaliza $1.198,5$ ha y 4,2 millones de $\mathrm{m}^{2}$ repartidos en tan sólo 27 sectores. Dado que sólo hay 10 sectores industriales de superficie menor de 10 Has y otros 2 de extensión comprendida entre 10 y 20 ha, el $92 \%$ de la superficie se distribuye en 15 sectores mayores de 20 ha, lo que da como resultado que su superficie media supere las 40 ha. La distribución territorial repite los patrones clásicos de concentración sobre las zonas industriales tradicionales: casi la mitad de la superficie se concentra en el sur de la capital leonesa y Onzonilla, en el entorno de los grandes polígonos industriales existentes. De este modo, el Suelo Urbanizable industrial propuesto por el PG de León suma 286,5 ha, que suponen el 23,9\% del total, y el de Onzonilla 248,6 ha, el 20,7\%. También consolidan localizaciones productivas ya existentes el sector industrial previsto en San Andrés del Rabanedo (154,9 ha) ampliando el polígono de Trobajo, que supone el $12,9 \%$ sobre el total, y el planteado $(65,4$ ha) por el plan de Villaquilambre para la ampliación del polígono de Navatejera.

Como nuevas pautas de implantación territorial cabe destacar la propuesta de un gran polígono industrial y, sobre todo, logístico en Villadangos del Páramo, vinculado a su excelente accesibilidad desde la AP-66 (eje norte sur, enlazando con Asturias y la A6 en Benavente) y la AP-71 (enlazando hacia el oeste con la A6 en Astorga y hacia el este con la LE 30). Este polígono se ha urbanizado completamente y en él han implantado sus plataformas logísticas Mercadona y Decathlon. Justo al otro lado de la autopista se encuentra además el sector SUE/D/COD-I de Chozas de Abajo, con 27 ha, donde se ha desarrollado el Centro de Transportes Integrado de León (CETILE) de Logytrans. En total el Suelo Urbanizable Industrial en Villadangos suma 204,9 ha (el $17,1 \%$ ) sobre el total del área urbana leonesa y 147 Has el de Chozas, el 12,3\%.

El resto de la superficie se reparte en pequeñas piezas localizadas en Valdefresno y Garrafe de Torío ${ }^{45}$.

Finalmente, cabe destacar la existencia de 4 macrosectores industriales, cercanos o mayores a las 100 ha: el SUR-IND09 en Onzonilla, con 92,2 ha y $594.481 \mathrm{~m}^{2}$ edificables; el sector ULD24-01 en León, con 118,5 ha y $286.377 \mathrm{~m}^{2}$; el sector SUZ01 en San Andrés del Rabanedo, con 154,9 ha y $666.175 \mathrm{~m}^{2} ; \mathrm{y}$, finalmente, el mayor

4516,7 ha en Valdefresno (el 1,4\%) y 7,9 ha en Garrafe de Torío (el 0,7\%). 
de todos: el ya mencionado Polígono Industrial de Villadangos del Páramo, de 204,9 ha y $1.000 .000 \mathrm{~m}^{2}$. Además, en Chozas de Abajo, los sectores contiguos SUE/D/SOD18 y 19 (Pizuelos y El Sardonal) también suponen en conjunto 119 ha.

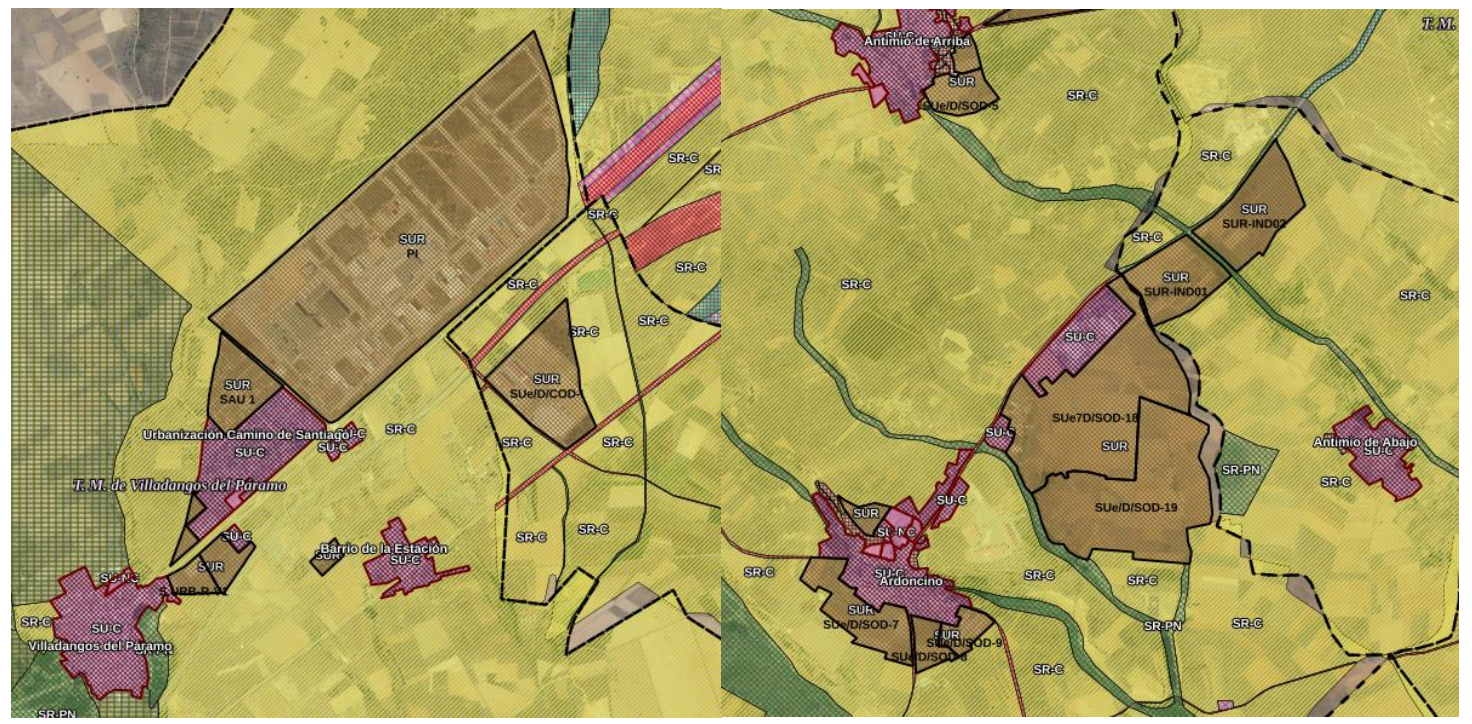

Figura 15. Izquierda: ejemplos de Suelo Urbanizable Industrial desarrollados: el SUR Polígono Industrial de Villadangos del Páramo y el SUE/D/COD-I de Chozas de Abajo. Derecha: ejemplos de Suelo Urbanizable Industrial pendiente de desarrollo: los sectores SUE/D/SOD-18 y 19 (Pizuelos y El Sardonal) en Chozas de Abajo y SUR-IND01 y 02 en Onzonilla.

Fuente: Elaboración propia a partir del Sistema de Información Urbanística de Castilla y León. https://idecyl.jcyl.es/siur/ 


\section{UNA LECTURA CUALITATIVA: LAS VARIADAS FACETAS DEL NEODESARROLLISMO EN EL PLANEAMIENTO MUNICIPAL DEL ÁREA URBANA DE LEÓN}

El análisis cuantitativo anterior se complementa en este capítulo con una lectura de los documentos de los planes urbanísticos municipales (consultados en el Archivo de Planeamiento Urbanístico del Sistema de Información Urbanística de Castilla y León), identificando en ellos elementos propios del discurso neodesarrollista, que, como se verá, no es un credo monolítico, sino un conjunto que muestra varios matices y facetas.

Entre los principios más comunes de este ideario se encuentran el del planeamiento "al límite de la capacidad" y la consideración del Suelo Urbanizable como suelo residual, siguiendo la idea propuesta por la Ley de Suelo estatal de 1998, pero también veremos cómo desde posicionamientos no estrictamente neoliberales también se asume -quizá con cierta hipocresía interesada- el crecimiento expansionista. En otros casos, analizaremos cómo el crecimiento se entiende con un carácter curativo o reparador, planteando los nuevos suelos a desarrollar como tejidos de relleno y sutura entre los existentes con supuesta capacidad cicatrizante de las heridas producidas por el desorden del crecimiento anterior. También se incluye un ejemplo que ilustra la supervivencia del credo desarrollista de los años 70 y su reconversión a lo largo del tiempo.

Finalmente, presentaremos la práctica espuria frecuentemente utilizada de las reclasificaciones de suelo a medida a través del instrumento de las Modificaciones de Planeamiento.

\subsection{El Plan General del León como resultado del marco normativo neodesarrollista: el planeamiento "al límite de la capacidad" y el carácter residual del Suelo Urbanizable}

El nuevo Plan General de Ordenación Urbana (PGOU) de León ${ }^{46}$, aprobado definitivamente el 5 de agosto de 2004, es un ejemplo muy interesante de planeamiento urbanístico municipal enmarcado en el contexto normativo neodesarrollista que propuso a nivel estatal la Ley de Suelo 6/1998. A diferencia de otros planes urbanísticos de la misma época ${ }^{47}$, que compartían la ideología neodesarrollista de la legislación estatal de referencia (esto es, la culpabilización a las supuestas restricciones en la clasificación de suelo del incremento del precio de la vivienda, cuyo corolario era la necesidad de liberalización del suelo, clasificando como urbanizable todo el que no hubiese que proteger expresamente), el PGOU de León tuvo que desenvolverse en este marco, sin compartirlo plenamente. $Y$ es por ello por

\footnotetext{
46 El anterior databa del 18 de junio de 1982 (fecha de aprobación definitiva).

47 Cuyo paradigma es el PGOU de Madrid de 1997. El Plan madrileño fue el pionero en esta visión -y su ejemplo más paradigmático en la aplicación de la idea del "planeamiento al límite de la capacidad"-, anticipándose incluso al marco normativo estatal de 1998, lo que significa que fue capaz de impulsarla incluso en un marco tan radicalmente diferente a esta visión como el del TR de la LS de 1992.
} 
lo que resulta especialmente expresivo del conflicto con una filosofía impuesta por el marco legal vigente que el Ayuntamiento debía acatar, pero que teóricamente no compartía ${ }^{48}$.

La explicación en la Memoria Vinculante (pp. 68-69) de los criterios para la clasificación del suelo y el trazado del perímetro del Suelo Urbanizable es muy ilustrativa:

"Es por lo que a esta clase de suelo se refiere donde se han producido los vuelcos conceptuales más espectaculares sobre la actividad urbanística en los últimos años. Así desde la conceptualización en la que tuvo que desenvolverse el Plan General vigente en León [se refiere al Plan anterior de 1982] según la cual la atribución de suelo a esta clase había de justificarse desde la estimación objetiva de su capacidad de crecimiento poblacional, se ha pasado al momento actual, en que lo que ha de justificarse es la exclusión del suelo del proceso urbanizador. [...]

La incidencia que sobre el planeamiento y la planificación urbanística tiene este vuelco conceptual es imaginable ${ }^{49}$. Baste decir por ejemplo que ello obliga a alterar las estrategias puestas en práctica por el urbanismo español de los últimos cuarenta años para resolver muchas de las carencias históricas de nuestras ciudades. Ya no se puede contar con determinaciones del planeamiento sobre esta clase de suelo para, desde su orden especial y temporal, conseguir la ejecución coordinada por partes de las infraestructuras urbanísticas. Los Planes han de encontrar otros mecanismos para atender a muchas situaciones dispares".

Y, como no podía ser de otra manera, pues era lo obligado por el marco legal vigente, "El Plan adecua sus formas de hacer y toma esas decisiones desde estas nuevas situaciones. Deducidos los terrenos que por mandato del legislador pertenecen a las clases de suelo urbana y rústico, el Plan asigna la taxonomía de Suelo Urbanizable a los suelos que no han resultado incluidos en aquellas clases". (Ibídem).

En la imagen adjunta puede apreciarse cómo el PGOU de León responde a la idea de "planeamiento al límite de la capacidad". Como se relataba en la Memoria, primero se realiza la clasificación del Suelo Urbano (que, como es sabido, es de carácter reglado), a continuación, la del Suelo Rústico, y finalmente, la del Suelo Urbanizable con carácter residual. Como Suelo Urbano se incluyen 1.764 ha (el 30,9\% del término municipal), de las cuales $1.312,1$ ha corresponden a Consolidado y 452,2 ha a No Consolidado50; y otras 1.075 ha (el 27,6\%) como Suelo Rústico Especialmente

\footnotetext{
${ }^{48}$ El Plan fue aprobado durante el mandato del alcalde socialista Francisco Javier Fernández Álvarez, llegado al poder el 16 de junio de 2003, en virtud del pacto municipal suscrito entre el PSOE y la UPL. Permaneció en la alcaldía 18 meses, hasta que se produjo una escisión de la UPL, y dos concejales de la misma (entre ellos su fundador), suscribieron una moción de censura junto al PP, que salió adelante en diciembre de 2004, llevando de nuevo a la alcaldía al anterior alcalde del PP, Mario Amilivia.

49 Sobre ello se ha escrito extensamente. Véase Menéndez Rexach (2006), De Santiago (2011).

${ }^{50}$ El Suelo Urbano No Consolidado asume una buena parte de la capacidad máxima de vivienda del PGOU, estimada en 47.701 unidades: según la Memoria (p. 90), su capacidad es de 18.638 viviendas, la del Suelo Urbanizable de 20.093, a las que hay que añadir otras 7.895 en sectores de planeamiento anterior asumido y 1.093 en áreas de ordenación asumida.
} 
Protegido, que comprenden: la masa forestal del monte San Isidro, los márgenes fluviales del río Bernesga, la zona de recreo y esparcimiento tradicional de la Candamia, la cornisa de Oteruelo - de valor geológico y paisajístico- y la zona húmeda de Trobajo. Como se aprecia, todo el suelo del municipio que no es ni Urbano ni Rústico con algún tipo de protección, se clasifica como Suelo Urbanizable, con una extensión total de 1.062 ha (el $28,7 \%$ ): de modo que no hay Suelo Rústico Común, que tradicionalmente era la clase residual ${ }^{51}$.

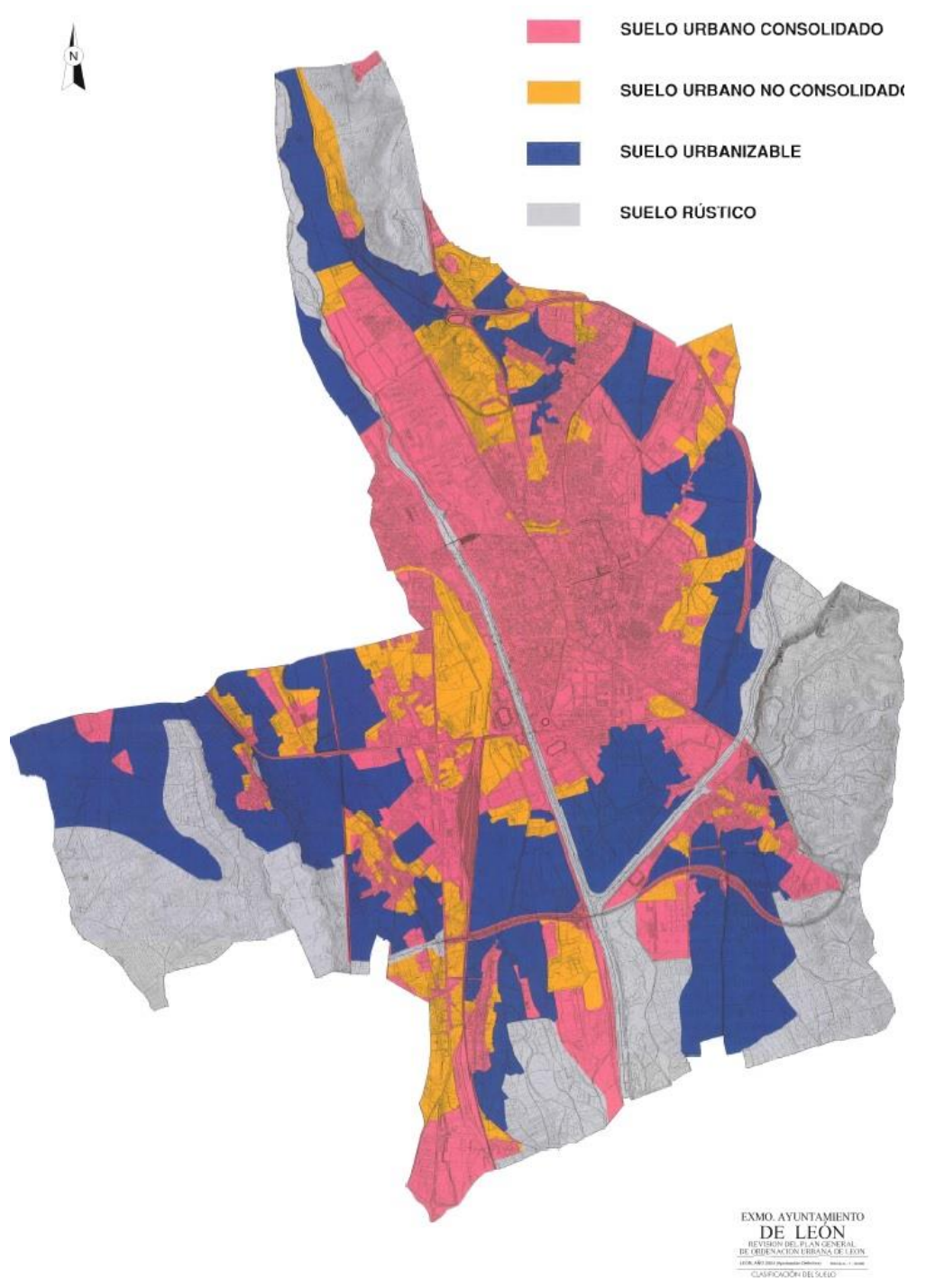

Figura 16. Clasificación del Suelo en el municipio de León. Fuente: PGOU de León.

\footnotetext{
${ }^{51}$ Entre otras cosas, esto implica la ausencia de holguras y la existencia de fronteras duras entre elementos con alto valor ambiental o natural y los espacios urbanizados o potencialmente urbanizables.
} 
Sin embargo, en este punto hay que tener en cuenta que, como hemos visto, la Ley castellanoleonesa 5/1999, en su art. 16, seguía permitiendo diferenciar entre las categorías del Suelo Rústico, además de varios tipos de Suelo Rústico Protegido, la de Suelo Rústico Común, que el PGOU de León finalmente no emplea. De este modo, se observa una divergencia entre el discurso de la Memoria del PGOU, donde parece justificarse la clasificación residual como única alternativa posible en base a la legislación estatal, y el margen -escaso, aunque real- que todavía dejaba abierto la normativa autonómica. Quizá esta divergencia no sea más que una forma contradictoria, cuando no hipócrita, de justificar - en un contexto donde este proceder era el habitual- la opción municipal por una clasificación de suelo expansiva, criticando la legislación estatal, pero al mismo tiempo interpretándola de forma maximalista sin acogerse al margen que había dejado abierto la normativa autonómica en una interpretación menos rígida.

Otro aspecto interesante del PGOU de León es su posicionamiento conceptual sobre la programación y la diferenciación entre las categorías de Suelo Urbanizable Delimitado y No Delimitado. En relación con la primera idea, en la Memoria Vinculante (pp. 68-69) se dice lo siguiente, comentando las novedades de la legislación estatal de suelo de 1998: "En esta situación, una segunda diferencia aparece lógica: la desaparición de la programación. Si en aquella extensión justificada desde la capacidad de crecimiento pudiera tener sentido el establecimiento del orden y plazos en que cada porción de este suelo debía incorporarse al desarrollo urbano, en una clasificación por exclusión, no soportada ni justificada en tales expectativas, sino derivada a las oportunidades empresariales según estas vayan surgiendo, resulta obvia la innecesaridad de determinaciones temporales o de orden espacial para el desarrollo".

Respecto la diferenciación de categorías dentro del Suelo Urbanizable, hay que comenzar recordando que esta posibilidad fue introducida en el artículo 14 de la Ley autonómica 5/1999 que permitía distinguir entre: a) Suelo Urbanizable Delimitado, constituido por los terrenos (agrupados o "delimitados" en ámbitos denominados en sectores) cuya transformación en Suelo Urbano se considerase adecuada a las previsiones del planeamiento urbanístico, y b) Suelo Urbanizable No Delimitado, constituido por los demás terrenos clasificados como Suelo Urbanizable. EI PGOU de León se posicionaba en contra de esta diferenciación con los siguientes argumentos:

"Aunque la Ley 5/1999 de Urbanismo de Castilla y León ha previsto por una parte el Suelo Urbanizable como áreas incluidas en determinados sectores a desarrollar urbanísticamente por medio de Planes Parciales, también prevé la posibilidad los suelos no previamente indicados [No Delimitado] mediante la formulación asimismo de Planes Parciales.

Así como para el caso de las dos categorías que se definen en la clase de suelo urbano el legislador da pautas concretas para la selección entre una u otra categoría, no es este el caso por lo que se refiere a la clase de Suelo Urbanizable.

La diferencia a la hora de decidir entre uno u otro tipo de este suelo aparece clara. No puede contarse con la segunda de estas categorías [se refiere al Suelo Urbanizable No Delimitado] como elementos para estructurar el territorio. Ni siquiera tienen para 
sí mismas, previamente a la formulación de su Plan Parcial, una estructura definida. Ello ha de reconocerse tiene una ventaja: libre a la administración de la responsabilidad de llevar a cabo determinadas actuaciones y con ello, quizás, de determinadas hipotecas. A cambio, tendrán una estructura coherente en y para sí mismas, pero no en su relación con el resto de las piezas, y mucho menos con la estructura [general] adoptada por el Plan". (Memoria Vinculante, pp. 68-69)

Se recordaba también que precisamente esta era una de las raíces de los problemas que el urbanismo de la ciudad de León venía arrastrando en el tiempo, pues habían sido muy escasos los desarrollos que habían contribuido realmente a generar infraestructuras o sistemas generales a escala de ciudad. De modo, que "en el caso concreto de León es imprescindible definir unas mínimas estructuras territoriales que ayuden a la integración de las diversas piezas que la componen, que garanticen la disponibilidad de elementos que favorezcan la relación entre las personas" (Memoria Vinculante, pp. 68-69).

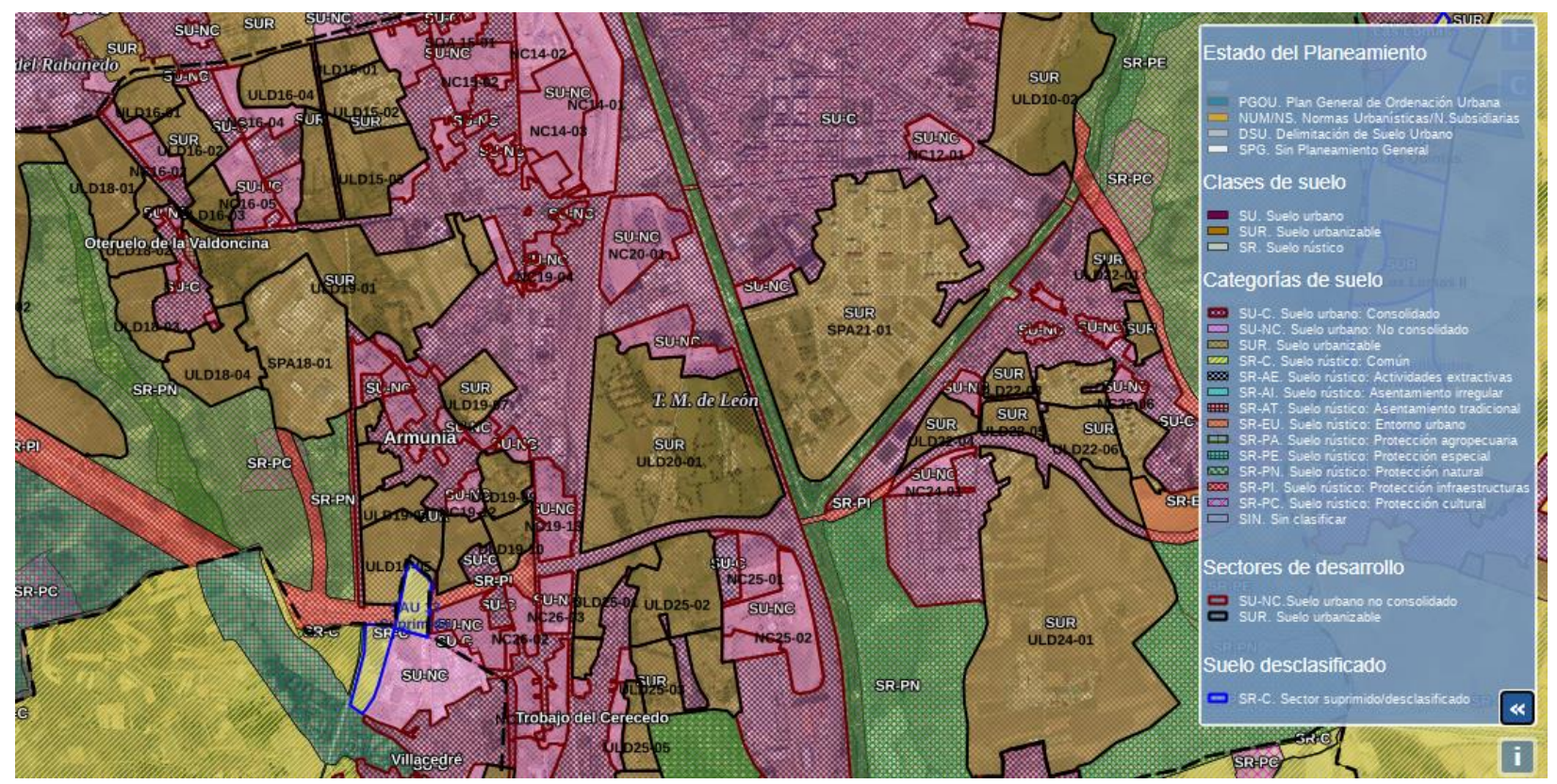

Figura 17. Detalle de la Clasificación del Suelo en la parte sur del municipio de León, indicando ámbitos de Suelo Urbano No Consolidado (SU-NC: rosa) y sectores de Suelo Urbanizable (SUR: marrón).

Fuente: Sistema de Información Urbanística de Castilla y León. https://idecyl.jcyl.es/siur/

Finalmente, se argumentaba también que el término municipal de la capital es relativamente pequeño en extensión y que la propiedad del suelo está muy fragmentada y no existen tampoco "prácticamente áreas de suelo extensas sobre las que un desarrollo urbanístico desestructurado pueda diluir sus efectos". En plena consecuencia con este razonamiento, y al contrario que otros planes del alfoz, el PGOU de León opta por no emplear la categoría de Suelo Urbanizable No Delimitado, adelantándose a la decisión que se terminaría tomando posteriormente a nivel 
autonómico de eliminar esta categoría52: "El Plan ha prescindido por ello de la utilización de la segunda de las categorías permitidas en esta clase de suelo. Alcanzar a construir la estructura física que este Plan ha entendido León necesita para garantizar su propio desarrollo, para encontrar su propio papel en el contexto global, requiere garantizar la confluencia de todos los esfuerzos en una única dirección, en un único objetivo, requiere dejar bien sentadas las bases de en qué dirección han de caminar sus desarrollos" (Memoria Vinculante, p. 69).

En la imagen de la Figura 17 puede verse la ordenación de la parte sur de la ciudad de León, donde aparece un mosaico de numerosas piezas conformado por los ámbitos de Suelo Urbano No Consolidado y los sectores de Suelo Urbanizable Delimitado, rellenando todos los intersticios no consolidados o no protegidos.

\subsection{Los expansivos planes de San Andrés del Rabanedo y Villaquilambre como ejemplos de la idea del crecimiento "curativo"}

A pesar de su alegría en la clasificación de Suelo Urbanizable, no puede decirse que los planes de San Andrés del Rabanedo y Villaquilambre sean estrictamente neodesarrollistas, pues no se basan como principio en el argumento de la necesidad de sobreclasificar suelo para reducir el precio de la vivienda. Al contrario, como veremos, incluso son críticos con esta simplista argumentación o proponen otras interpretaciones alternativas más complejas para las restricciones en el desarrollo de suelo. Lo que nos interesa destacar aquí es cómo ambos manifiestan otra nueva dimensión de la fe en las virtudes del crecimiento que también fue característica de cierto planeamiento municipal de finales del siglo XX y principios del XXI: la virtuosa capacidad curativa del crecimiento urbanístico.

Comenzando por el PGOU de San Andrés del Rabanedo, el punto de partida del plan es la escasez, pero no ya de Suelo Urbanizable clasificado -como en el paradigma neodesarrollista-, sino de Suelo Urbanizable desarrollado. Según consta en la Memoria Informativa (p. 63), transcurridos ya muchos años desde su

\footnotetext{
52 Tras los excesos en que derivó durante la década del boom inmobiliario, la Junta se rectificaría a sí misma y suprimió esta categoría mediante la Disposición Derogatoria a) de la Ley 4/2008, 15 septiembre, de Medidas sobre Urbanismo y Suelo. En paralelo se modificó el artículo 13, que en la actualidad tiene el siguiente tenor:

"1. Se clasificarán como suelo urbanizable los terrenos que cumplan simultáneamente las siguientes condiciones:

a) Que su transformación en suelo urbano se considere justificada a la vista de las demandas de suelo para usos residenciales, dotacionales o productivos.

b) Que sean colindantes al suelo urbano de un núcleo de población. Este requisito puede excusarse de forma justificada, y con las limitaciones que se señalen reglamentariamente:

1. ${ }^{\circ}$ Cuando el uso predominante sea industrial, logístico o vinculado a otras actividades productivas.

2.0 Cuando los terrenos estén separados del suelo urbano por otro sector de suelo urbanizable o por terrenos protegidos por la legislación sectorial.

3. ०- Cuando se trate de actuaciones previstas en un instrumento de ordenación del territorio".

Los epígrafes $1^{\circ}$ y $2^{\circ}$ de la letra b) del número 1 del artículo 13 se introdujeron por el número uno del artículo 18 de la Ley 7/2014, 12 septiembre, de medidas sobre rehabilitación, regeneración y renovación urbana, y sobre sostenibilidad, coordinación y simplificación en materia de urbanismo. Además, se establece también que el Suelo Urbanizable se agrupará en sectores, en los que la ordenación detallada podrá ser establecida por los instrumentos citados en el artículo 10 o ser remitida al planeamiento de desarrollo.
} 
aprobación: "Ni uno solo de los once sectores de suelo urbanizable delimitados por las [anteriores] Normas Subsidiarias de Planeamiento Municipal de San Andrés ha iniciado la tramitación administrativa para la aprobación de su planeamiento, lo que quiere decir que la previsión de urbanizar $594.100 \mathrm{~m}^{2}$ de suelo para incorporar al municipio $353.000 \mathrm{~m}^{2}$ de suelo y 2.583 viviendas ha sido incumplida por completo". Por tanto, el problema no era cuantitativo, de dimensionado, sino cualitativo, de gestión: la cuestión no era la escasez en la clasificación de suelo, sino la existencia de restricciones para su desarrollo ${ }^{53}$. La diferencia es importante, pues explica el mantenimiento del enfoque expansionista del plan, aun habiendo superado el estricto paradigma neodesarrollista. La idea se expresa del siguiente modo en la Memoria Justificativa (p.104): "Debido a las particulares condiciones de desarrollo acontecidas en el municipio de San Andrés del Rabanedo durante la vigencia de las NNSS aprobadas en 1999, con una elevada producción de viviendas paralela al nulo desarrollo de Suelos Urbanizables, que han provocado el ya citado agotamiento del Suelo Urbano Consolidado, el municipio de San Andrés del Rabanedo, tiene unos objetivos de clasificación de nuevo Suelo Urbanizable, basados en la necesidad real de nueva producción de suelo para abastecer la dinámica de crecimiento poblacional del municipio, y equilibrar el agotamiento del suelo urbano en el mismo". Esos objetivos son ambiciosos y se traducen en la clasificación de 456,6 ha de Suelo Urbanizable (con una capacidad de 8.823 viviendas), a los que hay que sumar otras 107 ha de Suelo Urbano No Consolidado (con capacidad para 5.076 viviendas), duplicando así las 511,3 ha clasificadas como Suelo Urbano Consolidado (con capacidad para 19.894 viviendas) y proponiendo en total una capacidad de 33.793 viviendas, triplicando casi las 12.241 existentes en el año 2001. En la Memoria Vinculante (p. 110) se reconoce incluso que estas superficies pueden ser excesivas: "La oferta de Suelo Urbanizable con un uso global Residencial se ha desarrollado de

\footnotetext{
53 La Memoria (pp. 191-192) intentaba explicar las razones por las cuales "en una época en la que para bien o para mal, España, Castilla y León, León y por supuesto San Andrés del Rabanedo han vivido el ciclo de mayor producción y consumo de Suelo Urbanizable de nuestra historia reciente" en este municipio no se habían desarrollado los Suelos Urbanizables previstos. "La razón de esta peculiar circunstancia, es que en el caso de las NNSS de San Andrés del Rabanedo [del año 1986, modificadas en 1999] se optó [...], por adscribir suelos no "concretados" y únicamente cuantificados, como Sistemas Generales "adscritos" a los sectores de Suelo Urbanizable, de manera que cuando un sector de Suelo Urbanizable pretendía desarrollarse, debía buscar estos Sistemas Generales, (ejemplo la previsión de la ronda Noroeste a su paso por el municipio), localizar a sus titulares y proponer su incorporación o adscripción concreta a la actuación, sin que estos estuvieran claramente definidos de antemano. Todo esto, teniendo en cuenta el ámbito de equidistribución municipal y los períodos de programación cuatrienales, típicos del TRLS 92 [Texto Refundido de la Ley de Suelo de 1992], provocaron que no se desarrollara ningún Sector de Suelo Urbanizable en el municipio. Con la entrada en vigor de la ley 6/1998 [...], y el cambio de tendencia económica y de explosión de la actividad urbanística, el municipio mostró signos de incapacidad de adaptación de su planeamiento [...]. Al no producirse la adaptación de las NNSS en este aspecto, ni siquiera en forma de modificación de planeamiento, se produce una situación de bloqueo de hecho, y una paralización no sólo de la producción de Suelo Urbanizable, sino de la obtención de Sistemas Generales, necesarios en muchos casos para el crecimiento urbanístico del municipio. En esta situación se produce un fenómeno "reacción": en un municipio como San Andrés del Rabanedo, en el que por su posición en torno a León, el Suelo Urbanizable habría sido la primera opción para el desarrollo de suelo más económico, y se produce una tremenda atomización de las actuaciones con el desarrollo de la mayor parte de las Unidades de Ejecución en Suelo Urbano No Consolidado, que en la mayor parte de los casos son unidades de reducido tamaño que no permiten obtener dotaciones ni Sistemas Generales y/o Locales en condiciones aceptables para el municipio". Todo ello produjo la canalización de la demanda sobre el municipio hacia el Suelo Urbano Consolidado, que se desarrolló completamente hasta su agotamiento, llegándose a conceder hasta 5.965 licencias destinadas al uso de vivienda, que supusieron en la práctica edificar "hasta el último solar disponible" mientras el Suelo Urbanizable previsto quedaba sin desarrollar.
} 
acuerdo a la consecución del modelo determinado, que surge directamente del diagnóstico de información, lo que puede hacer caer en un ligero sobredimensionamiento". Aunque también se argumenta (Memoria Vinculante, p. 189) que, en realidad, "el modelo propuesto no es cerrado, el objetivo no es su colmatación completa (como de hecho ya no lo es excepto en municipios como Madrid o Barcelona, que han agotado su suelo potencial) sino la construcción progresiva de una estructura dentro de unos márgenes de flexibilidad".

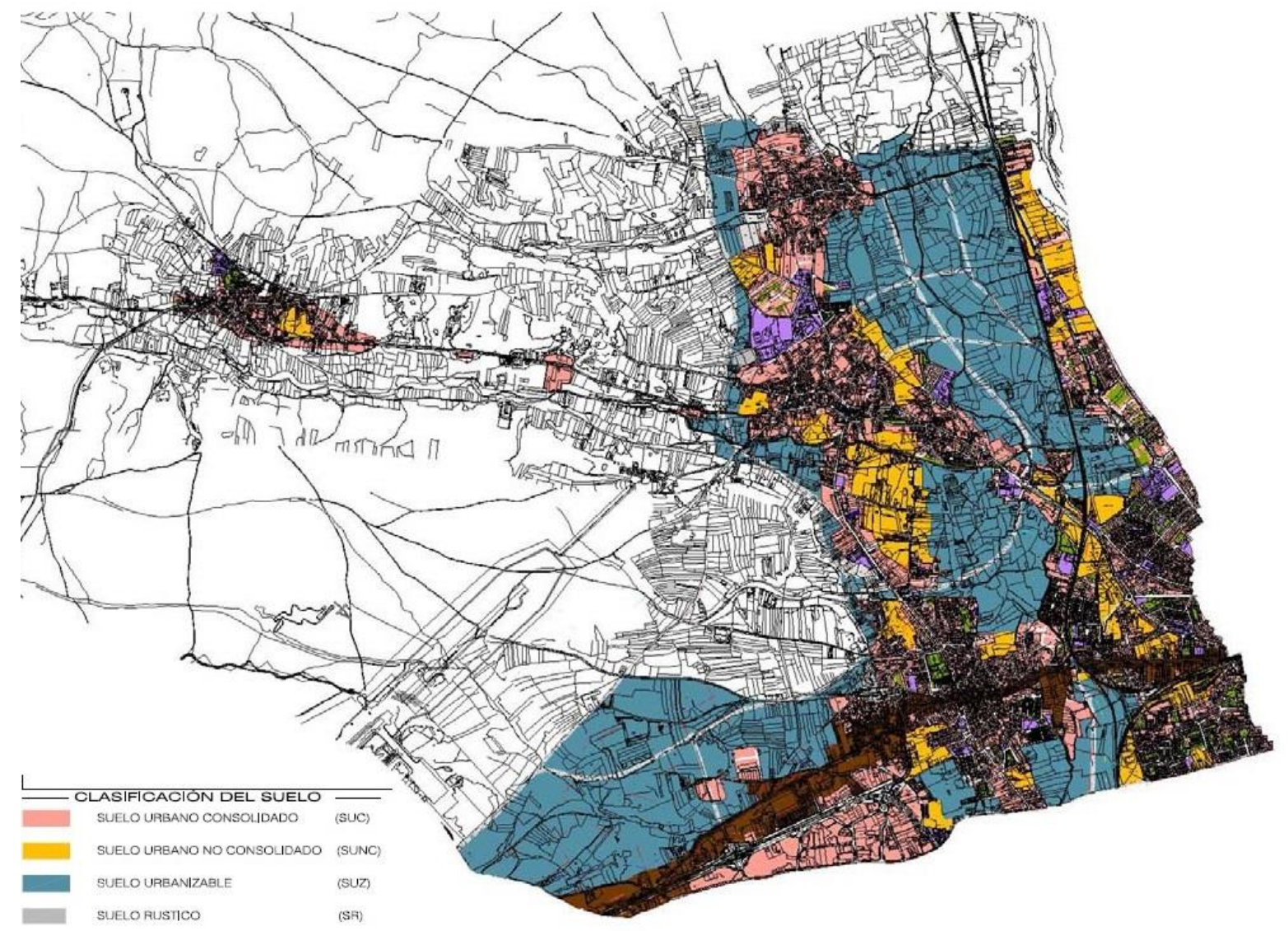

Figura 18. Plano resumen de Clasificación del Suelo en San Andrés del Rabanedo.

Fuente: PGOU de San Andrés del Rabanedo, 2010. Archivo de Planeamiento Urbanístico de Castilla y León.

Pero más allá de esta justificación de la generosidad en la clasificación de Suelo Urbanizable desde el punto de vista cuantitativo, lo que nos interesa recalcar aquí es un nuevo enfoque cualitativo que entiende que el crecimiento urbanístico tiene también una capacidad curativa, rellenando con nuevos tejidos de sutura las heridas y los vacíos dejados por el desorden del desarrollo urbano heredado54: "La

\footnotetext{
54 Este desorden se explicaba en la Memoria del modo siguiente: "Los polígonos planteados, de suelo urbano y urbanizable, raramente se desarrollan de manera completamente ortodoxa. No pocas veces han sido necesarios ajustes de límites o segmentación de polígonos en unidades menores (casi de propietario único, para bordear la gestión), cuando no cambios en los parámetros urbanísticos. El modelo resultante ha sido, cuando la ejecución del planeamiento ha sido llevada a cabo de manera formal, el desarrollo de polígonos de pequeño tamaño, dispersos,
} 
clasificación del Suelo Urbanizable responde al modelo de compactación e integración de los núcleos dispersos que constituyen el modelo presente en el municipio. A tal efecto, los crecimientos planteados lo son, en su mayor parte [...], de manera introspectiva, ocupando el espacio intersticial entre los desarrollos existentes y núcleos tradicionales" (Memoria Vinculante, p. 104). "Se trata de aprovechar la capacidad de esta clase de suelo [Urbanizable] para articular y establecer mejoras en la estructura urbana, y soportar las condiciones específicas para "generar ciudad" (Memoria Vinculante, p. 110).

En el plano inferior se observa bien ese entendimiento de los nuevos sectores como tejidos de sutura o remate de los tejidos existentes. En efecto, exceptuando el sector SUZ01, que corresponde a una gran pieza de uso industrial para ampliar el polígono de Trobajo, el resto de los 16 sectores propuestos por el PGOU puede agruparse en 4 bloques: los sectores SUZ06, 07, 08, 09 y 10 configuran un bloque que rellena el gran intersticio existente entre las vías del tren (al este) y el continuo urbano Trobajo del Camino-San Andrés-Villabalter (al oeste) ${ }^{55}$, los sectores SUZ11, $12,13,14,15$ y 16 rematan por el oeste este continuo urbano, al tiempo que los sectores SUZ 02 y 03 lo hacen por el sur, mientras que los sectores SUZ 04 y 05 rellenan el vacío central entre el barrio de Pinilla, Trobajo y San Andrés, proponiéndose como una pieza a modo de rótula central.

Se puede observar también cómo, con la excepción del sector industrial SUZ01 de 154,9 ha y el residencial SUZ 10 de 73,5 ha, el resto tiene un tamaño pequeño o medio: "El tamaño de dichos sectores se justifica por la propia naturaleza del modelo, que apuesta por unidades de planeamiento que permitan una concepción urbana de escala global, así como la consecución de dotaciones públicas de cierto tamaño y con una localización óptima" (Memoria Vinculante, p. 110).

raramente estableciendo un continuo urbano, y cuando sí había continuidad, con trazas desestructuradas o discontinuas, y con una heterogeneidad edificatoria importante. En otros casos, la clasificación de suelos ha generado tensiones que han hecho, en este caso de manera irregular, que se haya construido un buen número de edificaciones sobre suelos no clasificados al efecto, sin ningún tipo de planeamiento de desarrollo, dando lugar a cierto "salpicado" de edificación, con características parcialmente "urbanas" (cierta disposición de la trama, tipos parcelarios y edificatorios urbanos, algunos servicios e incipiente urbanización)". (Memoria Vinculante, pp. 186-187).

55 Dulcificando un poco el carácter expansionista en la clasificación de suelo, "Precisamente, y a pesar de su clasificación de urbanizable, los objetivos que el PGOU señala para casi el $50 \%$ de estos nuevos suelos son de "Protección", de manera que lo que se pretende es que se obtengan e incorporen al Sistema General de Espacios Libres Públicos, como espacios no urbanizados en su mayor parte, protegiéndose de esta forma las características actuales de estos suelos, y los valores naturales que atesoran". (Memoria Vinculante, p. 105). 


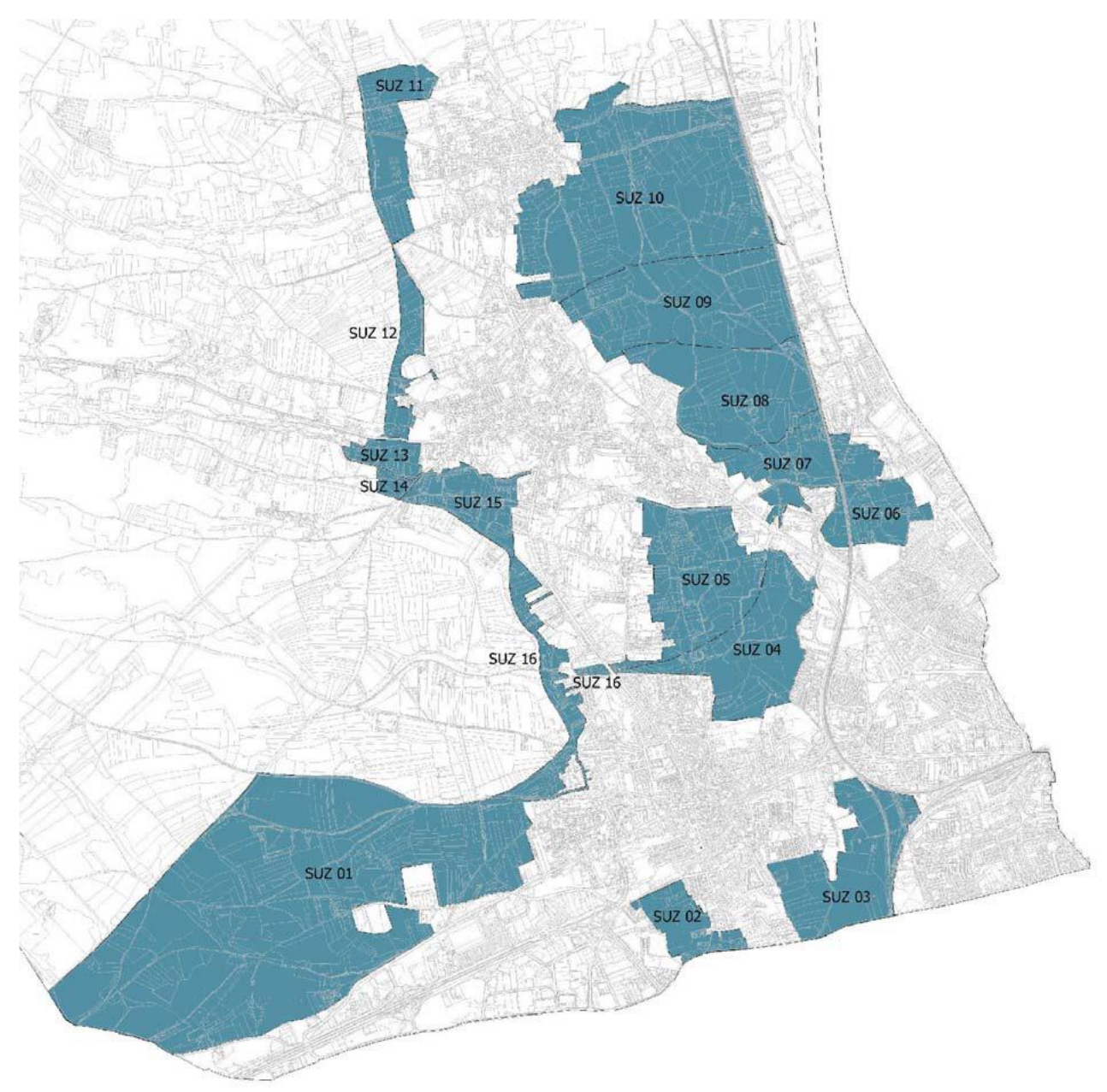

Figura 19. Sectorización del Suelo Urbanizable propuesto por el PGOU de San Andrés del Rabanedo. Fuente: Memoria del PGOU, p. 109.

El caso del PGOU de Villaquilambre es muy similar. En primer lugar, se trata de un plan también claramente expansionista que plantea una superficie de Suelo Urbanizable que asciende a 575,6 ha, lo que supone la práctica duplicación de la superficie de Suelo Urbano Consolidado (555 ha) y No Consolidado (76,1 ha). En términos de viviendas, el crecimiento previsto es aún más espectacular: frente a 5.829 viviendas existentes en el año 2001, el nuevo PGOU propone una capacidad de 19.399 viviendas en Suelo Urbano Consolidado, 2.687 en No Consolidado y 14.541 en Suelo Urbanizable, con un total de 36.627 viviendas.

En segundo lugar, y desde el punto de vista cualitativo, el PGOU de Villaquilambre también comparte la misma idea de la capacidad curativa del crecimiento urbanístico. Tanto es así, que en la Memoria se repite exactamente la misma frase que en el PGOU de San Andrés del Rabanedo: "La oferta de Suelo Urbanizable con un uso global Residencial se ha desarrollado de acuerdo a la consecución del modelo determinado, que surge directamente del diagnóstico de información. Se trata de aprovechar la capacidad de esta clase de suelo para articular y establecer mejoras en la estructura 
urbana, y soportar las condiciones específicas para "generar ciudad". (Memoria del PGOU de Villaquilambre, p. 89).

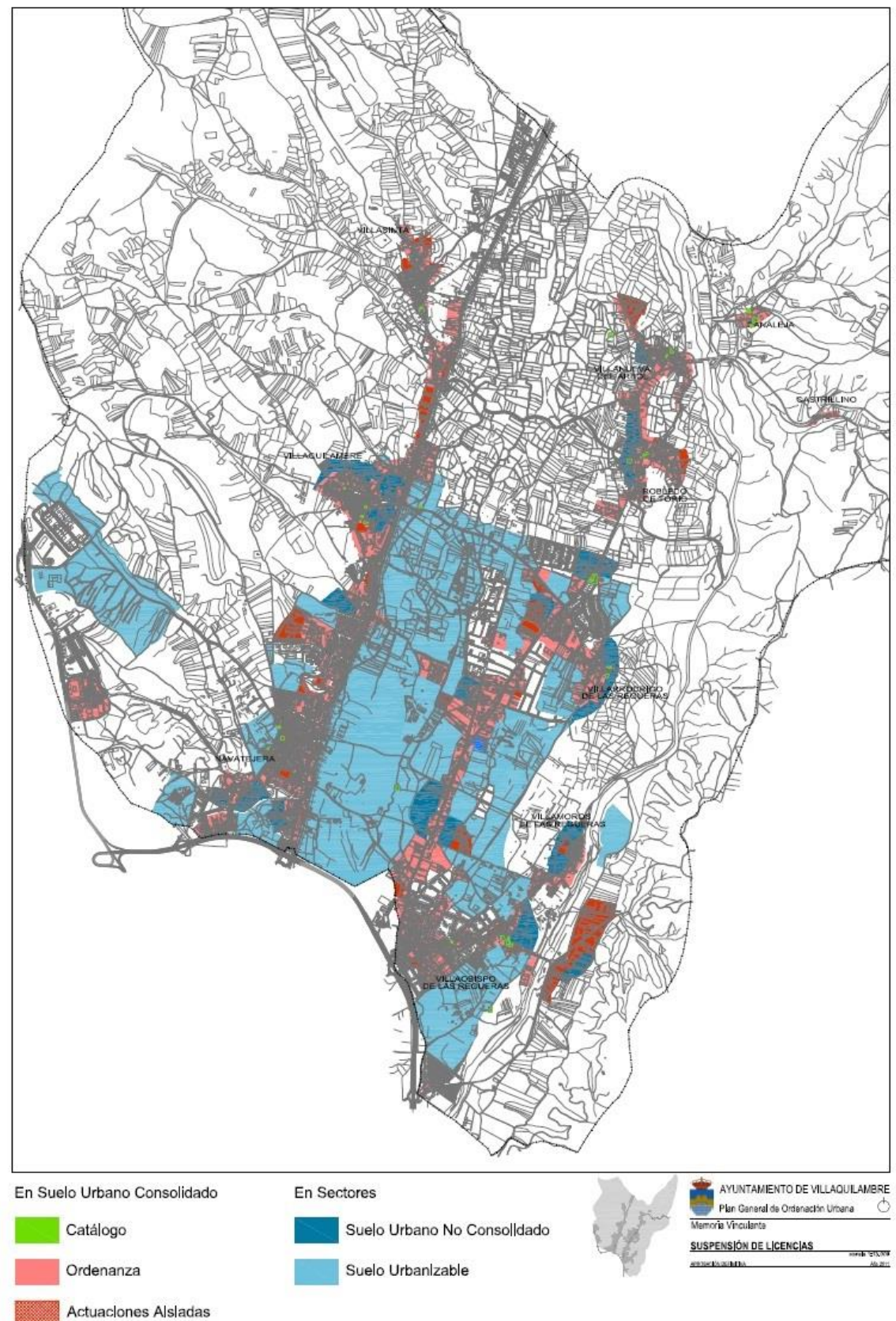

Figura 20. Plano resumen de Clasificación del Suelo en Villaquilambre.

Fuente: PGOU de Villaquilambre, 2011. Archivo de Planeamiento Urbanístico de Castilla y León.

Esta idea se traduce en la propuesta de colmatar con varias piezas de Suelo Urbanizable residencial el gran vacío central existente entre los 2 ejes que históricamente han articulado el desarrollo urbano del municipio: la LE-311 (pasando 
por los núcleos de Navatejera y Villaquilambre) y la N-621 (Villaobispo, Villamoros, Villarodrigo, y Robledo). De esta forma, se pasaría del actual desarrollo lineal a modo de rosario -en torno a los pequeños núcleos rurales tradicionales- a una gran mancha de suelo urbanizado en el futuro, con una red viaria transversal que complementaría los dos ejes citados existentes, configurando así una nueva estructura urbana con morfología de tipo reticular ${ }^{56}$.

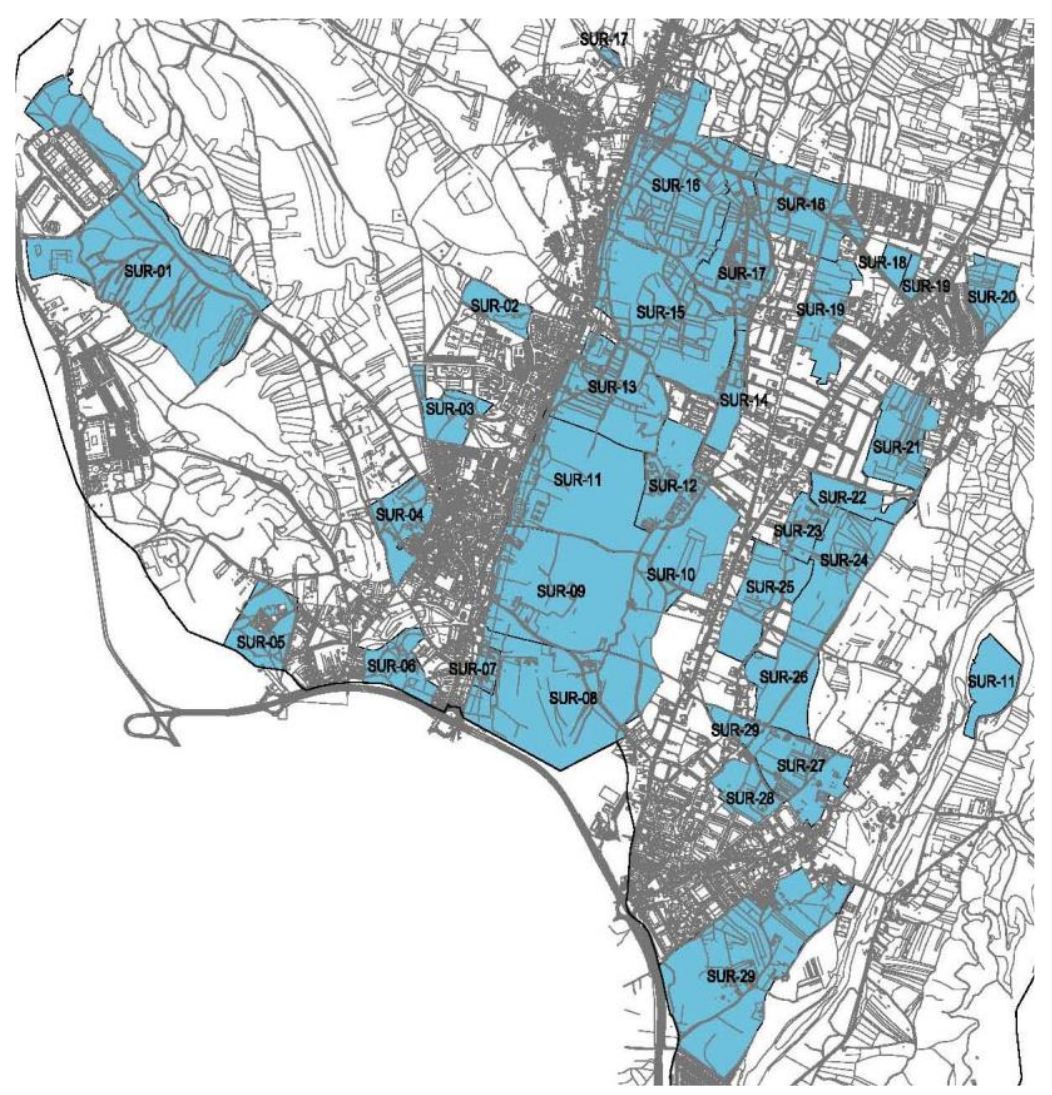

Figura 21. Sectorización del Suelo Urbanizable propuesto por el PGOU de Villaquilambre. Fuente: Memoria del PGOU, p. 89.

Igualmente, el PGOU de Villaquilambre comparte la propuesta de sectores de tamaño pequeño y medio, justificada también con la misma frase que el PGOU de San Andrés: "Se plantea, como se ha apuntado, un conjunto de sectores destinados a uso predominante residencial más un sector de considerable tamaño destinado a uso industrial. El tamaño de dichos sectores se justifica por la propia naturaleza del modelo, que apuesta por unidades de planeamiento que permitan una concepción urbana de escala global, así como la consecución de dotaciones públicas de cierto tamaño y con una localización óptima". (Memoria del PGOU, p. 89). Además, con el

\footnotetext{
56 Además, y de forma completamente autónoma con este modelo, el PGOU también propone otra pieza importante de Suelo Urbanizable de uso industrial (de casi $67 \mathrm{Has}$ ) en la carretera N 630, ampliando el polígono industrial de Navatejera ya existente.
} 
objeto de facilitar aún más su posterior desarrollo, para varios de estos sectores (como los SUR-01, SUR-07, SUR-08, SUR-09, SUR-10, SUR-11, SUR-12 y SUR-29), el PGOU de Villaquilambre incluye directamente su ordenación pormenorizada.

\subsection{Las modificaciones de planeamiento como mecanismo para la reclasificación de suelo: el caso de Villatoldanos en Villaturiel}

Además de la generosidad en la clasificación de suelo de los instrumentos convencionales de planeamiento urbanístico municipal, durante todo el boom inmobiliario fue muy común el recurso al atajo de las Modificaciones Puntuales para la reclasificación de suelo ${ }^{57}$. Este mecanismo permitió saltarse todo el complejo proceso de revisión formal del planeamiento y dar una respuesta rápida a las supuestas necesidades del mercado de suelo en aquellos municipios cuyos instrumentos de planeamiento municipal eran más antiguos y no habían sido convenientemente ambiciosos en su dimensionado de la oferta de suelo. Además, aunque ello exceda el enfoque de este trabajo-, el mecanismo también se prestaba a ciertas prácticas de favor, cuando no directamente a la corrupción urbanística, en beneficio de los propietarios de suelo afectados por la reclasificación.

Un ejemplo paradigmático del uso y abuso de las Modificaciones Puntuales es el caso del pequeño municipio de Villaturiel, que contaba con unas Normas Subsidiarias (NNSS) del año 2001 que -dado su carácter fundamentalmente rural- habían sido relativamente comedidas en el dimensionado de suelo. No obstante, apenas unos meses después de su aprobación, y con la idea de que determinados suelos del municipio bien posicionados podrían beneficiarse también del desarrollo urbanístico que se estaba produciendo en otros municipios del alfoz de León, el 3 de julio de 2001 se suscribió un Convenio Urbanístico entre el Ayuntamiento de Villaturiel y un particular para la reclasificación de unos terrenos ubicados en el norte del término municipal, que presentaban una localización óptima desde el punto de vista de la accesibilidad, al situarse junto a la N-601 (que une Mansilla de las Mulas con León, siguiendo el Camino de Santiago) y en la proximidad de la autovía A-60 -aunque evidentemente aún no tenían ejecutado el acceso directo a estas infraestructuras-.

A diferencia de la lentitud habitual en la tramitación del planeamiento general ${ }^{58}$, el expediente de la Modificación Puntual (MP) se movió con gran rapidez, de modo que el 19 de noviembre de 2004 se aprobó definitivamente la MP no 3 de las NNSS vigentes de Villaturiel, mediante la cual se creaban dos nuevos sectores de Suelo Urbanizable Delimitado en el municipio. Esta MP no 3 comprendía dos sectores perfectamente diferenciados, que se trataban de forma individualizada:

\footnotetext{
57 Por ejemplo, en León - según la web del Ayuntamiento- se han aprobado definitivamente 39 Modificaciones del PGOU y en estos momentos hay dos pendientes; en un municipio más pequeño como Sariegos, las Modificaciones de las NUM desde 2001 son más de 14.

58 El mismo caso de Villaturiel lo ilustra: aunque las NNSS se habían comenzado a redactar a principios de los años 90, e incluso se había aprobado un Avance en 1994, la redacción y tramitación se dilató durante casi una década, hasta la aprobación definitiva el 22 de marzo de 2001.

Véase también la nota 39, sobre el culebrón de la aprobación del planeamiento en San Andrés del Rabanedo.
} 
- El Sector Villatoldanos I, de $198.560,36 \mathrm{~m}^{2}$, correspondiente al Convenio, situado junto al límite municipal con Valdefresno y próximo a la entrada desde la carretera N60 a la población de Sanfelismo.

- El Sector Villatoldanos II, de $216.217,5 \mathrm{~m}^{2}$, rellenando el suelo comprendido entre el Sector Villatoldanos I y el pequeño núcleo existente de Toldanos, de manera que, una vez desarrollado, todo el conjunto formaría un continuo edificado.

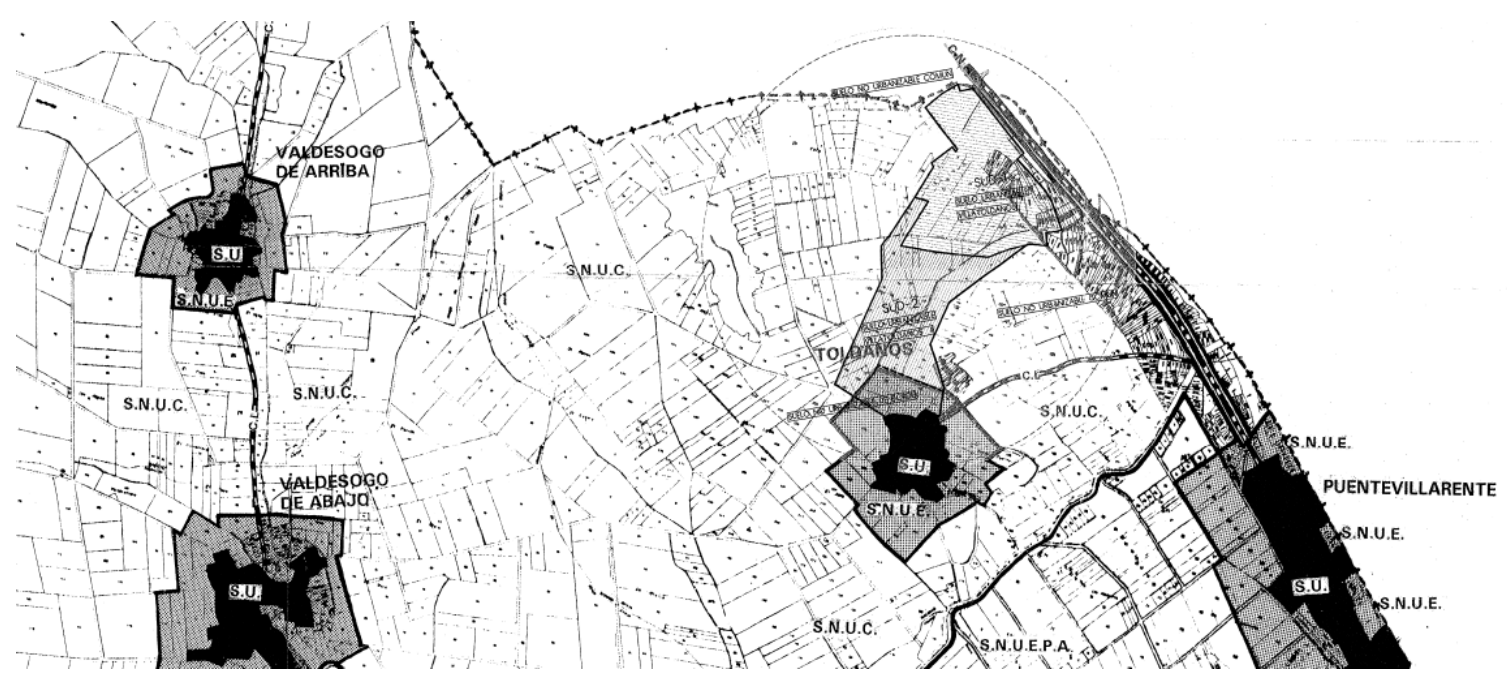

Figura 22. Plano de localización de los nuevos sectores Villatoldanos I y II según la Modificación Puntual n०3 de las NNSS de Villaturiel.

Fuente: Archivo de Planeamiento Urbanístico de Castilla y León.

Como suele ser frecuente, las razones para justificar la modificación de las NNSS y reclasificar los terrenos eran bastante peregrinas:

"La conveniencia es manifiesta para el Ayuntamiento de Villaturiel, [sic] el que se conviertan en urbanizables ciertos sectores periféricos para acomodarse al entorno y dar una mayor salida a la carretera general, auspiciado ello por el desarrollo de los Ayuntamientos colindantes y sobre todo por el propio desarrollo del término municipal en consonancia con aquellos.

Este es el motivo principal [sic] de además de incluir las fincas afectadas por el Convenio Urbanístico referido "ut supra", se amplíe a otras fincas colindantes haciendo más extenso el sector, no dejando parcelas del difícil desarrollo posterior y enclavadas por límites naturales existentes, facilitando su gestión y su integración en el entorno urbano y en los límites del término municipal con la carretera general". (Memoria de la MP no 3, pp. 13-14).

Además, se incluía también una justificación de las buenas intenciones del promotor: "Todo esto da una idea clara de la intención voluntarista y gestora del promotor de esta modificación, que en ningún caso pretende la inclusión de un suelo de su propiedad en un régimen de suelo específico, para dejar baldía la ordenación sin una posterior ejecución de toda ella. Muy por el contrario, lo que se pretende, es 
la ordenación racional, fundamentada, que incluya además de sus propios terrenos, el resto para alcanzar de esta manera la sinergia de todos los intereses existentes o que en el futuro puedan existir" (Memoria de la MP no 3, pp. 13-14). Excusatio non petita: accusatio manifesta.

El argumento se remataba con otro también muy típico: hacer lo mismo que otros municipios. "En una palabra, pretende el desarrollo integral del municipio con el resto de los municipios colindantes, en los que existe una actividad urbanística importante, que es lo que se contempla en la actual modificación que aquí se justifica" (Memoria de la MP no 3, pp. 13-14).

Respecto al Sector Villatoldanos II la justificación es la siguiente: "se estima la oportunidad y la conveniencia de la reclasificación a efectos de establecer una clasificación del suelo coherente y homogénea que permita conectar y estructurar el área afectada con la trama urbana de Toldanos y por tanto unir la actuación que se pretende desarrollar al Suelo Urbano". Es decir, tras haber planteado una pieza autónoma, desvinculada de los tejidos existentes, después se justificaba la necesidad de rellenar el espacio intermedio.

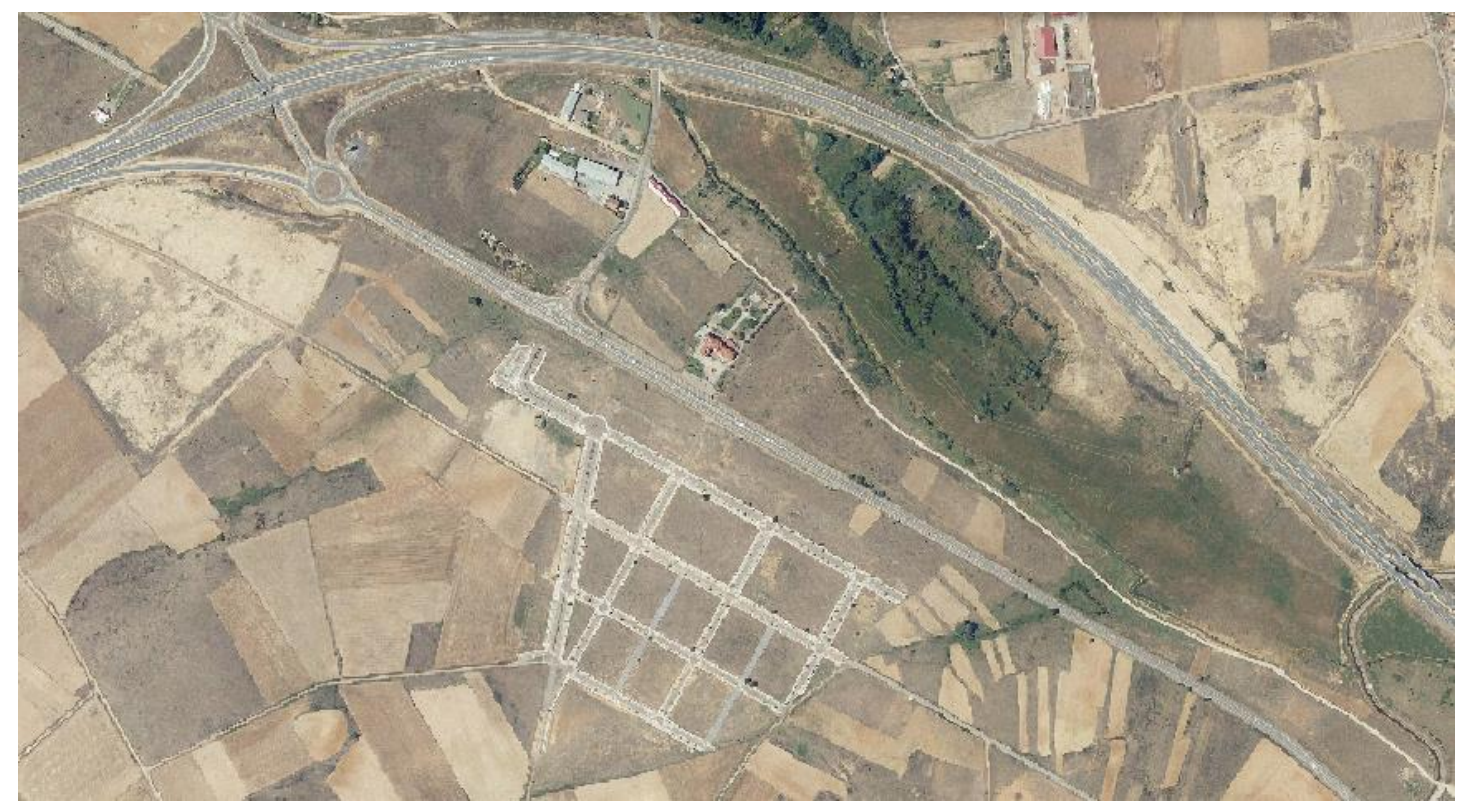

Figura 23. Estado actual del Sector Villatoldanos I. Fuente: PNOA 2017. Fototeca CNIG.

Para el Sector Villatoldanos I se establecía un número máximo de viviendas de 592 (de las cuales, 418 eran para residencial colectiva) y de 648 (todas unifamiliares) para el Sector Villatoldanos II.

En otro ejemplo de eficacia administrativa en el momento que interesa, el mismo 19 de noviembre de 2004 en que se aprobó la Modificación Puntual no 3 para crear los 2 sectores de Suelo Urbanizable Delimitado también se aprobó simultáneamente el Plan Parcial que desarrollaba el Sector Villatoldanos I. 
La urbanización se ejecutó en la segunda mitad de los 2000, pero el estallido de la burbuja inmobiliaria hizo que no se llegase a edificar ninguna vivienda de las previstas. Como puede verse en la ortofoto adjunta, en la actualidad la zona es una urbanización fantasma en la que además llama mucho la atención cómo se interrumpen las calles urbanizadas en mitad de ninguna parte. En efecto, no hay acceso directo desde la cercana carretera nacional N601 que discurre por el norte del sector, realizándose la conexión con el acceso desde Puente de Villarente por un simple camino mal asfaltado; hacia el sur, tampoco hay conexión con el núcleo Toldanos.

\subsection{La supervivencia de un viejo proyecto del desarrollismo y su reconversión: el sector Venta de la Tuerta en Garrafe de Torío.}

Las primeras Normas Subsidiarias de Planeamiento (NNSS) de Garrafe de Torío fueron redactadas por la Diputación Provincial de León y se aprobaron en diciembre de 1976. Gestadas en el contexto propio del desarrollismo y a pesar del éxodo rural que afectaba entonces a los municipios de toda la provincia - Garrafe, incluido-, las NNSS confiaban en las posibilidades de desarrollo de "segundas residencias", para lo cual clasificaban amplias zonas del término como "Suelo Apto para Urbanizar", remitiendo su mayor concreción a los correspondientes Planes Parciales.

En julio de 1977 se aprobó uno de estos Planes Parciales, denominado PP "Urbanización Venta de la Tuerta", delimitando 105 ha de una finca de propietario único de unas 600 ha $^{59}$, ubicadas en el límite oeste del municipio, junto a la carretera nacional N-630 Adanero-Gijón. El PP preveía la edificación de 1.040 viviendas en total: 805 colectivas de baja densidad (denominadas "residencial semi-intensiva") y 230 unifamiliares.

Apenas comenzadas las obras de urbanización, y con alguna vivienda aislada construida, en 1981 ya se produjo una primera Modificación del Plan Parcial "Urbanización Venta de la Tuerta", justificada en el cambio de la demanda que había provocado la crisis económica de finales de los 70 . El nuevo proyecto aprobado aunque apenas alteraba el número total de viviendas- proponía un reajuste de la ordenación, la modificación del reparto entre viviendas unifamiliares y colectivas y la reducción de los tamaños de parcela, todo ello con el objeto de hacer más asequible la promoción a un espectro social más amplio en un contexto de grave parálisis del mercado inmobiliario. No obstante, y a pesar de la Modificación, las obras continuaron paralizadas durante muchos años.

\footnotetext{
${ }^{59} \mathrm{El}$ análisis de la propiedad del suelo -que en este caso es obvio- es un factor clave en el desarrollo de las grandes piezas, aunque excede las posibilidades de este trabajo.
} 


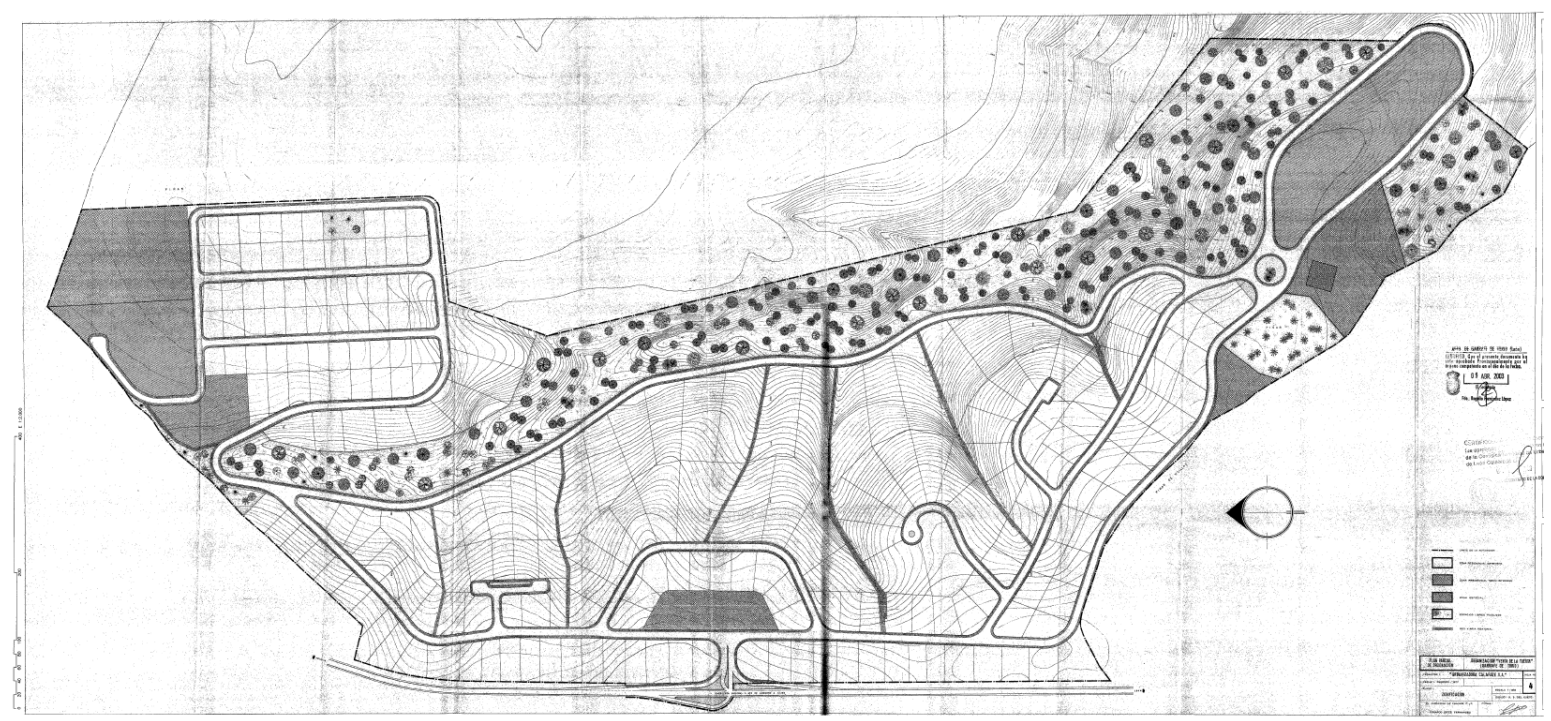

Figura 24. Plano de ordenación y parcelación del Plan Parcial Urbanización Venta de la Tuerta de 1977. (El norte está a la izquierda).

Fuente: Archivo de Planeamiento Urbanístico y Ordenación del Territorio de Castilla y León.

En la segunda década de los años 90 se comenzaron a revisar las NNSS de Garrafe, que entonces ya tenían casi veinte años de antigüedad, aprobándose finalmente unas nuevas en 1997. En ellas se planteaban 9 Unidades de Ejecución en Suelo Urbano, con una superficie total de 19,3 ha y una capacidad de 272 nuevas viviendas, y 12 Sectores en Suelo Urbanizable, con una superficie de 167,4 ha y una capacidad de 929 viviendas. Entre estos sectores, el S-11 era precisamente el viejo proyecto desarrollista de la Venta de la Tuerta, cuyas determinaciones y ordenación, ya aprobadas mediante los PP anteriores, se incorporaban directamente así a las nuevas NNSS de 1997.

Sin embargo, hacia el cambio de siglo, todavía continuaba inacabado el desarrollo de la urbanización de la Venta de la Tuerta: en diversos puntos aislados del interior y sin un orden establecido se había realizado alguna construcción más, principalmente destinada a vivienda unifamiliar; y, al mismo tiempo, se habían retomado algunas obras de urbanización, consistentes en la apertura de vías y la instalación de diversos servicios, pero no se habían llegado a rematar, de modo que el acceso a varias viviendas continuaba haciéndose a través de caminos de tierra en los que únicamente se había realizado la explanación.

En mayo de 2003 se produjo otra Modificación -que ya era la tercera- del PP del Sector 11 Venta de la Tuerta, con dos objetivos fundamentales: desatascar la gestión y relanzar el proyecto apostando por la calidad ambiental como estrategia inmobiliaria diferenciadora.

Por un lado, se trataba de reconducir, de una vez por todas y de manera definitiva, el tema pendiente del atasco de la gestión urbanística buscándose "la regulación de la actual situación, de modo que sea posible la gestión del planeamiento que no se 
completó con el Plan Parcial vigente, de modo que se ejecuten todas las dotaciones urbanísticas para la población del sector" (Memoria del PP, p.5).

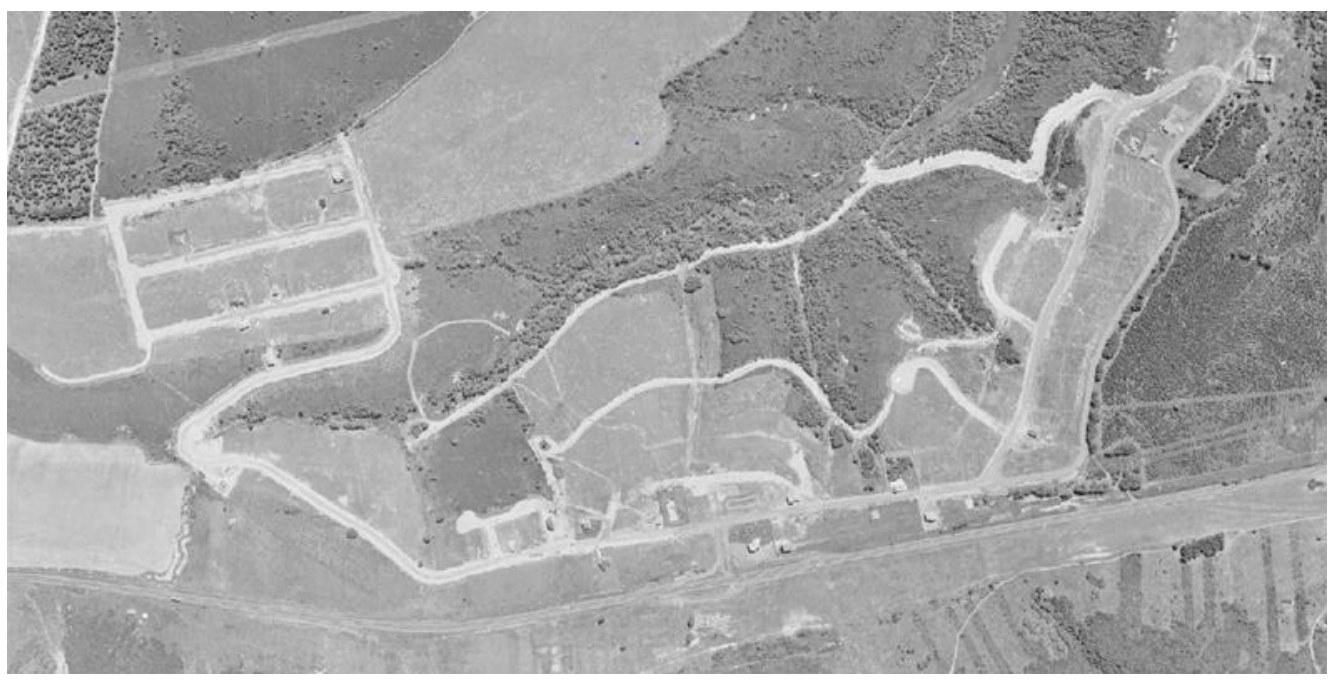

Figura 25. Ortofoto mostrando el estado de la urbanización de la Venta de la Tuerta en los primeros años 80. (El norte está a la izquierda)

Fuente: Vuelo Interministerial 1973-1986. Fototeca CNIG.

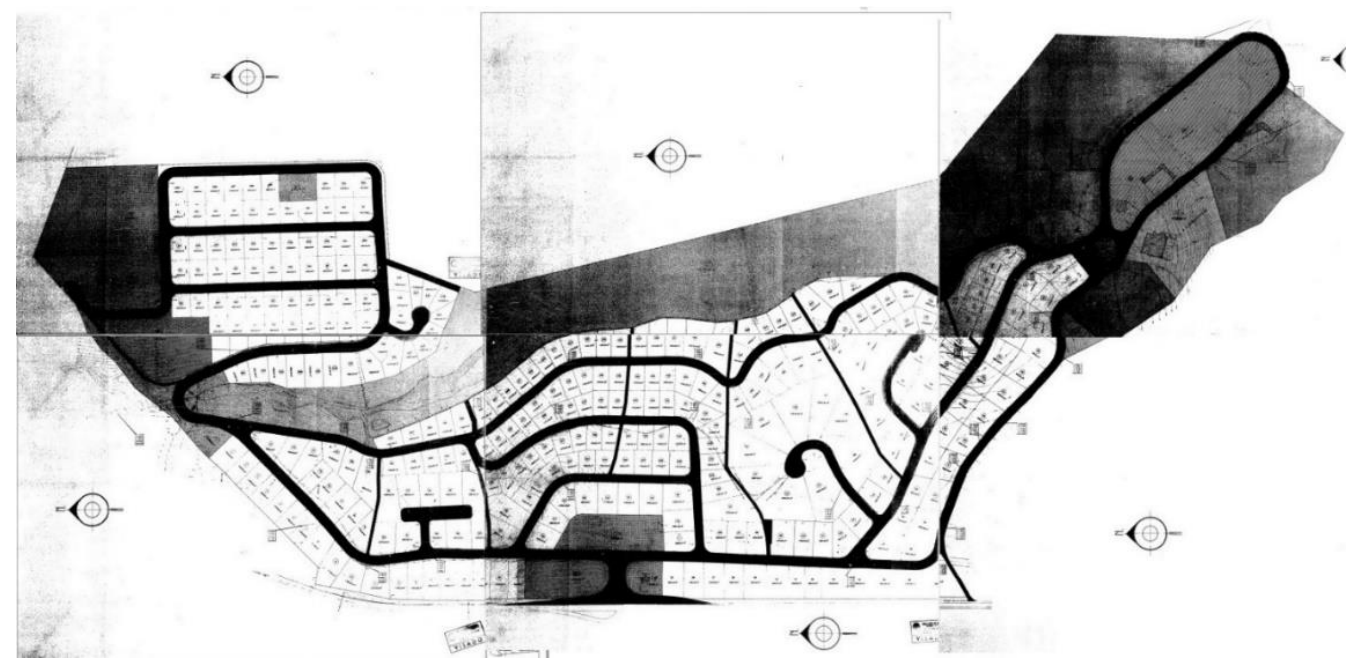

Figura 26. Plano de ordenación y parcelación de la Modificación del Plan Parcial Urbanización Venta de la Tuerta de 1981. (El norte está a la izquierda).

Fuente: Archivo de Planeamiento Urbanístico y Ordenación del Territorio de Castilla y León.

Por otra parte, y transcurridos casi 25 años desde que se aprobase el primer PP, la paralización de la urbanización parecía haberse convertido en un tema enquistado y ello disuadía a los posibles compradores, lo que hacía necesario relanzar el proyecto inmobiliario. Para ello se buscó una nueva imagen corporativa, que, en primer lugar, cambió el nombre de la urbanización "Venta de la Tuerta", estigmatizado después de tantos años, por el mucho más sonoro de "Estrella de Izar". Además, se decidió 
apostar por un desarrollo urbanístico enfocado a acoger la demanda que entonces estaba saliendo de la capital leonesa hacia los municipios limítrofes de su área urbana, buscando los típicos productos inmobiliarios de esos años: la vivienda unifamiliar, el adosado en condominio o la vivienda en manzana cerrada con servicios comunes (piscina, pistas deportivas, etc.). Dado que había varios municipios apostando por un modelo similar, la estrategia empresarial hacía necesario diferenciar el producto que podía ofrecerse, pues, aunque sólo hay una distancia de $11 \mathrm{Km}$ a León, otras localizaciones eran aún más cercanas a la capital y por tanto mucho más apetecibles a priori para la demanda. Se decidió apostar por la calidad ambiental como estrategia diferenciadora, y así quedaba explícito tanto en la Memoria de la Modificación del PP, como en la posterior estrategia publicitaria de promoción de la urbanización:

"Estrella de Izar es el mayor y más innovador proyecto urbanístico de la provincia de León, responde a un concepto urbanístico que aúna naturaleza, calidad de vida y todos los servicios necesarios. Está ubicada en un enlace excepcional de robledales y monte bajo.

La finca tiene una extensión de más de 3 millones de metros, de los cuales actualmente hay urbanizados 1 millón, en donde se contempla la construcción de más de 1.000 viviendas. La Urbanización Estrella de Izar nos ofrece todas las ventajas de vivir en el campo, rodeado de naturaleza, en un marco natural incomparable, sin renunciar a todos los servicios de la ciudad. Es un proyecto que concede tanta importancia a los aspectos técnicos y estéticos como a los aspectos prácticos y funcionales. El equilibrio entre interior y exterior, a través de las grandes aberturas, favorece la entrada de luz natural, creando ambientes más luminosos" ${ }^{\prime 60}$.

La Modificación, además de reajustar la ordenación para potenciar los valores paisajísticos y naturales, reajustó el número de viviendas para adaptarse nuevamente a las tendencias de la demanda inmobiliaria de la época: se incrementó el número de unifamiliares adosadas hasta 547 y se redujo el de viviendas unifamiliares aisladas a 105. En cuanto a las viviendas colectivas, 336 se destinaban a pequeños bloques exentos y otras 50 se planteaban en una gran manzana cerrada central, junto a la entrada a la urbanización desde la carretera, donde se proponía desarrollar una "plaza mayor" con comercio y servicios, a modo de centro urbano.

\footnotetext{
${ }^{60}$ https://www.facebook.com/pg/EstrellaDeIZAR/about/
} 

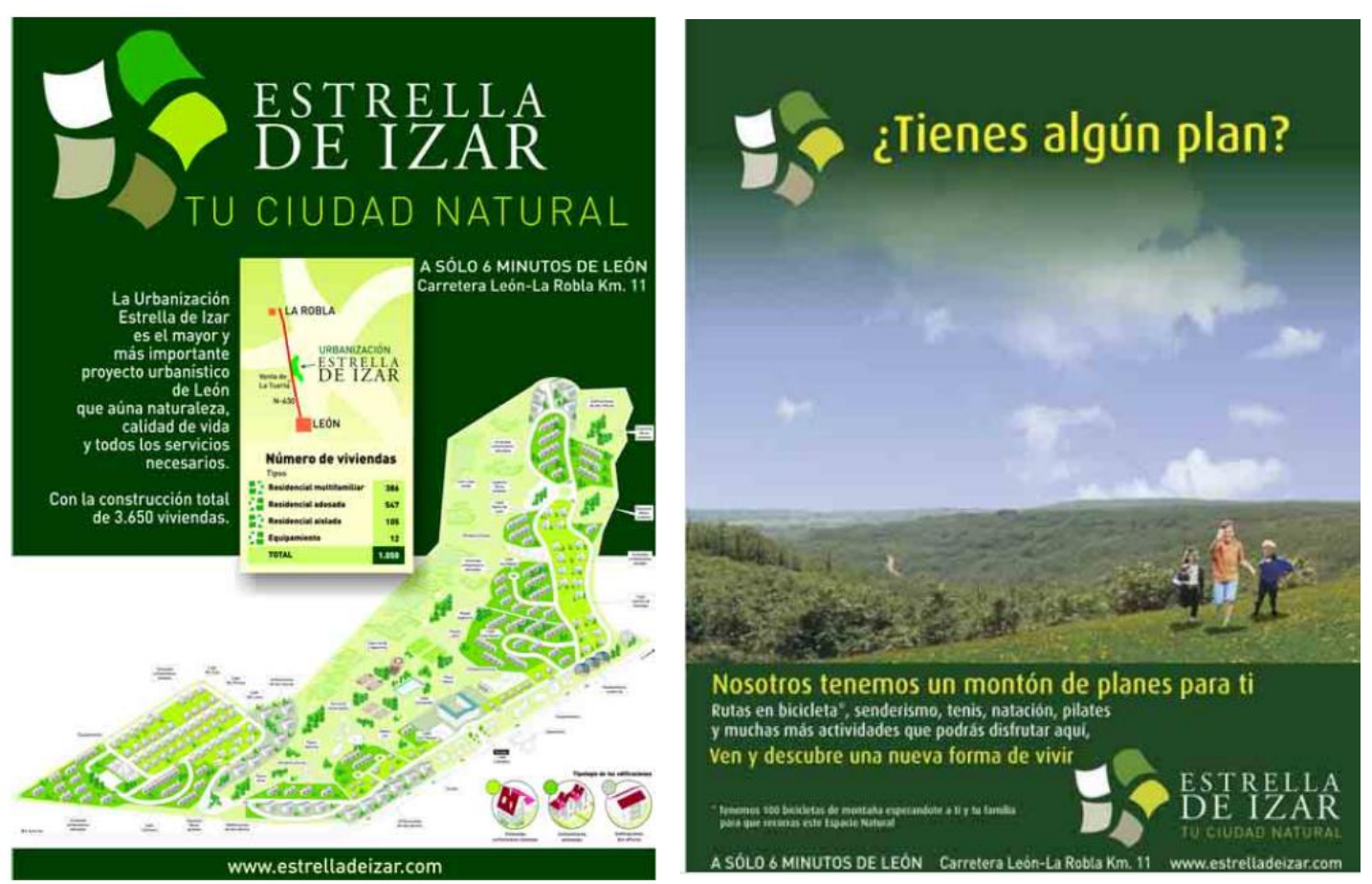

Figura 27. Publicidad de la urbanización Estrella de Izar.

Fuente: Anuncios publicitarios de Estrella de Izar (recogiendo ya los cambios en la ordenación tras la Modificación del PP de 2003).

Pero en pleno boom inmobiliario, la Modificación del PP no fue suficiente, y el mismo día que se aprobaba ésta reordenando el sector S-11, también se modificaron las Normas Subsidiarias municipales de Garrafe de Torío ${ }^{61}$, con 3 objetivos: recoger la modificación del sector S-11, crear de 2 nuevos sectores de Suelo Urbanizable Delimitado que se denominaban S-13 y S-14, y una nueva área de Suelo Urbanizable No Delimitado denominada $A 1$, con unas superficies respectivas de 23,$1 ; 26,5 ; y$ 196,5 ha. Los argumentos empleados para justificar estos nuevos crecimientos se desplazan ahora de la falta de ejecución de la urbanización -que, en definitiva, era un problema de inversión por parte de la promotora- al mantra de la liberalización del suelo invocando expresamente la Ley estatal de Suelo de 1998 entonces vigente, y, en segundo lugar, al modo de conseguir viabilizar los equipamientos. Este último argumento resulta especialmente curioso, pues se realizaba todo un alambicado razonamiento para justificar la necesidad de ampliar el número de viviendas (clasificando más suelo para ello, en los sectores S-12, S-13 y A-1) pasando así de las 1.050 viviendas originales del viejo proyecto de la Venta de la Tuerta a las 3.650 del nuevo de la Estrella de Izar.

Esta facilidad de justificación, basada en el principio de que "el papel soporta cualquier cosa", es otra de las características del planeamiento urbanístico neodesarrollista, y muestra tanto el desparpajo de los técnicos para justificar lo injustificable como - sobre todo, $y$, esto es lo verdaderamente problemático- el de

${ }^{61}$ Nuevamente, otro ejemplo de eficacia administrativa interesada. 
la ancha manga de la Administración Autonómica, responsable de la Aprobación Definitiva de los planes.

Finalmente, el último episodio urbanístico de Garrafe de Torío son unas nuevas Normas Urbanísticas Municipales (NUM) aprobadas en 2014, que vienen a ser el tercer documento de planeamiento de este municipio -después de los de 1977 y 1997- y que ilustran perfectamente esta última idea: se trata de un cambio de discurso meramente retórico sin cuestionar el crecimiento, con argumentos que justifican una cosa y realmente hacen la contraria.

En efecto, aprobadas en plena crisis inmobiliaria, era difícil seguir sosteniendo entonces un discurso expansionista, de manera que se puede constatar claro un cambio en la retórica frente a los viejos argumentos desarrollistas y neodesarrollistas ya conocidos, en base al cual las nuevas NUM dicen apostar por "un modelo urbanístico conservador, muy próximo al existente, que, más que modificarlo, debe ser ordenado y encauzado para evitar situaciones disonantes y discordancias de cualquier tipo"62.

El reconocimiento de ese modelo existente pasa por recoger íntegramente como Suelo Urbano - a pesar de no estar completada la urbanización ni los servicios y, por tanto, de no cumplirse estrictamente los requisitos legales para ello- el antiguo sector S11, que se grafía con la denominación "planeamiento asumido", junto al cual además incluyen en una única gran bolsa de Suelo Urbanizable -denominada ahora Sector S-SUR-01- los 2 sectores clasificados por la Modificación de las NNSS de 2003 -S13 y S14-, así como el área de Suelo Urbanizable No Delimitado A1 igualmente propuesta en 2003. Aunque a primera vista, se pueda constatar una reducción de la superficie total del conjunto, que pasaba de $2.462 .526 \mathrm{~m}^{2}$ a $867.707 \mathrm{~m}^{2}$, en realidad el recorte realizado es todo a costa del área A1 - pues los sectores S13 y S14 se mantenían íntegros dentro del perímetro del nuevo S-SUR-01-. Este hecho, junto con el mantenimiento del número total de viviendas nuevas proyectadas $-2.156-$ induce a pensar que se trata más bien de un reajuste de la superficie total del sector, eliminando suelo innecesario para su desarrollo, que de un cambio sustancial del modelo previsto.

Pero es que, además y a pesar de su retórica, las NUM de 2014 añadieron otros 4 nuevos sectores más de Suelo Urbanizable, con 124 viviendas a sumar a las 2.156 previstas en el sector S-SUR-01. A pesar de que debe reconocerse que estos sectores tienen una cierta lógica ${ }^{63}$, si realmente se quería apostar por un nuevo modelo

\footnotetext{
62 La Memoria resume así las intenciones: "Procede mantener la estructura territorial de las vías de comunicación, cuyos requerimientos son más de conservación y mejora y que atañen a esferas de otro ámbito, complementadas por la mejora de vías locales; la clasificación de suelos urbanos muy ceñidos a los cascos actuales; insistir en la protección del patrimonio, tanto natural como cultural e histórico, y garantizar la adecuación y calidad arquitectónica de las intervenciones, tanto de reforma como de nueva construcción".

${ }^{63}$ Su tamaño es bastante acotado y su localización razonable: uno se sitúa en Garrafe de Torío -que es la cabeza del municipio y donde, por tanto, se concentran ciertas posibilidades de desarrollo urbanístico-; y los otros tres de San Felices podrían justificar su viabilidad por ser la localidad más cercana a León (apenas 5 Kms), tener accesibilidad mediante FEVE y desarrollarse sobre suelos públicos. Pero claro, esta lógica compite con la de reflotar simultáneamente el macroproyecto de Estrella de Izar. No hay demanda para tanto suelo ni tanta vivienda.
} 
descentralizado a base de pequeños crecimientos sobre los núcleos existentes ${ }^{64}$, entonces quizá habría que haber reprogramado el modelo anterior de las macrourbanizaciones, cuyo fracaso se había demostrado sobradamente en el tiempo. Porque en plena crisis inmobiliaria, el número de 2.280 nuevas viviendas totales previstas por las NUM de 2014 parece excesivo para un municipio que contaba con sólo 1.060 viviendas en 2011, de las cuales además apenas 575 eran principales. Seguir insistiendo en el crecimiento, en especial en la apuesta por el Sector S-SUR01, contradice la retórica bienintencionada del discurso de la Memoria de las NUM. Lo verdaderamente consecuente habría sido desclasificar este suelo que estaba sin desarrollarse.

\section{EL PANORAMA DESPUÉs DE LA BATALLA: EL MERCADO INMOBILIARIO TRAS EL ESTALLIDO DE LA BURBUJA Y SU IMPACTO SOBRE EL TERRITORIO}

Como es sabido, el estallido de la burbuja inmobiliaria en España se produjo hacia finales de 2007, como consecuencia de una serie de factores tanto internos como externos (García Montalvo, 2004; Naredo, 2009; Observatorio Metropolitano, 2010). Entre los primeros, la crisis de las hipotecas subprime en Estados Unidos en agosto de 2007 dio lugar a una falta de liquidez en el sistema financiero internacional. Esto tuvo un fuerte impacto en toda la economía mundial, que resultó especialmente demoledor en nuestro país, por el notable peso que había adquirido el sector de la construcción ${ }^{65}-$ y la financiación asociada al mismo66 - en la economía española. En efecto el estrangulamiento del crédito hipotecario condujo a una reducción súbita de la demanda, que -a su vez- desplomó la rentabilidad de las inversiones en el sector inmobiliario; todo lo cual arrastró consigo al conjunto de la economía española, por la ausencia de financiación y el agotamiento del modelo económico neodesarrollista impulsado por el motor de la construcción y el negocio crediticio asociado a la financiación del suelo, la promoción inmobiliaria y la compraventa de vivienda.

El pinchazo de la burbuja y el hundimiento del mercado se reflejó fundamentalmente en el desplome de los precios y la paralización de la construcción de viviendas nuevas. En la Figura 4 puede verse cómo, en el caso de León, los precios de compraventa cayeron más de un $40 \%$ entre 2008 y 2018 (de $1.802 € / \mathrm{m}^{2}$ a 1.051 ). Por su parte, las transacciones de vivienda nueva (Figura 28) pasaron del máximo de 2.982 a tan sólo 226 en 2019. Aunque como se ve en el gráfico de la Figura 29, el mercado de segunda mano se ha mantenido por encima de un umbral mínimo durante todo el período, de forma que el volumen total de transacciones ha acusado una caída

\footnotetext{
64 Lo cual es más que dudoso, porque - según consta en la propia Memoria- en la Aprobación Inicial se habían propuesto 30 sectores, que la Comisión Provincial de Urbanismo había conseguido rebajar a 5, igual que la superficie del sector S-SUR-01, recortada de $1.408 .847 \mathrm{~m}^{2}$ a $867.707 \mathrm{~m}^{2}$. Por tanto, la supuesta contención no habría sido fruto tanto fruto de una rectificación municipal del rumbo expansionista como de un tijeretazo por orden superior.

65 El peso del sector de la construcción en el PIB había pasado del 4,7\% en 1997 al 9,3\% en 2007.

${ }^{66}$ Debido a esta relación estructural, el derrumbamiento posterior de todo el sistema como un castillo de naipes tuvo graves consecuencias para el sector financiero, provocando la quiebra de numerosas entidades (Caja Castilla-La Mancha, CajaSur, Caja Mediterráneo-CAM, Novacaixagalicia, Caixa Catalunya, Unnim y Bankia) que tuvieron que ser rescatadas con fondos públicos, así como el incremento de los desahucios, en aplicación de la ley hipotecaria.
} 
relativamente menor ${ }^{67}$, el mercado en su conjunto se ha reducido y el de vivienda nueva está prácticamente estancado.

Este hundimiento de la demanda y los precios coincide además con la existencia de un importante stock de vivienda terminada sin vender, cuya digestión está siendo muy difícil. Tras el estallido de la burbuja, el stock total de la provincia de León se estimaba en el año 2011 en 9.972 viviendas, y casi 10 años después (a fecha $31 / 12 / 2019$ ) sólo se ha reducido en 1.843 viviendas, de manera que, a ese ritmo se tardarían nada menos que otros 35,3 años en absorberse las 8.129 viviendas construidas que aún permanecen vacías ${ }^{68}$.

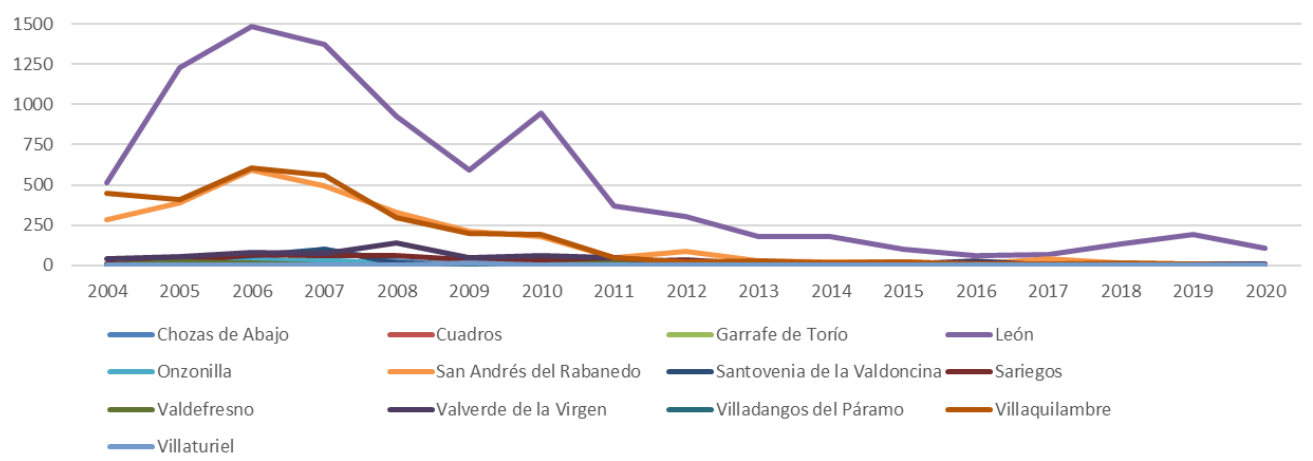

Figura 28. Transacciones anuales de vivienda nueva en el Área Urbana de León. Fuente: Elaboración propia a partir del MITMA.

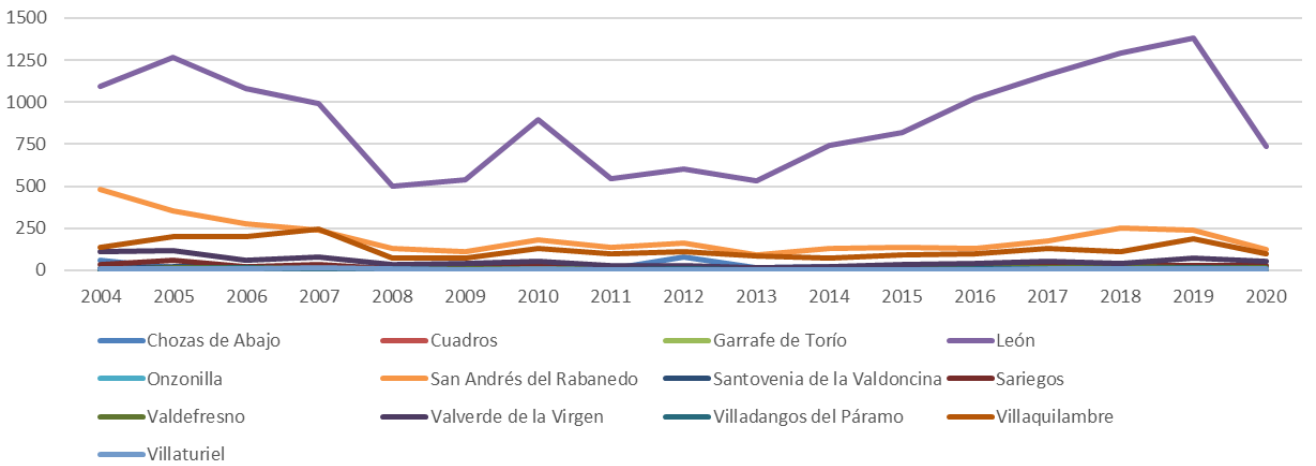

Figura 29. Transacciones anuales de vivienda usada en el Área Urbana de León. Fuente: Elaboración propia a partir del MITMA.

\footnotetext{
${ }^{67}$ En cualquier caso, notable -superior al 50\%-, pasando de 4.742 transacciones en 2006 a 2.236 en 2.019 .

${ }^{68}$ En la Comunidad Autónoma de Castilla y León, el stock ha pasado de 40.620 viviendas en 2011 a 31.703 a finales de 2019, de forma que se han absorbido 8.917 viviendas en estos 8 años, con lo que aún se tardarían 28,4 en absorber todo el stock. Los ritmos de absorción aún son peores que en León en Ávila y Soria, donde se tardarían, respectivamente 43,7 y 53,7 años en vender las viviendas vacías existentes.
} 


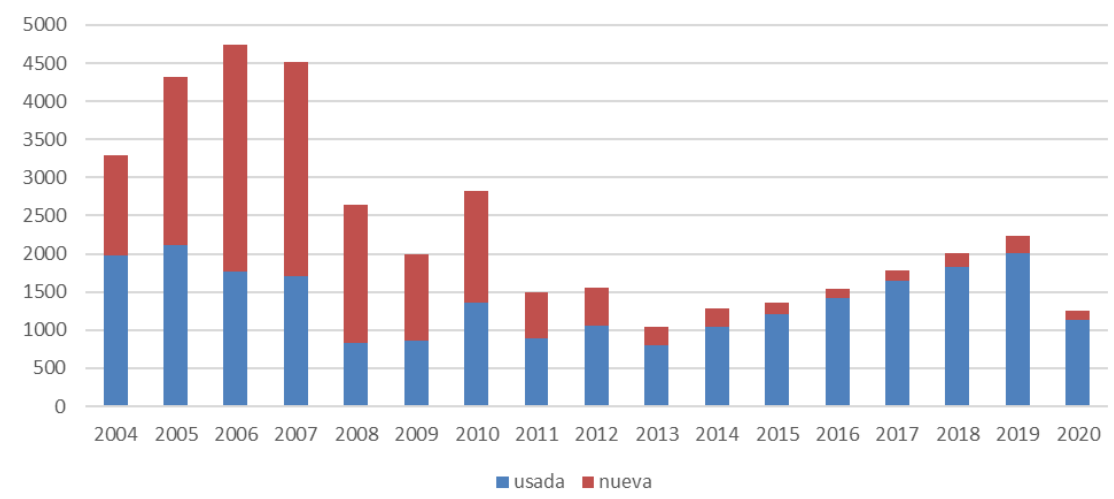

Figura 30. Transacciones anuales de viviendas (usadas y nuevas) en el Área Urbana de León. Fuente: Elaboración propia a partir del MITMA.

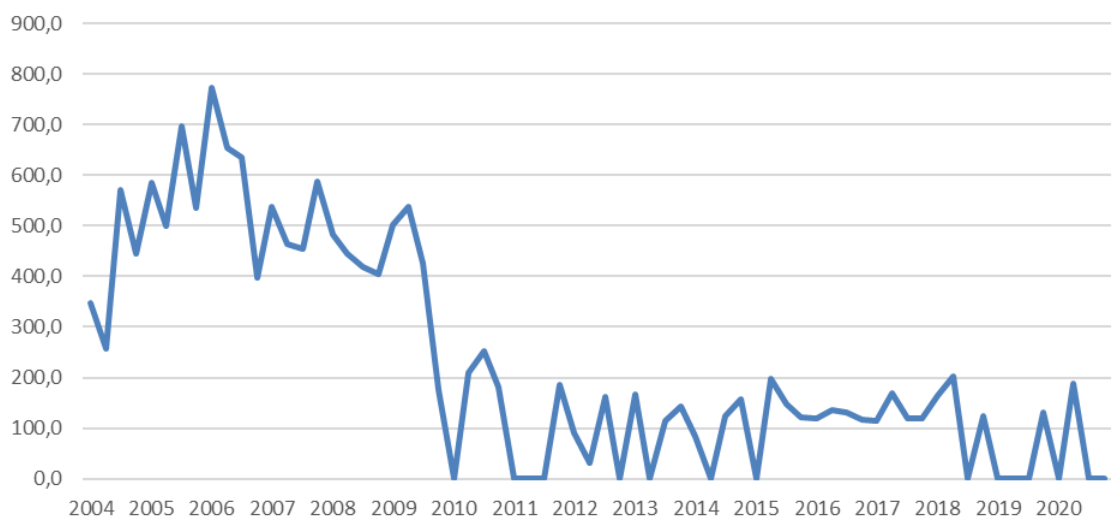

Figura 31. Evolución del precio del suelo $(€ / \mathrm{m} 2)$ en León.

Fuente: Elaboración propia sobre Serie Estadística precio medio del metro cuadrado de Suelo Urbano en municipios de más de 50.000 habitantes. MITMA.

Aún más intensa es la absoluta parálisis del mercado local de suelo. En el gráfico adjunto se muestra la evolución del precio medio del $\mathrm{m}^{2}$ de Suelo Urbano en León, apreciándose el rápido crecimiento que tuvo durante el boom inmobiliario (cuando pasó del entorno de los $300 € / \mathrm{m}^{2}$ a casi 800 ), para descender primero a una meseta en torno a $400 € / \mathrm{m}^{2}$ y desplomarse definitivamente a partir de finales de 2009 , de modo que en los últimos años no se han superado los $200 € / \mathrm{m}^{2}$, al tiempo que ha habido varios trimestres sin transacciones (lo que es indicativo del alto grado de parálisis de este mercado).

En este contexto, lo que nos interesa analizar de forma detallada es la posible digestión del stock de suelo existente en el área urbana de León, así como las estrategias para afrontar esta situación en el futuro. 


\section{EL URBANISMO POSTERIOR A LA BURBUJA: DEL CAMBIO DE PARADIGMA AL URBANISMO DE LA GOMA DE BORRAR}

\subsection{El cambio de paradigma urbanístico en la legislación estatal de suelo}

Como han señalado numerosos autores (Romero, 2010; Gaja, 2015; Calderón y García Cuesta, 2017) la legislación española sobre suelo y urbanismo no reaccionó a la burbuja inmobiliaria hasta un momento muy tardío69. Coincidiendo casi en el tiempo con los primeros síntomas de su estallido a nivel internacional ${ }^{70}$, el 28 de mayo de 2007 se aprobó en España la Ley de Suelo 8/2007, que intentaba poner freno a los excesos urbanísticos que se venían cometiendo en los últimos años al amparo de la liberalización de suelo operada por la Ley de 1998, así como a las prácticas neodesarrollistas y expansivas que hemos visto a nivel municipal. En su Preámbulo declaraba: "en tercer y último lugar"1, la del urbanismo español contemporáneo es una historia desarrollista, volcada sobre todo en la creación de nueva ciudad. Sin duda, el crecimiento urbano sigue siendo necesario, pero hoy parece asimismo claro que el urbanismo debe responder a los requerimientos de un desarrollo sostenible, minimizando el impacto de aquel crecimiento y apostando por la regeneración de la ciudad existente". Intentado conjugar desarrollo y sostenibilidad ${ }^{72}$, enunciaba en su art. 2 el "Principio de desarrollo territorial y urbano sostenible", según el cual las políticas públicas de regulación, ordenación, ocupación, transformación y uso del suelo debían procurar "la protección, adecuada a su carácter, del medio rural y la preservación de los valores del suelo innecesario o inidóneo para atender las necesidades de transformación urbanística". En el Preámbulo se desarrollaba esta idea, sosteniendo que "el suelo, además de un recurso económico, es también un recurso natural, escaso y no renovable.

Desde esta perspectiva, todo el Suelo Rural tiene un valor ambiental digno de ser ponderado y la liberalización del suelo no puede fundarse en una clasificación indiscriminada, sino, supuesta una clasificación responsable del Suelo Urbanizable necesario para atender las necesidades económicas y sociales, en la apertura a la libre competencia de la iniciativa privada para su urbanización y en el arbitrio de

\footnotetext{
${ }^{69}$ EI PSOE, que tanto había criticado la Ley de Suelo de 1998, llegó al poder en 2004, en la cresta de la ola del boom, y aún tardó 3 años en aprobar la Ley de Suelo de 2007.

70 Aunque el inicio de la denominada "Gran Recesión" suele situarse en el verano de 2008, con la quiebra del banco estadounidense Lehman Brothers, y el rescate por la Reserva Federal de las dos principales entidades hipotecarias norteamericanas -Fannie Mae y Freddie Mac-, ya en el año 2007 se habían producido los primeros signos del desplome con la crisis de las hipotecas subprime: el cierre de un fondo de inversiones de Bear Stearns, la quiebra de Blackstone y de la American Home Mortgage (entonces décimo banco hipotecario de los Estados Unidos), el National City Home Equity, etc.

${ }^{71}$ El orden resulta significativo. En primer lugar, y atendiendo al deslinde competencial que había hecho el Tribunal Constitucional, la Ley afirmaba no ser una norma urbanística, sino referida al régimen del suelo y la igualdad en el ejercicio de los derechos constitucionales a él asociados, prescindiendo por primera vez desde 1956 de regular técnicas específicamente urbanísticas, tales como los tipos de planes o las clases de suelo. En segundo lugar, destacaba como novedad la superación de la tradición de reservar solamente "a la propiedad del suelo el derecho exclusivo de iniciativa privada en la actividad de urbanización", introduciendo la figura del agente urbanizador.

72 En ese término de "desarrollo sostenible" que J. M. Naredo ha calificado como oxímoron en numerosas ocasiones.
} 
medidas efectivas contra las prácticas especulativas, obstructivas y retenedoras de suelo, de manera que el suelo con destino urbano se ponga en uso ágil y efectivamente. $Y$ el Suelo Urbano, la ciudad ya hecha, tiene asimismo un valor ambiental, como creación cultural colectiva que es objeto de una permanente recreación, por lo que sus características deben ser expresión de su naturaleza y su ordenación debe favorecer su rehabilitación y fomentar su uso". En la práctica, y pesar de no entrar en la técnica de la clasificación del suelo, esto significaba revertir los efectos de la liberalización operada por la anterior Ley 6/1998, devolviendo el carácter residual al suelo rural y obligando en su art. 10 a las administraciones correspondientes a posibilitar el paso de la situación de suelo rural a la de suelo urbanizado, mediante la urbanización, solamente del "suelo preciso para satisfacer las necesidades que lo justifiquen", impidiendo la especulación y preservando "de la urbanización al resto del suelo rural". (Cardoso Delso, 2020, p. 212).

Esto ha supuesto un importante cambio en la clasificación de suelo de los planes posteriores a la Ley de Suelo de 2007, que, además, ha creado ya incluso jurisprudencia sobre esta necesidad de justificar - por encima de la discrecionalidadel dimensionado de suelo en base a las necesidades objetivas (Calderón, 2017; Cardoso Delso, 2020). Así, por ejemplo, la Sentencia del Tribunal Supremo (STS) de fecha 2 de julio de 2012 (Rec. 4066/2010) anuló el Acuerdo de aprobación por parte de la CCAA del desarrollo de la Ecociudad de Logroño, pues pretendía reclasificar suelo para 3.000 nuevas viviendas cuando el Plan General vigente aún tenía capacidad para albergar 38.224. O la STS de 17 de junio de 2015 (Rec. 3367/2013) anulando la Modificación Puntual no 6 del Plan General de Ávila, que pretendía reclasificar suelo para 3.396 viviendas cuando en los suelos inicialmente previstos por el Plan General todavía quedaba una capacidad para 10.670 viviendas sobre 17.278. O la STS de 16 de marzo de 2016 (Rec. 3402/2014) contra la revisión del Plan General de Zamora, "por la falta de acreditación suficiente de que la extensión de las superficies destinadas al Suelo Urbanizable por el Plan General de Ordenación Urbana de Zamora son las que se precisan para satisfacer las necesidades de suelo de esta índole". O, la STS de 27 de septiembre de 2018 (Rec. 2339/2017) sobre la revisión del Plan General del municipio madrileño de Pedrezuela, donde se exige la acreditación y "debida justificación de que ese gran suelo industrial que se proyecta y (que sirve de base para pretender triplicar la población del municipio) proceda de unas previsiones económicas reales".

Dando un paso más en el cambio de paradigma, pero con igual perspectiva económica, en el momento más intenso de la crisis, y constatado el hundimiento del sector de la construcción, la Ley 2/2011, de 4 de marzo, de Economía Sostenible pretendió, según declaraba en su Preámbulo, dar un "impulso de la recuperación del sector de la vivienda mediante una serie de reformas centradas en el impulso a la rehabilitación y la renovación urbanas". Este primer impulso fue completado 2 años después con la Ley 8/2013, de Rehabilitación, Regeneración y renovación Urbanas, que afirmaba que "el camino de la recuperación económica, mediante la reconversión del sector inmobiliario y de la construcción y también la garantía de un modelo sostenible e integrador, tanto ambiental, como social y económico, requieren volcar todos los esfuerzos en aquellas actuaciones, es decir, las de rehabilitación y de 
regeneración y renovación urbanas, que constituyen el objeto esencial de esta Ley". Según se recogía en el Preámbulo, en aquellos momentos se estimaba que existía un stock de 723.043 viviendas vacías de nueva construcción y suelo clasificado capaz de acoger nuevos crecimientos urbanísticos para los próximos 45 años, gran parte de ellos situados en entornos donde no se preveía ningún incremento de la demanda en los próximos años. Por ello, se consideraba que "tanto a corto, como a medio plazo, será muy difícil que los sectores inmobiliario y de la construcción puedan contribuir al crecimiento de la economía española y a la generación de empleo si continúan basándose, principalmente y con carácter general, en la transformación urbanística de suelos vírgenes y en la construcción de vivienda nueva", de lo que se derivaba la necesidad de reorientar el urbanismo español desde el crecimiento hacia la regeneración de la ciudad consolidada y el sector de la construcción desde la vivienda nueva a la rehabilitación edificatoria.

Sin embargo, a pesar de estas propuestas de reorientación profunda de la máquina inmobiliaria, ninguna de estas leyes abordó el problema de qué hacer con los excesos cometidos durante los años precedentes: con los cadáveres inmobiliarios y las urbanizaciones fantasma que proliferaban por doquier, $y$, mucho menos, con los enormes paquetes existentes de suelo medio urbanizado o simplemente clasificado por el planeamiento expansionista del boom.

Muy al contrario, la Administración se preocupó e hizo un gran esfuerzo por salir al rescate del sistema inmobiliario y financiero que había provocado dichos excesos ${ }^{73}$, en lo que Calderón (2017) ha calificado como "un ejemplo más de la subordinación del sector inmobiliario al financiero, y de la inconsistencia y volatilidad de la legislación". En relación con el tema del urbanismo, tras el estallido de la burbuja había dos cuestiones urgentes -vinculadas entre sí y hasta cierto punto contradictorias - que afectaban a los amplios paquetes de suelo ${ }^{74}$ de que disponían

\footnotetext{
73 Los mayores esfuerzos se han realizado para paliar los efectos de la burbuja en el plano económico, no en el territorial. En 2009 se creó el FROB (Fondo para la Reestructuración Ordenada Bancaria) para impulsar los procesos de reestructuración de las entidades bancarias y reforzar la estabilidad del sistema financiero, que finalmente ha dado como resultado la práctica desaparición de las Cajas de Ahorro y fuerte un proceso de fusiones y concentración. En junio de junio de 2012, el Gobierno español solicitó la asistencia financiera externa a la Unión Europea (lo que se conoció como el "rescate bancario") para la reestructuración y recapitalización de la banca española y al mes siguiente se firmó el Memorandum of Understanding "On Financial-Sector Policy Conditionality", que establecía la posibilidad de acceder hasta 100.000 millones de $€$ del Fondo Europeo de Estabilidad Financiera (EFSF, en sus siglas en inglés), a cambio de una serie de contrapartidas para el sistema financiero español. Entre las 32 condiciones para recibir la ayuda financiera estaba la constitución de la SAREB como una entidad gestora (en ocasiones denominada por la prensa como "banco malo", aunque nada tiene que ver con un "banco") a la que transferir los activos inmobiliarios de las entidades que atravesaban dificultades (sobre todo, las Cajas de Ahorros), con el objetivo de reducir los riesgos de las mismas y liquidar de forma ordenada los activos problemáticos. En el momento de su creación, su cartera (adquirida a las entidades con problemas) estaba formada por unos 200.000 activos, de los cuales el $80 \%$ eran activos financieros (préstamos a promotores, por encima de $250.000 €$ como mínimo; no hipotecas a particulares) y el $20 \%$ activos inmobiliarios (suelo, viviendas, oficinas, locales, etc.). La mayor parte de su capital es privado, $55 \%$, mientras que el $45 \%$ está en manos del FROB. Su principal mecanismo de financiación es la emisión de deuda avalada por el Estado español. Su previsión es vender en un plazo de 15 años todos los activos financieros e inmobiliarios recibidos y cumplir con la devolución de la deuda avalada por el Estado. En sus 6 años de vida han conseguido reducir su cartera en 18.117 millones de $€$ y cancelar deuda por importe de 15.676 millones de $€$.

74 En relación con el tema de la vivienda, que excede el objeto de este artículo, también había otra serie de temas pendientes: la absorción del stock de vivienda terminada y sin vender, así como el problema social de los desahucios hipotecarios.
} 
las empresas promotoras y el sector financiero ${ }^{75}$ : la primera, evitar el desplome en la valoración -a efecto de sus balances ${ }^{76}$ - de los suelos clasificados como Urbanizables sobre los que súbitamente habían desaparecido las expectativas de desarrollo, provocando con ello el desplome de su valor real en el mercado, para contrarrestar lo cual interesaba seguir prorrogando al máximo las expectativas de urbanización del Suelo Urbanizable. Y la segunda, que los suelos Urbanizables sin desarrollar no estuvieran gravados con el Impuesto de Bienes Inmuebles (IBI) del Suelo Urbano, para lo que interesaba justo lo contrario: que se considerasen como rústicos.

La Administración fue capaz de resolver estos contradictorios requerimientos, aunque con ello no consiguió el objetivo final pretendido de evitar el naufragio a los sectores inmobiliario y financiero. En relación con la primera cuestión, el RD-Ley 6/2010, de 9 de abril, de Medidas para el impulso de la recuperación económica y el empleo, después, y el RD-Ley 20/2011, de 30 de diciembre, de Medidas Urgentes en materia presupuestaria, tributaria y financiera para la corrección del déficit público, modificaron la Disposición Transitoria Tercera sobre valoraciones del Texto Refundido de la Ley de Suelo de 2008, prolongando -primero un año y luego otro más- el plazo inicial de 3 años para valorar - caso de no existir plazos de ejecución y estos no se hubieran vencido- de forma más ventajosa para los propietarios el Suelo Urbanizable que no se hubiera desarrollado, impidiendo su valoración automática como Rústico y evitando así perjudicar las cuentas de resultados de las empresas y entidades financieras propietarias ${ }^{77}$.

Sobre la consideración del suelo a efectos catastrales (Ruiz Arnáiz, 2015; Lozano \& Muiña, 2014; Calderón, 2017), la Ley 13/2015 de 24 de junio, de Reforma de la Ley Hipotecaria y del Texto Refundido de la Ley del Catastro Inmobiliario, recogió el criterio jurisprudencial del Tribunal Supremo (STS de 30 de mayo de $2014^{78}$ ) que

\footnotetext{
75 Ambas íntimamente relacionadas, no sólo por el endeudamiento de las empresas, sino porque tras la quiebra de muchas de éstas, sus activos tóxicos de suelo y viviendas terminaron en manos del sector financiero. Véase la nota 65.

${ }^{76}$ Sometidos a las condiciones del Memorandum of Understanding desde 2012 y al escrutinio del Banco de España y del Banco Central Europeo (Bank Stress Test) desde 2019.

77 Esta Disposición Transitoria Tercera establecía que, a partir de su entrada en vigor, se aplicarían sus reglas de valoración, que sólo distinguían entre suelo las situaciones básicas de urbanizado y de rural -eliminando las expectativas del urbanizable-. No obstante, de modo transitorio en su apartado segundo permitía prorrogar las valoraciones de la anterior Ley 6/1998, que sí permitían contemplarlas: "2. Los terrenos que, a la entrada en vigor de aquélla, formen parte del Suelo Urbanizable incluido en ámbitos delimitados para los que el planeamiento haya establecido las condiciones para su desarrollo, se valorarán conforme a las reglas establecidas en la Ley 6/1998, de 13 de abril, sobre Régimen de Suelo y Valoraciones, tal y como quedaron redactadas por la Ley 10/2003, de 20 de mayo, siempre y cuando en el momento a que deba entenderse referida la valoración no hayan vencido los plazos para la ejecución del planeamiento o, si han vencido, sea por causa imputable a la Administración o a terceros". De no existir previsión expresa sobre plazos de ejecución en el planeamiento ni en la legislación de ordenación territorial y urbanística, en la redacción original se consideraban 3 años, que primero se modificaron para subirlos a 4, y después a 5 .

${ }^{78}$ En esta Sentencia, la Sala Tercera del confirmaba la interpretación del artículo 7.2.b) del Texto Refundido de la Ley del Catastro Inmobiliario, según la cual para que un suelo sea considerado como urbano a efectos catastrales no basta con que esté clasificado como urbanizable o incluido en un sector o ámbito delimitado para ser urbanizado, sino debe contar con una ordenación pormenorizada a través del planeamiento general o de desarrollo. El tenor literal del art. 7.2.b del Real Decreto Legislativo 1/2004 dice: "Se entiende por suelo de naturaleza urbana: a) El clasificado o definido por el planeamiento urbanístico como urbano, urbanizado o equivalente. b) Los terrenos que tengan la consideración de urbanizables o aquellos para los que los instrumentos de ordenación territorial y urbanística prevean o permitan su paso a la situación de suelo urbanizado, siempre que estén incluidos en sectores o ámbitos espaciales
} 
considera que los Suelos Urbanizables sin planeamiento de desarrollo aprobado deben ser gravados como bienes inmuebles de naturaleza rústica, y aprobó nuevos criterios para su valoración en el caso de desclasificarse, teniendo en cuenta sus circunstancias de localización ${ }^{79}$.

\subsection{Las novedades en la normativa urbanística de Castilla y León: el urbanismo de la "goma de borrar"}

A nivel autonómico, tras el cambio de paradigma en la legislación estatal de 2007, Castilla y León revisó en 2008 y 2009 la definición de las clases de suelo, eliminando el carácter residual del Suelo Urbanizable, y devolviéndoselo - como había sido tradicional desde 1956 a 1998- al Suelo Rústico.

Primero, en 2008 se modificó la Ley 5/1999, rehaciéndose el art. 14 para eliminar el carácter residual de la categoría de Suelo Urbanizable No Delimitado, que quedaba suprimida, y exigiendo -en plena sintonía con el nuevo principio estatal de desarrollo urbano sostenible - una mínima racionalidad en los nuevos desarrollos urbanísticos, intentando atajar el modelo de ciudad dispersa a base de piezas autistas que había sido tan común en la era del boom. En este sentido, se acotó la discrecionalidad, hasta entonces absoluta, de los municipios para clasificar cualquier como Urbanizable, al exigirse dos condiciones que aún siguen vigentes: la primera (en línea con la jurisprudencia antes citada), "que su transformación en Suelo Urbano se considere justificada a la vista de las demandas de suelo para usos residenciales, dotacionales o productivos", demandas que deben analizarse en la memoria del instrumento correspondiente que clasifique los terrenos; $y$, la segunda, intentando evitar la dispersión ${ }^{80}$, que se incluyan en un sector cuyo perímetro sea colindante en al menos un $20 \%$ con el Suelo Urbano de un núcleo de población existente (salvo en determinadas excepciones ${ }^{81}$ ).

\footnotetext{
delimitados, así como los demás suelos de este tipo a partir del momento de aprobación del instrumento urbanístico que establezca las determinaciones para su desarrollo".

${ }^{79}$ Lo que venía a contradecir el nuevo régimen de valoraciones de la Ley de Suelo de 2007, al reconocerse (Calderón 2017) "en cierto modo, una tercera categoría según la cual el suelo que retorne a la situación de rural por carecer de instrumento de desarrollo puede ser valorado en función de su localización, siendo así que este modo de incorporar plusvalías al suelo había quedado erradicado en la mencionada ley [..]". El tenor literal del art. 30.2. b de la Ley 13/2015 es el siguiente: "Cuando tuviera por causa una modificación de planeamiento que varíe el uso de los bienes inmuebles, dichos bienes se valorarán tomando como valor del suelo el que corresponda a su ubicación, que en todo caso deberá estar comprendido entre el máximo y el mínimo de los previstos para el uso de que se trate en el polígono de valoración en el que se hallen enclavados tales bienes según la ponencia vigente."

${ }^{80}$ En la Exposición de Motivos se insiste en el concepto de crecimiento compacto, que "es ya protagonista del debate y la práctica del urbanismo, comprobadas sus ventajas sociales frente al desarrollo disperso: permite optimizar servicios e infraestructuras [...]y preservar la identidad cultural [...]."

81 Tras una nueva modificación en 2016, en la actualidad las excepciones son cuatro:

1. Cuando el sector tenga uso predominante industrial, logístico u otros vinculados a otras productivas como explotaciones agropecuarias intensivas.

2. ${ }^{\circ}$ Cuando el sector que se va a clasificar esté separado del Suelo Urbano por otro sector de Suelo Urbanizable, con el cual sea colindante en al menos un $20 \%$ de su perímetro.

3. ${ }^{\circ}$ Cuando el sector que se va a clasificar esté separado del Suelo Urbano por terrenos protegidos por la legislación sectorial, con una distancia máxima de 2.000 metros.

4. ${ }^{\circ}$ Cuando se trate de actuaciones previstas en un instrumento de ordenación del territorio.
} 
Posteriormente, estos cambios se trasladaron al Reglamento de Urbanismo, modificándose el enunciado de los criterios de clasificación del Suelo Urbanizable del artículo 27, que originalmente establecía que "deben clasificarse como Suelo Urbanizable los terrenos que no puedan ser clasificados como Suelo Urbano ni como Suelo Rústico según los criterios señalados en este Reglamento". Tras la modificación de 2009, el Suelo Urbanizable ha pasado a definirse exclusivamente como "el conjunto de terrenos aptos para ser incorporados al proceso de urbanización o en curso de incorporación al mismo".

Pero lo más destacable es el carácter pionero que tuvo a nivel autonómico la Ley castellano-leonesa 7/2014, de 12 de septiembre (publicada en el BOE n० 239 de 2 de octubre de 2014), de Medidas sobre Rehabilitación, Regeneración y Renovación Urbana, y sobre Sostenibilidad, coordinación y simplificación en materia de urbanismo, al proponer medidas no sólo ya para evitar nuevos desmanes, sino para reconducir los ya cometidos. Como se decía en la Exposición de Motivos, se "pretende acelerar la deseada reconversión del sector inmobiliario, estableciendo plazos para demostrar la viabilidad de los terrenos clasificados en su día como Suelo Urbanizable, que en otro caso retornarán a su condición previa de Suelo Rústico." En efecto, esta ley se atrevió a proponer por primera vez en España el mecanismo "de la goma de borrar" para hacer frente a los excesos del urbanismo del "pinta y colorea" de los años precedentes: de la alegría en la clasificación expansiva de suelo se pasaba a la desclasificación masiva, mediante un calendario reglado de aplicación en todo el territorio regional.

Así, la Ley 7/2014 introdujo, en su Disposición Transitoria Tercera, la obligación de que la ordenación detallada de los terrenos clasificados como Suelo Urbanizable deba ser aprobada definitivamente antes de que transcurran los siguientes plazos, contados a partir de la fecha de su entrada en vigor (19 de octubre de 2014), incumplidos los cuales quedarán clasificados de forma automática y a todos los efectos como Suelo Rústico Común:

"a) Para los terrenos clasificados como suelo urbanizable conforme a la legislación urbanística anterior a la Ley 5/1999, de 8 de abril, de Urbanismo de Castilla y León: Dos años.

b) Para los terrenos clasificados como suelo urbanizable no delimitado en el marco de la Ley 5/1999, de 8 de abril, de Urbanismo de Castilla y León: Cuatro años.

c) Para los terrenos clasificados como suelo urbanizable delimitado en el marco de la Ley 5/1999, de 8 de abril, de Urbanismo de Castilla y León: Ocho años".

Transcurridos ya 6 años desde su entrada en vigor, se han producido ya dos rondas de desclasificación de Suelo Urbanizable en Castilla y León. 


\subsection{Las rondas autonómicas de desclasificación de Suelo Urbanizable de 2016 y 2018: sus efectos en el área urbana de León}

En la primera ronda, y en aplicación del apartado a) de la Disposición Transitoria Tercera de la Ley 7/2014, el 19 de octubre de 2016, quedaron desclasificados automáticamente ${ }^{82}$ como Suelo Urbanizable - pasando a ser Suelo Rústico Comúnlos terrenos clasificados como Suelo Urbanizable conforme a la legislación urbanística anterior a la Ley 5/1999 de Urbanismo de Castilla y León, cuya ordenación detallada no hubiese sido aprobada definitivamente con anterioridad.

En toda la Comunidad Autónoma esta ronda supuso la desclasificación de 521 sectores en 153 municipios, afectando a una superficie total de suelo desclasificado de 11.389 ha. En el área urbana de León sólo afectó al municipio de Santovenia de la Valdoncina, cuyas NNSS databan de 1995 y, por tanto, eran el único instrumento de planeamiento municipal de alfoz anterior a la Ley 5/1999. Como se ve en el cuadro y el plano adjunto, resultaron desclasificados 10 pequeños sectores de Suelo Apto para Urbanizar de tamaño comprendido entre 3 y 9,3 ha (con un tamaño medio de 4,6 ha): 8 residenciales, con una extensión de 39,1 ha y una capacidad estimada para 700 viviendas, y 2 industriales, con una superficie total de 9,5 ha.

\begin{tabular}{|l|l|l|r|}
\hline \multicolumn{5}{|c|}{$\begin{array}{c}\text { TERRENOS AFECTADOS POR EL APARTADO b) DE LA DISPOSICIÓN } \\
\text { TRANSITORIA TERCERA DE LA LEY 7/2014 }\end{array}$} \\
\hline \multicolumn{1}{|c|}{ M UNICIPIO } & \multicolumn{1}{|c|}{ A M B ITO } & \multicolumn{1}{c|}{ Uso } & $\begin{array}{c}\text { Superficie } \\
\text { (m2) }\end{array}$ \\
\hline Santovenia de la Valdoncina & SAU 10 & Residencial & 43.500 \\
\hline Santovenia de la Valdoncina & SAU 12 & Residencial & 36.200 \\
\hline Santovenia de la Valdoncina & SAU 13 & Industrial & 46.500 \\
\hline Santovenia de la Valdoncina & SAU 14 & Residencial & 34.000 \\
\hline Santovenia de la Valdoncina & SAU 2 & Residencial & 37.200 \\
\hline Santovenia de la Valdoncina & SAU 3 & Residencial & 93.700 \\
\hline Santovenia de la Valdoncina & SAU 4 & Residencial & 68.900 \\
\hline Santovenia de la Valdoncina & SAU 6 & Industrial & 49.100 \\
\hline Santovenia de la Valdoncina & SAU-1 & Residencial & 30.100 \\
\hline Santovenia de la Valdoncina & SAU-11 & Residencial & 46.850 \\
\hline Total Área Urbana de León & & & 486.050 \\
\hline
\end{tabular}

Figura 32. Terrenos afectados por la primera ronda de desclasificación de suelo el 19 de octubre de 2016, en virtud del apartado a) de la DT Tercera de la Ley 7/2014.

Fuente: Elaboración propia a partir de Junta de Castilla y León (2016): "Fichas de municipios de terrenos desclasificados. Apartado $\mathrm{A}^{\prime \prime}$. https://vivienda.jcyl.es/web/es/urbanismo-ordenacion-territorio/desclasificacion-suelo-urbanizable.html

\footnotetext{
82 Como relata A. Marinero (2018), a pesar de lo que podía pensarse a priori, la desclasificación apenas encontró más oposición que la de algunos propietarios de suelo y, por el contrario, "en la esfera pública y a nivel regional, las reacciones fueron unánimemente favorables. Hay que considerar que, en 2016, aunque técnicamente España ya no estaba en situación de crisis económica, aún estaba muy extendida la sensación de que el "estallido de la burbuja inmobiliaria" había tenido mucho que ver en la intensidad del declive socio-económico sufrido, de modo que cualquier iniciativa que se orientara a combatir sus causas, aunque fuera a posteriori, tenía muchas posibilidades de ser bien recibida".
} 
Dos años después, tuvo lugar la segunda ronda de desclasificación ${ }^{83}$, en aplicación del apartado b) de la Disposición Transitoria Tercera. En virtud de ella, el 19 de octubre de 2018, quedaron desclasificados, pasando a ser Suelo Rústico Común, los terrenos que estuvieran clasificados como Suelo Urbanizable No Delimitado en el marco de la Ley 5/1999 y no tuvieran aprobada en esa fecha la ordenación detallada, lo que implicaba la delimitación o sectorización previa y la aprobación del correspondiente Plan Parcial.

Esta ronda afectó a 270 paquetes de suelo en 95 municipios de toda la Comunidad, con una superficie total desclasificada de 28.131 ha. En comparación con la ronda anterior, afectó a un número mucho menor de municipios, pero a paquetes de suelo de mayor extensión, ya que se trataba de las bolsas de Suelo Urbanizable No Delimitado considerado generalmente con carácter residual en determinados planes urbanísticos municipales de tipo desarrollista gestados durante la primera parte del boom inmobiliario. Su análisis detallado a nivel de toda la Comunidad Autónoma es muy interesante y ha sido realizado por A. Marinero ${ }^{84}$.

\footnotetext{
83 Según Marinero (2018) esta segunda ronda tuvo una mayor repercusión en los medios de comunicación, con un enfoque positivo, entendiéndose como parte del proceso de superación de los excesos de la burbuja inmobiliaria. Incluso los Ayuntamientos de las ciudades grandes (Valladolid, Soria, Salamanca) que resultaron afectados en esta ronda, la aceptaron bien, absteniéndose de crítica alguna.

${ }^{84}$ Este autor ha reconocido varias tipologías, ilustradas con ejemplos. La más llamativa, es la de los municipios que realizaron una "clasificación total", aplicando el ideal de la Ley del Suelo de 1998, y por tanto clasificando como Urbanizable todo el suelo que no estuviera protegido. Esta tipología dio lugar a clasificaciones espectacularmente llamativas por su desmesura en municipios que tenían pocos suelos protegidos y, en cambio, mucho menos aparatosas en aquellos donde las protecciones afectaban a mayores porcentajes de la superficie municipal. A pesar de su espectacularidad, en realidad afectaron a un número de municipios relativamente pequeño.

Más frecuentes fueron aquellos otros que clasificaron como Suelo Urbanizable No Delimitado una generosa orla o corona en torno al núcleo existente, proponiendo su crecimiento por extensión en mancha de aceite. También hubo otra tipología que concentró la clasificación del Suelo Urbanizable No Delimitado en uno o varios paquetes de grandes dimensiones, de forma claramente vinculada a grandes propiedades donde se planteaba un proyecto urbanístico ambicioso.
} 


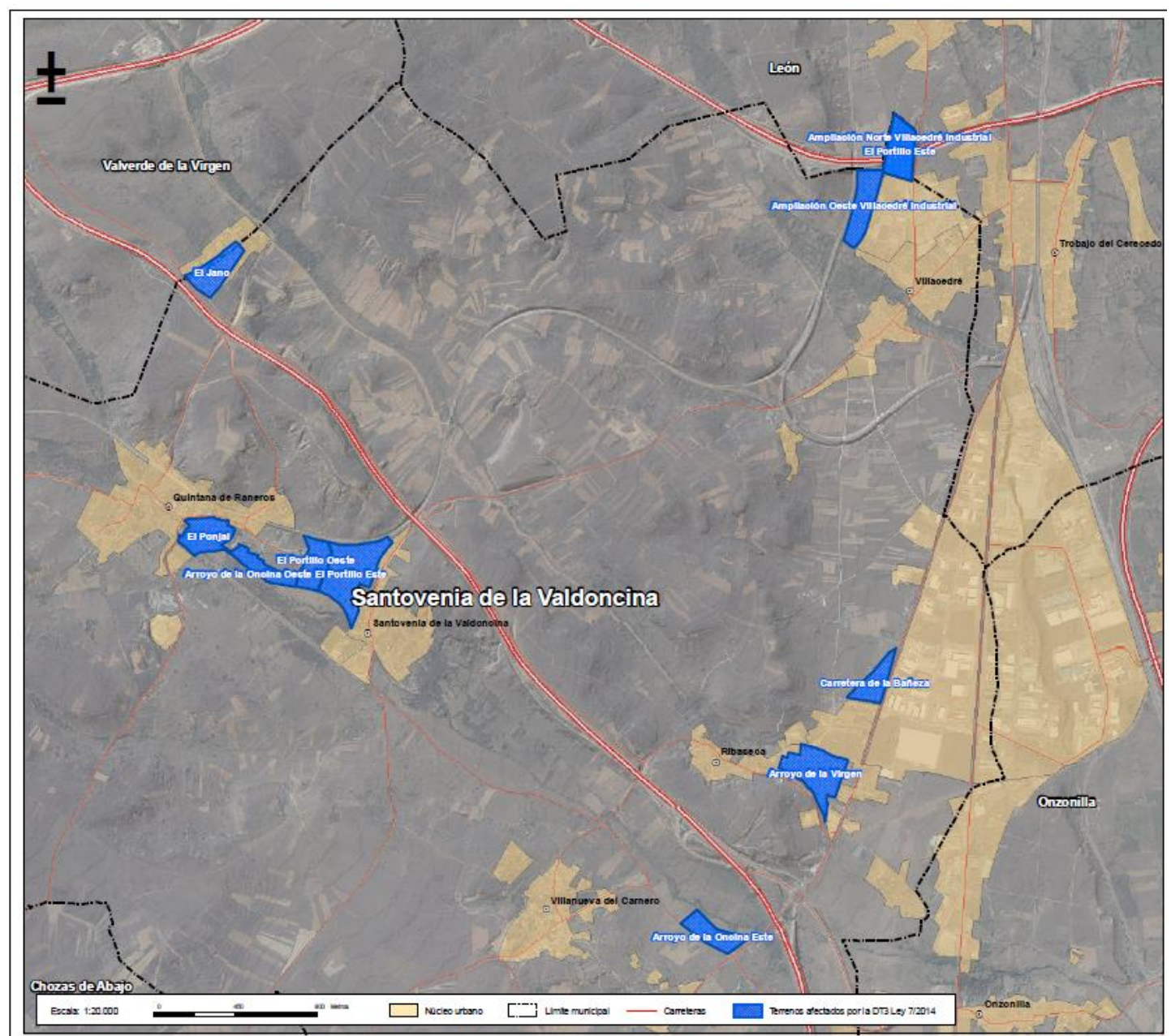

Figura 33. Sectores de Suelo Urbanizable desclasificados en 2016 en Santovenia de la Valdoncina.

Fuente: Junta de Castilla y León (2016): "Fichas de municipios de terrenos desclasificados. Apartado A". https://vivienda.jcyl.es/web/es/urbanismo-ordenacion-territorio/desclasificacion-suelo-urbanizable.html

En el área urbana de León, esta segunda ronda afectó a 454,9 ha, repartidas en 9 paquetes en los 3 únicos municipios que habían clasificado bolsas significativas de Suelo Urbanizable No Delimitado.

\begin{tabular}{|}
$\mid$\begin{tabular}{|l|l|l|}
\hline \multicolumn{1}{|c|}{ TERRENOS AFECTADOS POR EL APARTADO b) DE LA DISPOSICIÓN TRANSITORIA TERCERA DE LA LEY 7/2014 } \\
\hline \multicolumn{1}{|c|}{ M UNICIPIO } & \multicolumn{1}{c|}{ USO } & \multicolumn{1}{c|}{ Superficie } \\
(m2)
\end{tabular} \\
\hline Sariegos & SURND/ SN O1 & Residencial & 2.658 .100 \\
\hline Valdefresno & Residencial & 233.800 \\
\hline Valdefresno & SURND Arcahuejas & 473.999 \\
\hline Valverde de la Virgen & SURND Colindante a León/Villaquilambre & Residencial & 109.389 \\
\hline Valverde de la Virgen & SUZN 1 & Residencial & 138.407 \\
\hline Valverde de la Virgen & SUZN 2 & Residencial & 214.308 \\
\hline Valverde de la Virgen & SUZN 4 & Residencial & 281.991 \\
\hline Valverde de la Virgen & SUZN 5 & Industrial & 378.275 \\
\hline Valverde de la Virgen & SUZN 6 & Residencial & 61.075 \\
\hline Total Area Urbana León & & Residencial & $\mathbf{4 . 5 4 9 . 3 4 4}$ \\
\hline
\end{tabular}

Figura 34. Terrenos afectados por la segunda ronda de desclasificación de suelo el 19 de octubre de 2018, en virtud del apartado b) de la DT Tercera de la Ley 7/2014.

Fuente: Elaboración propia a partir de Junta de Castilla y León (2018): "Fichas de municipios de terrenos desclasificados. Apartado B". https://vivienda.jcyl.es/web/es/urbanismo-ordenacion-territorio/desclasificacion-suelo-urbanizable.html 
Sariegos es un claro ejemplo de la aplicación del credo de la liberalización del suelo y de planeamiento al límite de la capacidad. De acuerdo con el principio de asignación del carácter residual al Suelo Urbanizable, las Normas Urbanísticas Municipales (NUM) de 2001 habían clasificado como Suelo Urbanizable No Delimitado (SURND) todos los terrenos del término municipal no clasificados como Suelo Urbano o Rústico Protegido, agrupándolos en un único paquete de carácter discontinuo, con una extensión total de 265,8 ha.

Al no haberse desarrollado más que una pequeña pieza ${ }^{85}$ de este paquete, todo el resto - donde no se había dado paso alguno para iniciar su desarrollo- quedó reclasificado como Rústico en 2018.

En el caso de Valdefresno, los suelos desclasificados tienen una extensión total de 70,8 ha y se concentran en dos localizaciones: la primera, en el borde con el término municipal de Villaquilambre, donde las NUM de 2003 habían previsto un desarrollo lineal paralelo a este borde, aprovechando la existencia de una vía de acceso la urbanización de vivienda unifamiliar de Las Lomas, previamente existente. Del rosario de piezas de toda esta banda de Las Lomas, en el momento de entrada en vigor de la segunda ronda de desclasificación, se habían aprobado ya 2 pequeños Planes Parciales (PP San Benito y PP Las Quintas), donde incluso se había ejecutado la urbanización e iniciado la construcción de algunas viviendas. Otras 2 piezas tenían PP aprobado, pero no se había iniciado aún la urbanización: el sector SUND Las Lomas II (con PP aprobado el 12/09/2006) y el Plan Parcial del Sector Lomas Norte (de fecha $31 / 03 / 2009$ ). Esta última pieza es muy relevante, pues tiene un tamaño considerable de 47,7 ha y una capacidad prevista mínima de 943 y máxima de 1.415 viviendas. Finalmente, restaban otras 3 piezas sin planeamiento de desarrollo aprobado, que fueron las desclasificadas en 2018 , con una superficie total de 47,3 ha.

\footnotetext{
85 El sector Valdejarán I, promovido por ROLOGAR Inmobiliaria, con Plan Parcial aprobado el 27 de junio de 2008 , delimitando primero el sector correspondiente y estableciendo después su ordenación detallada. Su superficie es de 5,6 Has y las viviendas previstas 86 .
} 


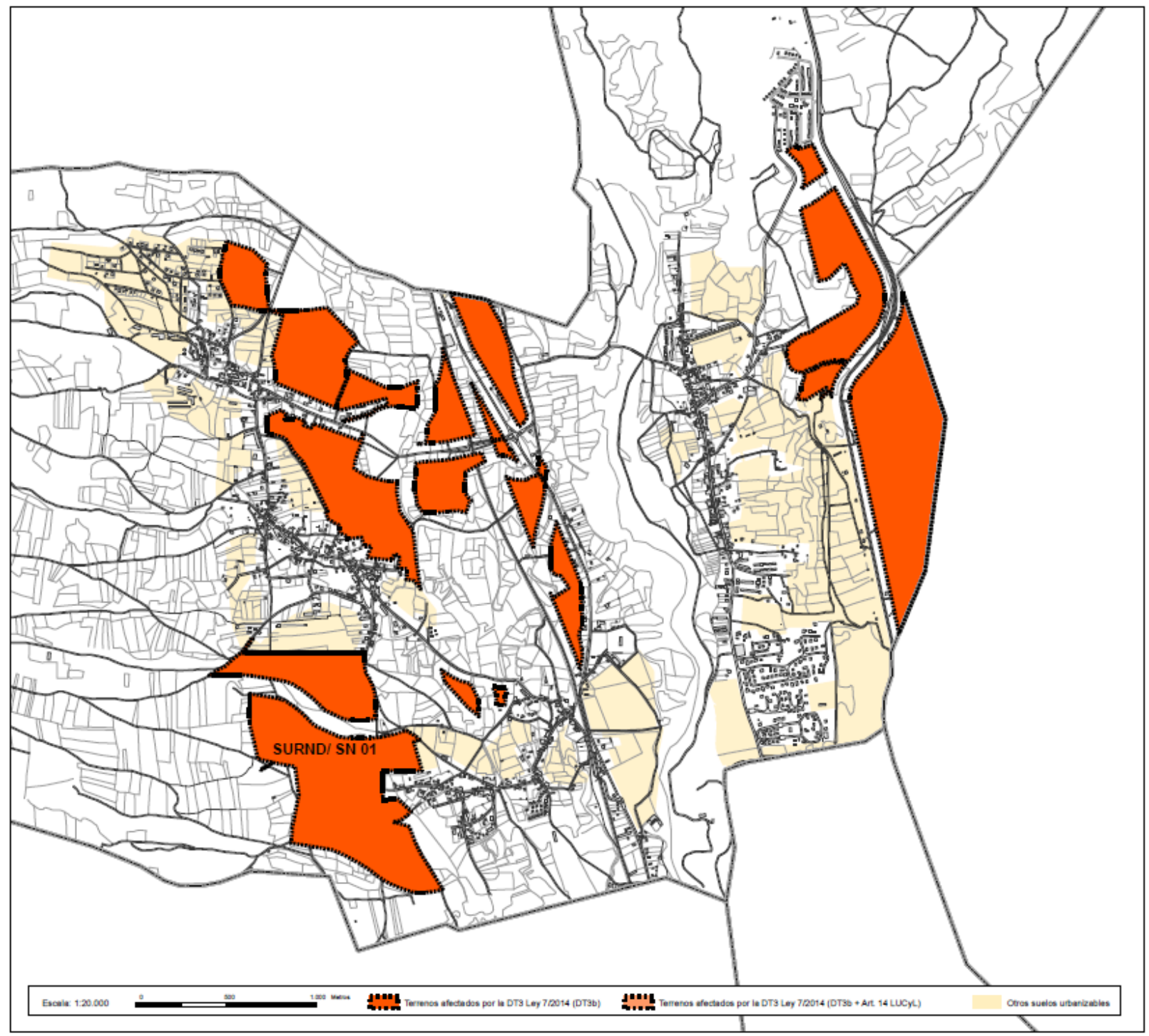

Figura 35. Suelo Urbanizable No Delimitado (SURND) desclasificado en 2018 en Sariegos.

Fuente: Junta de Castilla y León (2018): "Fichas de municipios de terrenos desclasificados. Apartado B". https://vivienda.jcyl.es/web/es/urbanismo-ordenacion-territorio/desclasificacion-suelo-urbanizable.html

El segundo paquete de suelo desclasificado corresponde con la zona del SURND de Arcahuejas, donde las NUM habían previsto también una banda de desarrollo lineal, en este caso apoyándose sobre la carretera N601 a Mansilla de las Mulas (coincidente con el Camino de Santiago), articulando una serie de piezas a modo de rosario en torno a Arcahuejas y Valdelafuente, 3 de las cuales - con una extensión de 23,3 haresultaron desclasificadas por no tener aún planeamiento aprobado. 


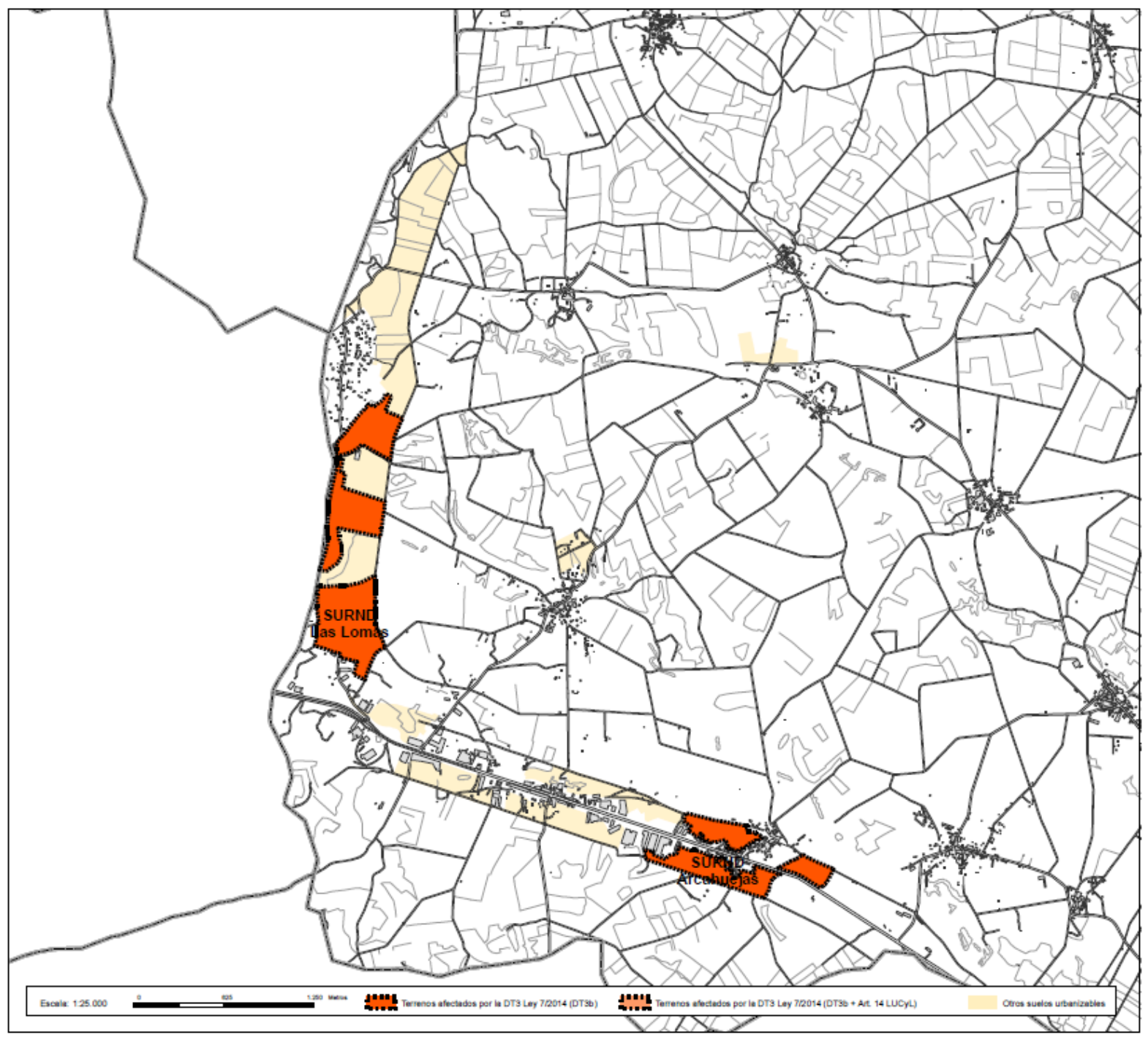

Figura 36. Suelo Urbanizable No Delimitado (SURND) Las Lomas y Arcahuejas desclasificados en 2018 en Valdefresno.

Fuente: Junta de Castilla y León (2018): "Fichas de municipios de terrenos desclasificados. Apartado B". https://vivienda.jcyl.es/web/es/urbanismo-ordenacion-territorio/desclasificacion-suelo-urbanizable.html

Finalmente, en Valverde de la Virgen, los suelos afectados por la desclasificación suman un total de 118,3 ha, divididas en 6 pequeñas bolsas correspondientes a las extensiones no desarrolladas que habían previsto las NNSS del año 2000, que además de la gran pieza del PP Campo de Golf el Cueto, ya mencionada- incluían algunos pequeños crecimientos en torno a los núcleos de La Virgen del Camino (a modo de corona norte hasta las instalaciones militares del aeropuerto), sobre la carretera N-120 junto a Valverde y San Miguel del Camino, y entre Montejos y Valverde. 


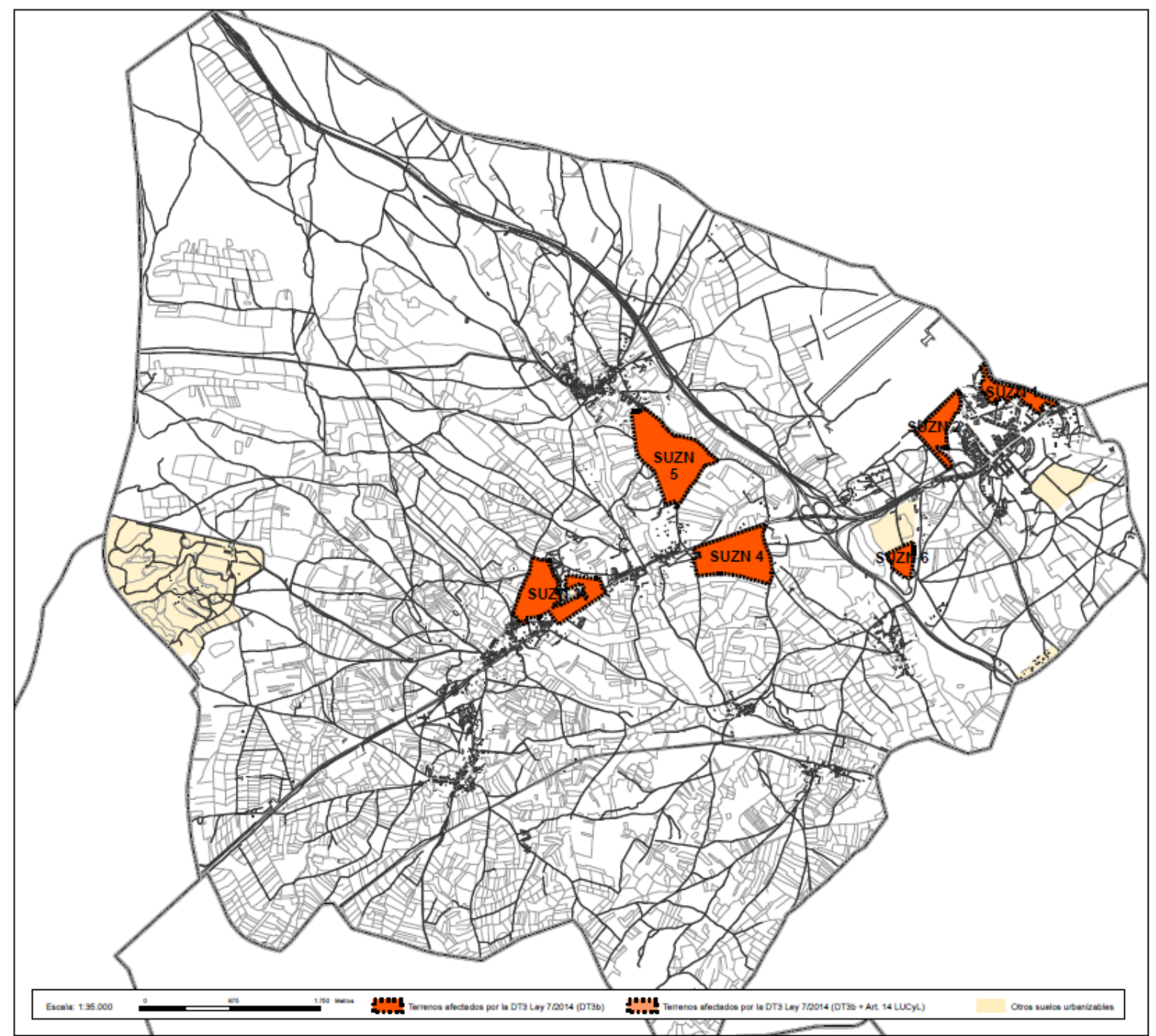

Figura 37. Suelo Urbanizable No Delimitado (SUZND) desclasificado en 2018 en Valverde de la Virgen. Fuente: Junta de Castilla y León (2018): "Fichas de municipios de terrenos desclasificados. Apartado B". https://vivienda.jcyl.es/web/es/urbanismo-ordenacion-territorio/desclasificacion-suelo-urbanizable.html

Resumiendo, el proceso en la escala regional, la desclasificación operada en 2018 fue prácticamente total, suprimiendo casi todos los suelos que se habían clasificado en su día como Suelo Urbanizable No Delimitado. Así, como reconoce el que fuera Director General de Urbanismo entre 2007 y 2019, A. Marinero (2018), "ello lleva fácilmente a la conclusión de que el proceso de clasificación de Suelo Urbanizable No Delimitado fue, en lo esencial, un error; no solo visto con una perspectiva ambientalista o aplicando criterios desarrollo sostenible, sino incluso con una visión propia de la promoción inmobiliaria: porque no se desarrolló nada o casi nada. Es más, si se piensa en que la intención del legislador de 1998 era actuar sobre los precios del suelo y la vivienda mediante el simple juego de la ley de la oferta y la demanda, el fracaso fue también total. En suma, puede decirse que el Suelo Urbanizable No Delimitado fue un error en su mismo concepto. Y la desclasificación 
de 2018 simplemente corrigió, una docena de años más tarde, un proceso esencialmente erróneo".

\section{ANÁLISIS DEL EXCESO DE SUELO CLASIFICADO PARA EL DESARROLLO URBANO EN EL ÁREA URBANA DE LEÓN Y ESTRATEGIAS A FUTURO PARA SU POSIBLE DIGESTIÓN: LAS DIFICULTADES DE UN URBANISMO CORRECTOR}

\subsection{Una primera aproximación a la cuantificación del suelo sin desarrollar}

Pero en urbanismo, los errores tienen consecuencias. En este apartado se aborda una primera aproximación a la cuantificación del suelo clasificado para el desarrollo urbano (Suelo Urbano -Consolidado y No Consolidado- y Urbanizable) a partir de los datos del Sistema de Información Urbana (SIU, 2020), del MITMA. Según los datos elaborados para los 5 municipios principales del área urbana de León, una vez desclasificado el Suelo Urbanizable anterior a 1999 y el No Delimitado sin ordenación, la superficie total clasificada para el desarrollo urbano puede estimarse en unas $5.702,9$ ha.

Dado que la clasificación del Suelo Urbano es de carácter reglado en base a unos criterios objetivos y que teóricamente en el Suelo Urbano Consolidado sus propietarios ya han cumplido con el reparto de cargas y beneficios, incluyendo la ejecución de la urbanización, es muy complicado reclasificar estos suelos, de forma que centraremos el análisis sobre las áreas en desarrollo, correspondientes a las clases de Suelo Urbano No Consolidado y Suelo Urbanizable, que -en los municipios analizados - tienen una extensión de 3.073,1 ha. Esta superficie supone más que duplicar el suelo desarrollado hasta la actualidad (es decir el Urbano Consolidado), y tiene una edificabilidad residencial máxima prevista de más de 11,6 millones de $\mathrm{m}^{2}$, capaces de albergar casi 90.000 viviendas.

El análisis de su grado de desarrollo a partir de los datos del MITMA indica que $2.122,2$ ha (el 69,1\% sobre el total) corresponden a terrenos clasificados como Suelo Urbano No Consolidado o Urbanizable, pero donde no se ha iniciado aún la urbanización. Dentro de éstos, los correspondientes al Suelo Urbanizable permanecen - a los efectos de la ley estatal en la situación de Suelo Rural o no urbanizado- y podrían ser fácilmente sujeto de una desclasificación, pasándolos de nuevo a Suelo Rústico. Como veremos más adelante, estos serían los suelos sobre los que operaría -concretamente sobre los que no tuvieran ordenación aprobada- la tercera ronda descalificación de 2022 propuesta por el apartado c) de la Disposición Transitoria Tercera de la Ley 7/2014.

El 30,9\% restante de las áreas de suelo en desarrollo han iniciado al menos la urbanización: 408,7 ha estarían en proceso de urbanización, mientras que otras 422,1 ha ya estarían urbanizadas y con algún grado de edificación (11,3 ha en proceso de edificación, 174,9 ha estarían prácticamente edificadas y otras 235,9 ha completamente consolidadas). 


\begin{tabular}{|c|c|c|c|c|c|c|c|c|c|c|c|}
\hline & \multirow[b]{2}{*}{$\begin{array}{c}\text { Suelo } \\
\text { Desarrollado } \\
\text { (Urbano } \\
\text { Consolidado) }\end{array}$} & \multirow[b]{2}{*}{\begin{tabular}{|} 
Areas de Suelo \\
en Desarrollo \\
(Urbano No \\
Consolidado y \\
Urbanizable)
\end{tabular}} & \multicolumn{2}{|c|}{ Areas de Suelo en Desarrollo } & \multirow[b]{2}{*}{$\begin{array}{c}\text { Suelo } \\
\text { Urbanizable } \\
\text { No Delimitado } \\
\text { (desclasificad } \\
\text { o 2018)+Suelo } \\
\text { Rústico }\end{array}$} & \multicolumn{6}{|c|}{ Areas de Suelo en Desarrollo (Urbano No Consolidado y Urbanizable) } \\
\hline & & & $\begin{array}{l}\text { S Urbano No } \\
\text { Consolidado }\end{array}$ & $\begin{array}{l}\text { SUrbanizable } \\
\text { Delimitado }\end{array}$ & & $\begin{array}{l}\text { Sin Iniciar la } \\
\text { Urbanización }\end{array}$ & $\%$ & $\begin{array}{c}\text { Urbanizado o } \\
\text { en proceso }\end{array}$ & $\begin{array}{c}\text { En proceso de } \\
\text { Edificación }\end{array}$ & Edificado & $\begin{array}{c}\text { Desarrollo } \\
\text { Consolidado }\end{array}$ \\
\hline LEON & $1.311,8$ & $1.512,1$ & 450,0 & $1.062,1$ & $1.075,0$ & $1.151,2$ & 76,1 & 186,5 & 11,3 & 98,7 & 72,8 \\
\hline SAN ANDRÉS DEL RABANEDO & 513,8 & 563,8 & 106,9 & 456,9 & $5.418,8$ & 546,0 & 96,8 & & & 6,3 & 10,9 \\
\hline SARIEGOS & 181,6 & 371,0 & 104,6 & 266,4 & $3.099,2$ & 166,6 & 44,9 & 86,8 & & 7,0 & \\
\hline VALVERDE DE LA VIRGEN & 239,5 & 165,8 & 10,4 & 155,4 & $5.962,6$ & 25,7 & 15,5 & 89,6 & & 47,0 & 3,6 \\
\hline VILLAQUILAMBRE & 383,1 & 460,4 & 102,8 & 357,6 & $4.607,6$ & 232,7 & 50,5 & 45,8 & & 15,9 & 148,6 \\
\hline TOTAL & $2.629,8$ & $3.073,1$ & 774,7 & $2.298,4$ & $20.163,2$ & $2.122,2$ & 69,1 & 408,7 & 11,3 & 174,9 & 235,9 \\
\hline
\end{tabular}

Figura 38. Cuadro resumen del suelo en desarrollo en el área urbana de León. Superficies y grado de consolidación. Unidades: Hectáreas (ha).

Fuente: Elaboración propia a partir de SIU.

La distribución por municipios indica grandes diferencias: por ejemplo, en el $96,8 \%$ de las áreas previstas en San Andrés del Rabanedo para el desarrollo urbano no se habría iniciado aún la urbanización, frente al caso contrario de Valverde de la Virgen, donde el $84,5 \%$ del suelo previsto ya estaría urbanizado.

En términos de capacidad residencial pendiente de ejecución, el porcentaje de viviendas por construir en toda el área urbana supone una media del $87,8 \%$ sobre las previstas, con muy pocas diferencias entre municipios; lo que, en términos absolutos arroja una capacidad de casi 80.000 viviendas.

\begin{tabular}{|l|r|r|r|r|r|r|}
\hline & \multicolumn{5}{|c|}{ Areas de Suelo en Desarrollo (Urbano No Consolidado y Urbanizable) } \\
\cline { 2 - 7 } & $\begin{array}{c}\text { Edificabilidad } \\
\text { residencial } \\
\text { prevista }\end{array}$ & $\begin{array}{c}\text { Edificabilidad } \\
\text { residencial } \\
\text { pendiente }\end{array}$ & \multicolumn{1}{c|}{$\%$} & $\begin{array}{c}\text { Número de } \\
\text { viviendas } \\
\text { previstas }\end{array}$ & $\begin{array}{c}\text { Número de } \\
\text { viviendas } \\
\text { pendientes }\end{array}$ & \multicolumn{1}{c|}{$\%$} \\
\hline LEON & 6.680 .452 & 5.615 .831 & 84,1 & 51.388 & 43.199 & 84,1 \\
\hline SAN ANDRÉS DEL RABANEDO & 2.127 .307 & 2.058 .395 & 96,8 & 16.364 & 15.834 & 96,8 \\
\hline SARIEGOS & 1.327 .886 & 1.227 .334 & 92,4 & 10.215 & 9.441 & 92,4 \\
\hline VALVERDE DE LA VIRGEN & 388.405 & 348.486 & 89,7 & 2.988 & 2.681 & 89,7 \\
\hline VILLAQUILAMBRE & 1.091 .878 & 948.635 & 86,9 & 8.399 & 7.297 & 86,9 \\
\hline TOTAL & $\mathbf{1 1 . 6 1 5 . 9 2 8}$ & $\mathbf{1 0 . 1 9 8 . 6 8 1}$ & $\mathbf{8 7 , 8}$ & $\mathbf{8 9 . 3 5 4}$ & $\mathbf{7 8 . 4 5 2}$ & $\mathbf{8 7 , 8}$ \\
\hline
\end{tabular}

Figura 39. Cuadro resumen del suelo en desarrollo en el área urbana de León. Edificabilidad y número de viviendas. Unidades Edificabilidad: $\mathrm{m}^{2} \mathrm{c} / \mathrm{m}^{2} \mathrm{~s}$.

Fuente: Elaboración propia a partir de SIU.

\subsection{Análisis del grado de consolidación de las piezas con más de 1.000 viviendas previstas: identificación de situaciones tipo}

A continuación, se presenta el análisis del grado de consolidación de las piezas residenciales en Suelo Urbanizable o Urbano No Consolidado con más de 1.000 de viviendas de capacidad según el planeamiento, que suponen un total de 767,5 ha, con una capacidad para 27.000 viviendas. A modo de resumen se identifican 3 situaciones tipo: en primer lugar, los sectores sin urbanizar (en color verde en el cuadro), que concentran casi la mitad de la superficie $(364,8$ ha) y de las viviendas a construir (13.976 unidades). En segundo, los sectores en proceso de urbanización (color ocre), con muy diferentes grados de ejecución, que suman 210,8 ha con 9.925 viviendas. Finalmente, los completamente urbanizados y en proceso de edificación 
(color gris), que ocupan 191,9 ha y aún tienen capacidad para construir el $75 \%$ de las 3.099 viviendas previstas en ellos.

\begin{tabular}{|c|c|c|c|c|c|c|c|c|c|}
\hline Municipio & Clase Suelo & sector & Superficie (m2) & $\begin{array}{c}\text { Edificabilid ad } \\
(\mathrm{m} 2)\end{array}$ & $\begin{array}{c}\text { Grado } \\
\text { Urbanización } \\
\text { (\%) }\end{array}$ & $\begin{array}{c}\text { Grado } \\
\text { Edificación } \\
\text { [96] }\end{array}$ & $\begin{array}{l}\text { Vivi endas } \\
\text { Previ stas }\end{array}$ & $\begin{array}{l}\text { Viviend as } \\
\text { Pendientes }\end{array}$ & $\%$ \\
\hline León & Suelo Urbanizable Delimitado o Sectorizado & PP LALASTRA & 941525 & 661.440 & 71 & 30,8 & 5.088 & 3.523 & 69,2 \\
\hline León & Suelo Urbanizable Delimitado o Sectorizado & PP UNIVERSIDAD & 326.119 & 163.308 & 100 & 32,4 & 1256 & 849 & 67,6 \\
\hline León & Suelo Urbano No Consolidado & SECTOR NC1401 & 263.177 & 151.541 & 100 & 23,6 & 1166 & 891 & 76,4 \\
\hline León & Suelo Urbano No Consolidado & SECTOR NC10-02 & 228.769 & 159.574 & 52 & 6,3 & 1227 & 1150 & 93,7 \\
\hline León & Suelo Urbanizable Delimitado o Sectorizado & SECTOR UDOB-01 & 446.564 & 223.678 & 6 & 5 & 1.721 & 1635 & 95,0 \\
\hline León & Suelo Urbanizable Delimitado o Sectorizado & SECTOR UDD10-02 & 350.263 & 175.198 & -1 & 0 & 1348 & 1348 & 100,0 \\
\hline León & Suelo Urbanizable Delimitado o Sectorizado & SECTOR UD 20-01 & 695.209 & 447.737 & 1 & 0 & 3.444 & 3.443 & 100,0 \\
\hline San Andrés del Rabanedo & Suelo Urbanizable Delimitado o Sectorizado & SUZ 03 & 255.402 & 152.623 & - & 0,2 & 1174 & 1171 & 99,7 \\
\hline San Andrés del Rabanedo & Suelo Urbanizable Delimitado o Sectorizado & SUZ 04 & 248.780 & 149.059 & 1 & 0,1 & 1147 & 1.145 & 99,8 \\
\hline San Andrés del Rabanedo & Suelo Urbanizable Delimitado o Sectorizado & SUZ 05 & 277.829 & 166.526 & - & 0,9 & 1.281 & 1.269 & 99,1 \\
\hline San Andrés del Rabanedo & Suelo Urbanizable Delimitado o Sectorizado & SUZ OB & 287.710 & 143.908 & - & 0 & 1107 & 1107 & 100,0 \\
\hline San Andrés del Rabanedo & Suelo Urbanizable Delimitado o Sectorizado & SUZ 09 & 373.935 & 168.442 & - & 0 & 1296 & 1.296 & 100,0 \\
\hline San Andrés del Rabanedo & Suelo Urbanizable Delimitado o Sectorizado & SUZ 10 & 736.774 & 257.383 & - & 0 & 1980 & 1980 & 100,0 \\
\hline Sariegos & Suelo Urbanizable Delimitado o Sectorizado & SECTOR 31 en el núcleo de Carbajal & 491159 & 245.579 & 62 & 0 & 1889 & 1889 & 100,0 \\
\hline Valverde de la Virgen & Suelo Urbanizable Delimitado o Sectorizado & CAMPO DE GOLF "EL CUETO" & 1.329 .769 & 237.123 & 100 & 13,7 & $6 \pi$ & 584 & 86,3 \\
\hline Villaquilambre & Suelo Urbanizable Delimitado o Sectorizado & Villaobispo SUR-11 & 422784 & 197.466 & - & 0 & 1199 & 1.199 & 100,0 \\
\hline \multicolumn{3}{|l|}{ Sin Urbanizar } & 3.648 .686 & 1.858 .342 & 0,3 & 0,1 & 13.976 & 13.958 & 99,9 \\
\hline \multicolumn{3}{|c|}{ En proceso de Urbanización } & 2.108 .017 & 1.290 .271 & 53,2 & 17,4 & 9.925 & 8.197 & 82,6 \\
\hline \multicolumn{3}{|c|}{ Urbanizado y en proceso de edificación } & 1.919 .065 & 551.972 & 100,0 & 22,0 & 3.099 & 2324 & 75,0 \\
\hline \multicolumn{3}{|c|}{ Total } & 7.675 .768 & 3.700 .585 & 39,8 & 9,4 & 27.000 & 24.479 & 90,7 \\
\hline
\end{tabular}

Figura 40. Análisis del grado de consolidación de las piezas con más de 1.000 viviendas previstas. Fuente: Elaboración propia a partir de SIU.

Como ejemplo de sector sin haber comenzado la urbanización se presenta el caso del SUZ 10 en San Andrés del Rabanedo. Tiene una extensión de 73,6 ha, con una edificabilidad máxima de $257.383 \mathrm{~m}^{2}$ y 1.980 viviendas. Dado que no se ha comenzado la urbanización ni, por supuesto, la edificación, queda pendiente por desarrollar el $100 \%$ de la edificabilidad y las viviendas previstas.
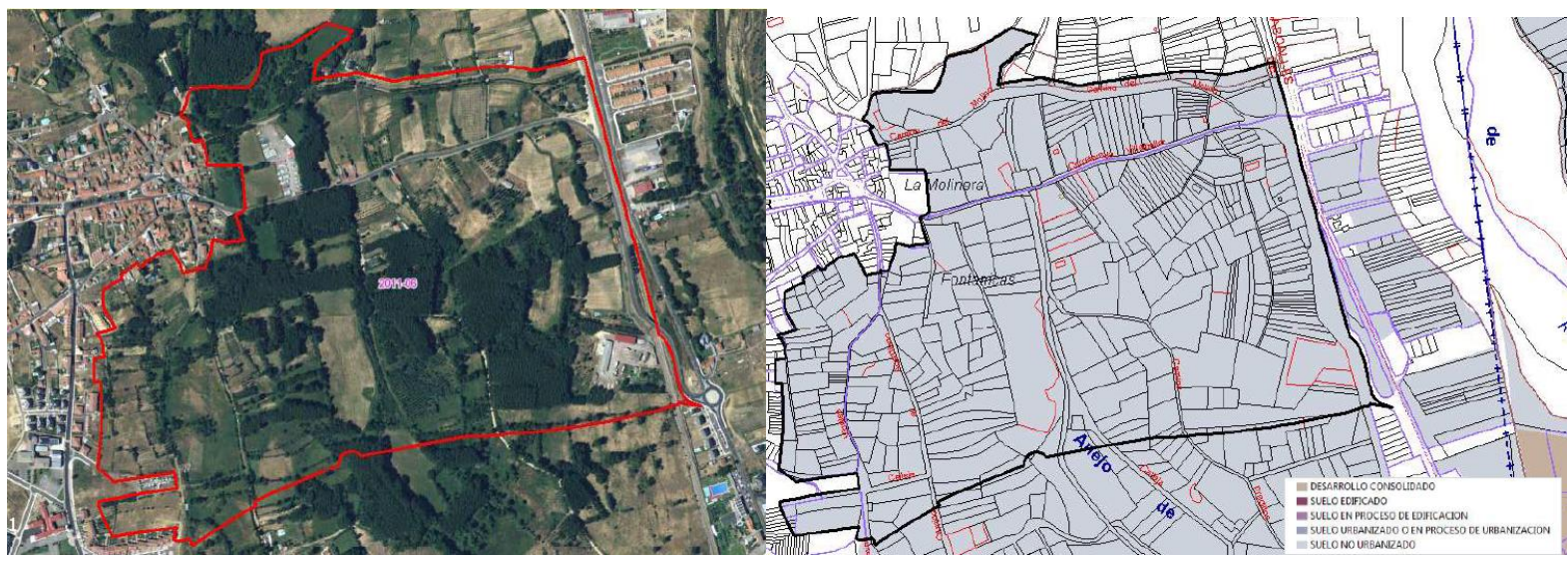

Figura 41. Imagen aérea del Sector SUZ 10 en San Andrés del Rabanedo y análisis de su grado de desarrollo.

Fuente: Ministerio de Fomento (2014). "Sectores Residenciales 2014: Estudio sobre la situación actual de ámbitos o sectores con especial potencialidad edificatoria incluidos en el Sistema de Información Urbana (SIU)". https://cpage.mpr.gob.es/producto/sectores-residenciales-2014/

Como ejemplo de sectores con la urbanización a medias de ejecutar un primer caso sería el que ejemplifica el Plan Parcial de la Lastra, en la ciudad de León. Este sector cubre una superficie de 94,1 ha, con unos techos máximos de 5.088 viviendas y $661.440 \mathrm{~m}^{2}$ de edificabilidad. Su grado de desarrollo de la urbanización es aproximadamente del $71,3 \%$ y el de la edificación del 30,8\%, quedando pendientes 
por desarrollar 3.523 viviendas. Dado el elevado grado de desarrollo y su excelente situación en la ciudad, este sector parecer tener asegurada - aunque sea en un plazo más o menos dilatado- la ejecución completa de la urbanización y la progresiva construcción de las viviendas pendientes según vaya absorbiéndose el stock y recuperándose el mercado inmobiliario.

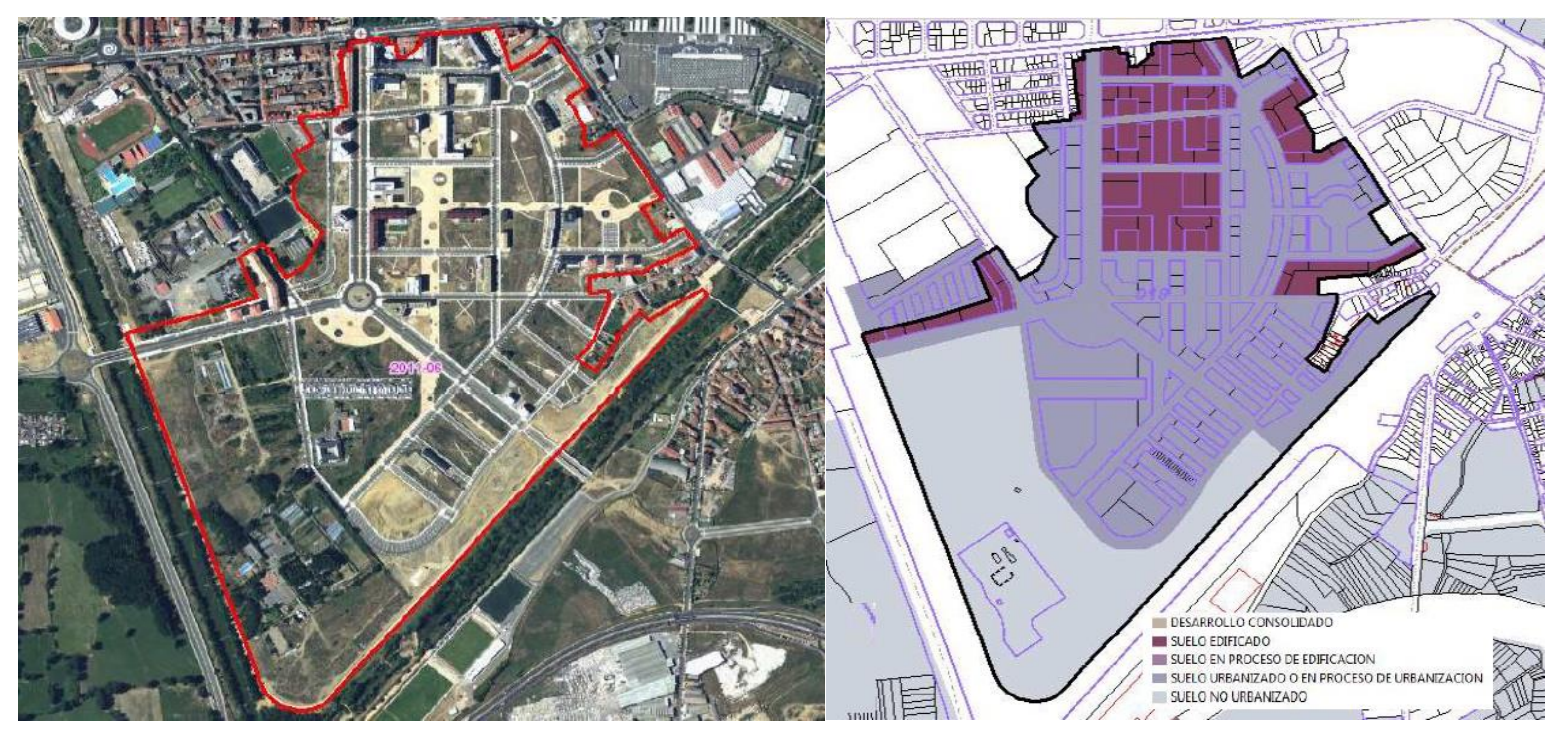

Figura 42. Imagen aérea del Sector La Lastra en León y análisis de su grado de desarrollo.

Fuente: Ministerio de Fomento (2014). "Sectores Residenciales 2014: Estudio sobre la situación actual de ámbitos o sectores con especial potencialidad edificatoria incluidos en el Sistema de Información Urbana (SIU)". https://cpage.mpr.gob.es/producto/sectoresresidenciales-2014/

Muchas más dificultades para su desarrollo tendrían otros sectores que han quedado también a medias de ejecutar, pero en localizaciones no tan bien posicionadas en el conjunto del área urbana. Este sería el caso del sector SUZ-31 en el núcleo de Carbajal de la Legua, en el municipio de Sariegos, que tiene una superficie de 49,1 ha y una edificabilidad máxima de $245.579 \mathrm{~m}^{2}$, con un techo de hasta 1.889 viviendas. En este ejemplo, la crisis inmobiliaria ha paralizado la ejecución de la urbanización en una fase muy preliminar, habiéndose realizado sólo la explanación y la pavimentación de la calle central. Teniendo en cuenta que su situación es bastante periférica en el conjunto del alfoz y que existen simultáneamente otras promociones similares en toda el área urbana de León, no está nada clara su posible reactivación aun cuando se produjera una hipotética reanimación de la demanda inmobiliaria, pues las distintas promociones del alfoz entrarían en competencia entre sí.

Finalmente, dentro de los sectores con la urbanización completamente terminada al $100 \%$ tendríamos también dos tipos de situaciones: por un lado, los sectores urbanizados en localizaciones bien posicionadas, como el Plan Parcial Universidad o el Suelo Urbano No Consolidado NC14-01 (ambos en la ciudad de León), que -con mayor o menor plazo- también seguramente se irán consolidando de forma progresiva, en paralelo a la paulatina reactivación de la demanda. 


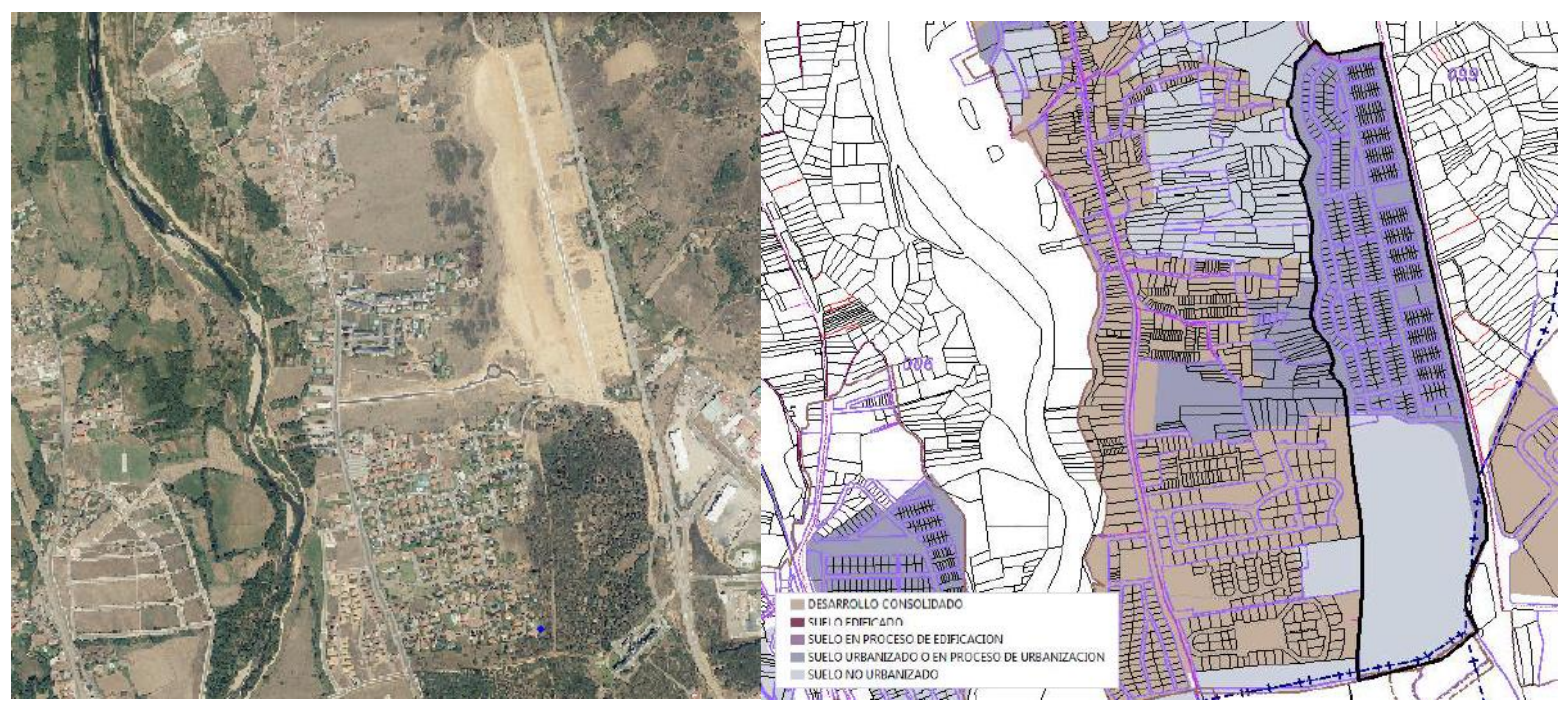

Figura 43. Imagen aérea del Sector SUZ-31 en Sariegos y análisis de su grado de desarrollo.

Fuente: Ministerio de Fomento (2014). "Sectores Residenciales 2014: Estudio sobre la situación actual de ámbitos o sectores con especial potencialidad edificatoria incluidos en el Sistema de Información Urbana (SIU)". https://cpage.mpr.gob.es/producto/sectoresresidenciales-2014/

Por otro lado, y a un pesar de tener completada la urbanización, otros sectores en ubicaciones más cuestionables, lo tendrían mucho más difícil. Es el caso del sector Campo de Golf "El Cueto", en Valverde de la Virgen. Se trata de un gran desarrollo con una superficie de 132,9 ha, una edificabilidad de $237.123 \mathrm{~m}^{2}$ y 677 viviendas previstas que ejemplifica bien el tipo de macroproyecto de urbanización residencial con un campo de golf como reclamo publicitario -distintivo de un pretendido estatus socioeconómico- que fue tan característico durante los años del boom.

El campo de golf fue previo a la urbanización, utilizándose claramente para la puesta en carga de unos terrenos sin otro atractivo más que su bajo precio para la promotora y situados en una localización bastante periférica con bastante mala accesibilidad. Como es habitual en este tipo de macroproyectos, el proceso administrativo de transformación de un suelo en principio sin interés alguno para la urbanización fue progresivo, y comenzó con la autorización de la implantación de un uso -en principio compatible- en Suelo No Urbanizable, en este caso, el campo de golf. Esta autorización fue concedida por Acuerdo de la Comisión Provincial de Urbanismo de 14 de febrero de 1991. A partir de este primer paso, los demás se iban justificando en el anterior: así, en 1992 se aprobó una Modificación Puntual de las NNSS de Valverde que tenía por objetivo no sólo ya "permitir la instalación de un campo de golf" sino además "complementariamente, paliar las necesidades de suelo para asentamientos de fin de semana, o de segunda vivienda surgidas en estos últimos años". Finalmente, en 1998 se aprobó el correspondiente Plan Parcial El Cueto, con una previsión de 677 viviendas. 
En la actualidad, aunque la urbanización ya está completada al $100 \%$, y el campo de golf ${ }^{86}$ en funcionamiento, sólo se ha materializado un $13,7 \%$ de la edificabilidad ${ }^{87}$, quedando pendientes 584 viviendas por ejecutar. De cara al futuro, no está nada claro que este tipo de producto inmobiliario (en principio planteado como de alto standing, que tuvo un cierto tirón -en muchos casos de tipo especulativo- durante el boom) pueda resultar atractivo para la demanda actual y la retenida que pueda reactivarse a medio plazo.

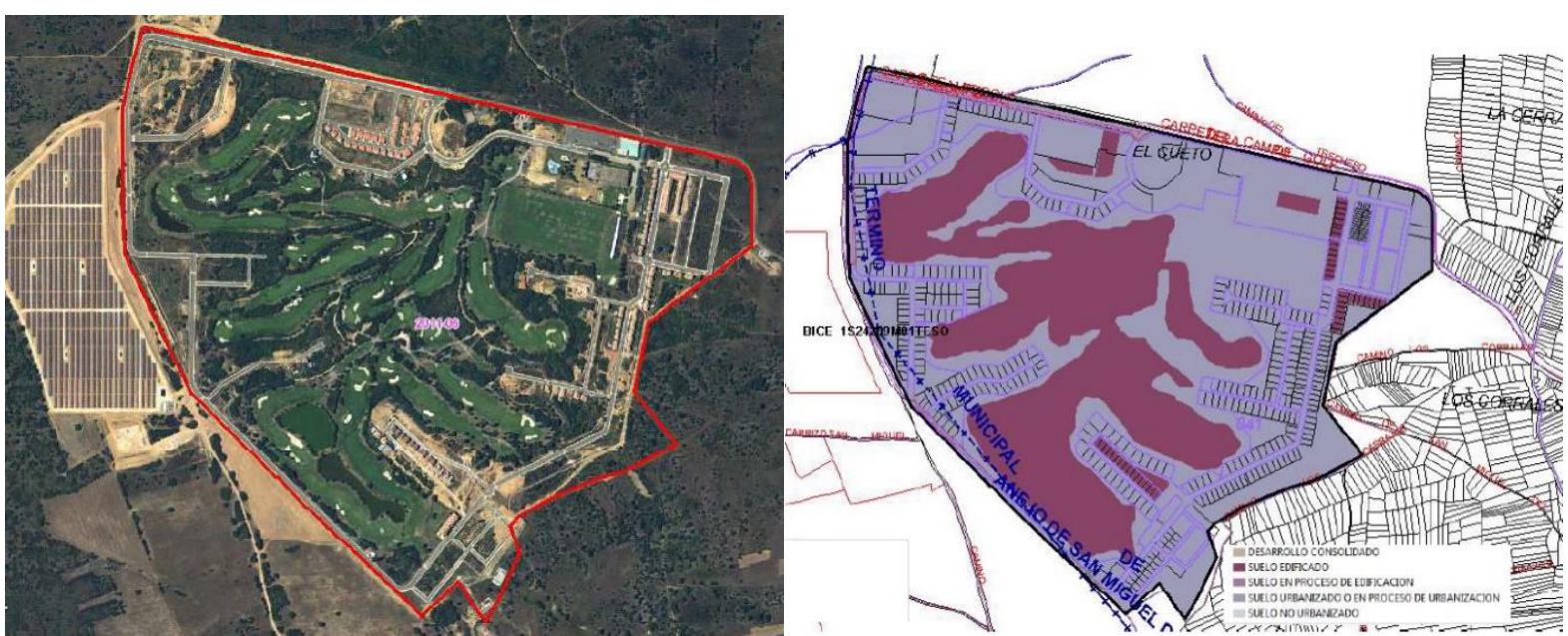

Figura 44. Imagen aérea del Sector Campo de Golf "El Cueto" en Valverde de la Virgen y análisis de su grado de desarrollo.

Fuente: Ministerio de Fomento (2014). "Sectores Residenciales 2014: Estudio sobre la situación actual de ámbitos o sectores con especial potencialidad edificatoria incluidos en el Sistema de Información Urbana (SIU)". https://cpage.mpr.gob.es/producto/sectoresresidenciales-2014/

A la vista de estos casos, y siguiendo otros trabajos anteriores (Amat, 2015; Górgolas, 2019) podemos enunciar de forma sistemática varios tipos de situaciones, en función de su grado de desarrollo, teniendo en cuenta: a) la clase y categoría de suelo (distinguiendo entre Suelo Urbano, y Urbanizable Delimitado y No Delimitado), b) si se dispone o no de ordenación pormenorizada (Plan Parcial aprobado), c) si se ha realizado o no la correspondiente equidistribución urbanística, d) si se ha ejecutado materialmente o no la urbanización, y, e) finalmente - una vez urbanizado el suelosu grado de consolidación por la edificación. Las situaciones serían las siguientes:

\footnotetext{
${ }^{86}$ El Campo León Golf tiene 18 hoyos con par 72. Cuenta también con dos putting green, un chipping green y un campo de prácticas de 350 x 120 m y 80 puestos. Asimismo, como complemento al Golf, dispone de 3 pistas de tenis, 1 de pádel, 1 pista polideportiva, 1 frontón y 1 pista de hierba de fútbol sala y una zona de recreo infantil, así como una piscina de verano. Su propietaria es Prosacyr Ocio, S.L.U., compañía del Grupo Sacyr.

${ }^{87}$ Aunque la fecha de fotointerpretación es de 2011 y la información sobre edificación de Catastro de 2014, en realidad apenas ha habido cambios desde entonces.
} 
- Suelo Urbanizable No Delimitado (o No Sectorizado, en otras CCAA) sin delimitar.

- Suelo Urbanizable Delimitado (o Sectorizado) sin ordenar.

- Suelo Urbanizable Delimitado (o Sectorizado) ordenado sin equidistribución.

- Suelo Urbanizable Delimitado (o Sectorizado) ordenado y con equidistribución.

- Suelo Urbanizado sin edificar.

- Suelo Urbanizado en proceso de edificación.

\subsection{Posibilidades de actuación en cada una de las situaciones identificadas: estrategias para un urbanismo corrector $y$ reparador}

Como es sabido, la clasificación del suelo no es inamovible. La jurisprudencia ha establecido en numerosas ocasiones que la Administración, en el ejercicio de la función pública inherente a la planificación urbanística, tiene reconocido el "ius variandi" o "derecho a modificar"88, lo que significa que puede modificarse la clasificación del suelo de acuerdo con los procedimientos legalmente establecidos para ello (normalmente, una Modificación del planeamiento, o -por supuesto- mediante la redacción de un nuevo planeamiento general).

La cuestión está en que -como también es sabido- el régimen urbanístico del suelo en España determina una serie de derechos para sus propietarios (que van adquiriéndose de forma progresiva, según se van cumpliendo los correspondientes deberes) y que la Administración no puede lesionar los derechos adquiridos sin generar indemnizaciones. En este sentido, el artículo 48 del Texto Refundido de la Ley del Suelo y Rehabilitación Urbana de 2015, regula los supuestos indemnizatorios estableciendo que "dan lugar en todo caso a derecho de indemnización las lesiones en los bienes y derechos provocada por la alteración de las condiciones de ejercicio de la ejecución de la urbanización, o de las condiciones de participación de los propietarios en ella, por cambio de la ordenación territorial o urbanística [...] siempre que se produzca antes de transcurrir los plazos previstos para su desarrollo o, transcurridos éstos, si la ejecución no se hubiere llevado a efecto por causas imputables a la Administración". Por tanto, como señala Górgolas (2019, p. 89) "para que no haya responsabilidad patrimonial de la Administración, se precisa que los promotores de las actuaciones urbanísticas hayan incurrido en el incumplimiento de los plazos establecidos para satisfacer sus deberes urbanísticos (de cesión, equidistribución, urbanización y edificación) y que, además, esta situación no sea imputable a la Administración actuante".

\footnotetext{
88 Por ejemplo, según la Sentencia del Tribunal Supremo de 22 septiembre 2011 (Recurso de Casación 1217/2008): "Esta Sala del Tribunal Supremo ha señalado en numerosas sentencias -sirvan de muestra las sentencias de 9 de marzo de 2011 (casación 3037/2008), 14 de febrero de 2007 (casación 5245/2003) y 28 de diciembre de 2005 (casación 6207 / 2002)- que la potestad para revisar o modificar el planeamiento es discrecional (ius variandi), de modo que, dentro de los márgenes establecidos en la normativa aplicable, el planificador urbanístico dispone de libertad para escoger, entre las distintas alternativas posibles, la que considere más conveniente para la mejor satisfacción del interés público".
} 
Como señala el mismo autor, hay que actuar con cautela y atendiendo a cada caso concreto, porque "muchos de los discursos que se despliegan en la actualidad, solicitando medidas de choque extremas (desclasificación de la mayor parte del Suelo Urbanizable, la desurbanización de la totalidad del Suelo Urbano vacante de edificación que no se considere preciso para satisfacer las necesidades reales de la población, etc.) no suelen tener en cuenta estas «reglas del juego», por lo que su aplicación puede hacer incurrir a las Administraciones en responsabilidades patrimoniales que devengan indemnizaciones económicas totalmente inasumibles para las maltrechas arcas públicas. Frente al, quizás excesivo, atrevimiento de estos enfoques, es recomendable actuar con sensatez y cautela, diagnosticando acertadamente la situación urbanística de partida para tomar decisiones ajustadas, racionales y mesuradas, al objeto de no gravar económicamente la acción planificadora de los ayuntamientos". (Górgolas, 2019, p. 89)

A continuación, se discuten estos supuestos en cada una de las situaciones identificadas.

\section{- Suelo Urbanizable No Delimitado (o No Sectorizado, en otras CCAA) sin delimitar.}

En este suelo, dada su concepción como suelo residual o "de reserva", mientras no se apruebe su delimitación o sectorización, el régimen aplicable en todas las CCAA es el del Suelo Rústico o No Urbanizable, de manera que cualquier alteración en su ordenación urbanística, incluso su reclasificación como Suelo Rústico, en principio no comportaría una indemnización. En el caso de Castilla y León, ya hemos visto cómo estos suelos han quedados desclasificados en el año 2018 sin mayor problema en virtud del apartado c) de la Disposición Transitoria Tercera de la Ley 7/2014.

\section{- Suelo Urbanizable Delimitado (o Sectorizado) sin ordenar.}

En estos suelos, una vez transcurridos los plazos para la redacción del correspondiente instrumento de ordenación pormenorizada (Plan Parcial) tampoco sería necesaria una indemnización por parte de la Administración. Para este tipo de situaciones, sin ejecución material ni compromisos adquiridos, la reclasificación como Suelo Rústico parece una opción clara. En este sentido, el apartado c) de la Disposición Transitoria Tercera de la Ley 7/2014, establece que el 19 de octubre de 2022 quedarán automáticamente desclasificados los sectores de Suelo Urbanizable Delimitado que no tengan aprobada su ordenación detallada de forma definitiva en esa fecha ${ }^{89}$.

\section{- Suelo Urbanizable Delimitado ordenado sin equidistribución.}

En los sectores de Suelo Urbanizable Delimitado donde se haya aprobado el Plan Parcial que realice la ordenación detallada precisa para legitimar la actividad de ejecución, pero no se haya procedido todavía a realizar la subsiguiente equidistribución de cargas y beneficios, habría que ver más concretamente si han vencido o no los plazos estipulados en el Plan de Etapas del Plan Parcial para el

\footnotetext{
${ }^{89}$ En otras CCAA sin esta previsión automática operando a nivel regional, la desclasificación debería hacerse en cada municipio mediante una Modificación del Planeamiento (en ocasiones, también denominada "innovación").
} 
cumplimiento de los deberes de cesión, equidistribución, urbanización y edificación. En caso de haber vencido, los propietarios tampoco tendrían derecho a indemnización, e incluso si no se hubiesen superado los plazos todavía, aún cabría también la desclasificación y reversión a Suelo Rústico, pues sólo sería indemnizable el coste de formulación de los documentos urbanísticos que se hubiesen elaborado. (P. Górgolas, 2019, p. 92). Aunque con carácter general parece prudente la aplicación automática del apartado c) de la Disposición Transitoria Tercera de la Ley $7 / 2014$ sólo a los suelos sin ordenación aprobada, un estudio más detallado permitiría también su extensión a los Suelos Urbanizables que, aun contando con Plan Parcial aprobado, no tuviesen aún iniciada la equidistribución.

\section{- Suelo Urbanizable Delimitado ordenado y con equidistribución.}

La progresiva adquisición de derechos en paralelo al cumplimiento de los deberes establecidos va complicando las situaciones y haciendo más difícil -pero no impidiendo- su reversión. En el caso del Suelo Urbanizable que ha alcanzado la "situación legal y real de ejecución", por contar con la ordenación pormenorizada y tener aprobado e inscrito en el Registro de la Propiedad el correspondiente instrumento de equidistribución de cargas y beneficios, la posible alteración de las determinaciones urbanísticas se complica, y mucho más una eventual desclasificación. Como recuerda Górgolas (2019, pp. 92-93) en este caso, a pesar de no haberse producido aún la modificación de la realidad física mediante la urbanización (que ya conllevaría una costosa indemnización por las obras ejecutadas), el hecho de haberse efectuado ya la equidistribución ${ }^{90}$ implica una modificación de la realidad jurídica que "desaconseja tomar decisiones que impidan el desarrollo urbanístico de la actuación, o promover cambios sustanciales en la ordenación detallada vigente". (Ibídem). El procedimiento para ello -sin duda, complejo- sería una "reparcelación inversa", que ya ha sido desarrollada legalmente por alguna CCAA ${ }^{91}$.

En cualquier caso, y como veremos a continuación -incluso en el Suelo Urbano-, siempre puede darse la posibilidad, desde el punto de vista legal, de modificar las determinaciones urbanísticas existentes, aunque ello suponga un nuevo reparto de cargas y beneficios y pueda conllevar indemnizaciones por parte de la Administración. La cuestión está en calibrar en qué situaciones compensa hacerlo.

\section{- Suelo urbanizado no edificado.}

El caso más complejo sería el de los suelos que, además del planeamiento de desarrollo y la equidistribución han completado todo el proceso, incluyendo la

\footnotetext{
$90 \mathrm{Y}$, con ella, el reparto del aprovechamiento lucrativo (y de las cargas urbanísticas) entre todos los participantes en la actuación -propietarios de suelo y/o agente urbanizador, propietarios de sistemas generales adscritos y Administración actuante- a los que, incluso, se han podido incorporar nuevos actores sobrevenidos caso de haberse realizado alguna transmisión patrimonial (venta de parcelas o manzanas).

${ }^{91}$ Castilla La Mancha: nuevo art. 59 bis, denominado procedimiento para la reversión de reparcelación, introducido en el Reglamento de la Actividad de Ejecución (Decreto 29/2011) por la modificación operada mediante el Decreto 86/2018. Comunitat Valenciana: nuevo art.164 de la Ley 5/2014, denominado reversión de la reparcelación, introducido mediante la Ley $1 / 2019$.
} 
urbanización, y por tanto se encuentran ya -a efectos legales- en la situación de urbanizado.

Para estos suelos existirían dos opciones extremas: la más radical de devolverlos a su estado previo, o la más conservadora de mantenerlos.

Para devolverlos a la situación original de Suelo Rústico serían necesarias dos operaciones: una primera de naturaleza jurídica mediante la desclasificación completa a través de una Modificación de Planeamiento, que implicaría un costoso desembolso público para indemnizar a los propietarios por el aprovechamiento urbanístico ya patrimonializado y las inversiones realizadas; y una segunda para restituir el estado natural de los terrenos, que implicaría demoler la urbanización ejecutada. En definitiva, siendo todo ello teóricamente posible, sin duda se trata de una solución de extrema complejidad y de un elevado coste económico que sólo podría ser asumible en situaciones de absoluta inconveniencia de lo ejecutado ${ }^{92}$.

La opción opuesta - que es la más habitual- sería la de su mantenimiento en barbecho hasta que el ciclo inmobiliario fuese remontando poco a poco y alimentando la demanda de construcción de nuevas viviendas en esos suelos.

Frente a estas, existen otras opciones intermedias, como la de mantener la clasificación, pero con una reprogramación temporal y un reajuste en la ordenación. Para ello conviene tener presentes dos cuestiones: la necesidad de canalizar la posible demanda que pueda generarse hacia las localizaciones más razonables desde el punto de vista territorial, lo que supone realizar una programación temporal y espacial a escala supramunicipal (reprogramación). Y, una segunda: la oportunidad de repensar la ordenación pormenorizada aprobada (reordenación). Porque, como bien señala Górgolas (2019, p. 93) "en innumerables ocasiones, este paisaje urbanizado abandonado y desatendido, pese a constituir jurídicamente un suelo urbano consolidado, presenta, en términos urbanísticos, patologías, deficiencias y disfuncionalidades que es preciso revertir. Podría decirse que se trata de un «suelo urbano consolidado equivocadamente»". En efecto, en muchos casos, estos suelos no sólo tienen una dudosa viabilidad económica, sino que ofrecen un tipo de producto inmobiliario (la vivienda unifamiliar) que no siempre se adapta a la demanda potencial ( $y$ aún menos en un contexto de crisis como el actual) y, sobre todo, responden a un modelo urbano hoy superado y criticado por su insostenibilidad propio de los años de la burbuja: baja densidad, ausencia de variedad urbana, sobredimensionamiento del viario y los espacios públicos, falta de articulación con la ciudad existente, etc. La buena noticia es que la crisis ofrece una segunda oportunidad: la paralización de estos suelos puede ofrecer una última ocasión para repensar su desastrosa ordenación y remediar o mitigar -si no todos-, al menos algunos de sus principales defectos.

\footnotetext{
92 Por ejemplo, el caso del PAI de la Zona de Actuación Logística (ZAL) La Punta del Puerto de València. Aun así, sus posibilidades de ejecución final serían seguramente escasas, por su casi segura judicialización. No hay que olvidar la tendencia que existe en nuestro país a consolidar lo existente, de forma que incluso urbanizaciones o edificaciones declaradas ilegales y con sentencia judicial de demolición, terminan encontrando vías para sobrevivir. El caso más flagrante es el de la Isla de Valdecañas, en Extremadura.
} 
Por tanto, parece razonable -para la gran mayoría de los casos- recurrir a la opción intermedia de mantenimiento con reprogramación y reordenación de estos suelos ya urbanizados. Como también señala Górgolas (2019, p. 93) "en este supuesto resultaría más conveniente plantear alteraciones puntuales y selectivas, vinculando la posibilidad de incrementar el aprovechamiento en determinadas parcelas con su liberación en otras donde localizar nuevas dotaciones y zonas verdes. De esta manera, se podrían suscitar mayores densidades netas (reformulaciones tipológicas) e hibridaciones funcionales a la búsqueda de una mejora sustancial en los índices de compacidad urbana del desarrollo urbanístico en cuestión".

La reprogramación consistiría en articular algún tipo de mecanismo -inexistente en el marco normativo actual- para reconducir la posible demanda inmobiliaria que pueda producirse en un futuro hacia los sectores de más clara viabilidad ${ }^{93}$. Una idea de partida para este instrumento podía ser una programación a escala supramunicipal, que - permitiendo ciertas holguras- fuera "llenando" primero los sectores más razonables desde el punto de vista territorial.

Las posibilidades para la reordenación son también varias:

- Evidentemente, la más expeditiva, pero también la más costosa, sería la expropiación.

- En ciertos casos, como los sectores con una estructura sencilla de la propiedad -por ejemplo, en los de propietario único, que hemos visto que son numerosos en el alfoz de León y que, salvo que haya habido compraventas, básicamente también habrán mantenido esta condición tras la reparcelación- puede ser posible abordar con relativa facilidad propuestas de reordenación profunda, trasvasando esos aprovechamientos -patrimonializados pero no materializados todavía - entre parcelas, incrementando con ello la densidad de ciertas partes al mismo tiempo que se liberan otras, donde pueden plantearse equipamientos o zonas verdes que mejoren la dotación de estos nuevos tejidos.

- En los casos más generales, la reordenación de estos suelos ya urbanizados buscando una mayor compacidad y variedad urbana- puede abordarse mediante las herramientas ya existentes en la legislación urbanística estatal y autonómica como las denominadas "actuaciones de reforma o renovación de la urbanización" y las "actuaciones de dotación"94. En realidad, esta reordenación de los suelos urbanizados vacantes debería enmarcarse en las más amplias estrategias de regeneración urbana a escala municipal que se están requiriendo desde las diferentes Agendas Urbanas (de Naciones Unidas, Europea y

\footnotetext{
93 Es posible incluso que algunos de los suelos afectados por la ronda de desclasificación obligatoria de 2022 entrasen dentro de esta categoría, por estar bien posicionados a escala territorial, y pudieran ser salvados de la desclasificación.

94 Ambas definidas en el Artículo 7 del TR de la Ley de Suelo y Regeneración Urbana de 2015 (Actuaciones de transformación urbanística y actuaciones edificatorias), apartados 1.a.2 y 1.b. Se consideran "actuaciones de dotación" "las que tengan por objeto incrementar las dotaciones públicas de un ámbito de suelo urbanizado para reajustar su proporción con la mayor edificabilidad o densidad o con los nuevos usos asignados en la ordenación urbanística a una o más parcelas del ámbito y no requieran la reforma o renovación de la urbanización de éste".
} 
Española) y desde la ERESEE $2020^{95}$. Siendo la tarea más importante del urbanismo del futuro repensar la ciudad heredada, la reordenación de los fragmentos urbanizados y no edificados heredados de la burbuja inmobiliaria debe enmarcarse en esa reflexión más amplia a escala municipal y supramunicipal, donde muchas de las tareas más urgentes (sutura de los tejidos no conectados, incremento de la compacidad y la variedad, incremento de las dotaciones y zonas verdes, etc.) son idénticas, así como los instrumentos necesarios para abordarlas.

Más allá de estos mecanismos conocidos, Górgolas (2019) ha propuesto algunos instrumentos innovadores más potentes, como el uso de las transferencias de aprovechamiento urbanístico a gran escala ${ }^{96}$, para concentrar el aprovechamiento de los sectores menos convenientes desde el punto de vista territorial en otros más pertinentes. Con ello se conseguiría aumentar la densidad media de los sectores receptores de las transferencias -que originalmente suele ser demasiado baja para garantizar una cierta eficiencia y vitalidad urbana- al tiempo que se liberarían los sectores emisarios, pudiendo ser destinados a funciones ambientales (huertos periurbanos, energías renovables, metabolismo urbano, bosques equipados captadores de $\mathrm{CO} 2$, etc.) o al patrimonio público de suelo.

\subsection{Conclusiones: las dificultades de un urbanismo corrector de los excesos de la burbuja inmobiliaria}

"En León se están urbanizando "islas" que van a quedar ahí, porque se están haciendo planes parciales situados a un kilómetro del casco urbano, sin infraestructuras intermedias. ¿Qué va a pasar con esas ciudades residenciales de 1.500 viviendas, 0 de 2.000, aisladas, solas?". Óscar García Luna (VV. AA., 2007).

"Lo más alarmante de la herencia recibida, además de su dimensión física y repercusión económica, es la parálisis de pensamiento que ha afectado, con especial intensidad, a las diferentes administraciones que, desnortadas y sin rumbo aparente, han reorientado sus políticas territoriales desde el "dejar hacer" efervescente de los años del tsunami, al "no saber qué hacer" de los años de crisis". (Górgolas, 2017 a, p. 60).

A la vista del mosaico fragmentado del planeamiento urbanístico en el área urbana de León, parece evidente que existen notorios problemas de coordinación y compatibilización, que la solución de este complejo puzle inacabado de islas sueltas no puede hacerse municipio a municipio y requiere una perspectiva de orden superior, una reflexión de escala supramunicipal.

\footnotetext{
95 Estrategia a largo plazo para la Rehabilitación Energética en el Sector de la Edificación en España 2020. https://www.mitma.gob.es/el-ministerio/planes-estrategicos/estrategia-a-largo-plazo-para-la-rehabilitacionenergetica-en-el-sector-de-la-edificacion-en-espana

${ }^{96} \mathrm{El}$ autor propone innovar para admitir un nuevo tipo de "Área de Reparto para la transferencia de aprovechamientos patrimonializables del Suelo Urbanizable". A nuestro entender, donde tendría más juego sería en el Suelo Urbano. En cualquier caso, estas transferencias ya se ensayaron en los años 90 y encontraron grandes dificultades, por su complejidad práctica.
} 
Para ello serían necesarios, al menos, dos elementos: un instrumento de ordenación territorial y un órgano de gestión supramunicipal que pudiese -primeroimpulsar esta reflexión, y -después- hacer una propuesta y poner en marcha las correspondientes medidas de actuación.

El problema no es el instrumento. Ya hemos visto cómo la Ley 10/1998 diseñó varios instrumentos de ordenación territorial en Castilla y León, entre ellos las Directrices de Ordenación de Ámbito Subregional, que se han aprobado en las áreas urbanas de otras capitales provinciales. Aunque quizá los contenidos que la ley pensó en su momento para este instrumento no cubrirían la totalidad de los retos provocados por el estallido de la burbuja, lo cierto es que este no sería un problema si realmente existiese voluntad política para ponerlas en marcha, pues el enunciado legal de sus determinaciones es suficientemente flexible como para poder incorporar las nuevas herramientas que se estimase necesario. La clave es, pues, la voluntad política: la Ley 10/1998 permite que la iniciativa de las Directrices de Ordenación de Ámbito Subregional provenga de la Junta de Castilla y León, a través de la Consejería competente en materia de Ordenación del Territorio, de las Diputaciones y Consejos Comarcales en su ámbito territorial, o de los Ayuntamientos que representen más del $50 \%$ de la población y superficie del ámbito propuesto.

La existencia de una voluntad política que tenga la iniciativa de redactar un instrumento de ordenación territorial está directamente relacionada con voluntad de crear un órgano de coordinación supramunicipal para la gestión de las medidas que este instrumento pudiera proponer. Planificación y gestión deberían ir de la mano: de nada serviría que existieran unas Directrices si no se crease simultáneamente un órgano de gestión para implementarlas. En este sentido, la Ley 7/2013, de 27 de septiembre, de Ordenación, Servicios y Gobierno del Territorio de la Comunidad de Castilla y León creó las Áreas Funcionales Estables (AFE), "espacios geográficos de carácter estable y permanente en el tiempo adecuados para constituir unidades homogéneas con potencialidades y recursos susceptibles de una utilización común, para la aplicación de los instrumentos y herramientas de ordenación territorial de escala intermedia, y para servir de base territorial óptima que propicie un especial ámbito de cooperación entre los municipios afectados mediante la posible creación de mancomunidades de interés general urbanas, que no constituyan nuevas estructuras político-administrativas más allá de las actualmente existentes". Están constituidas por el conjunto formado por una Unidad Básica de Ordenación y Servicios del Territorio Urbana (abreviado como UBOST; en la práctica, una ciudad de más de 20.000 habitantes), los municipios colindantes inmediatos y los adyacentes a estos últimos que estén a una distancia de unos $15 \mathrm{~km}$ en línea recta del municipio más poblado. Su delimitación precisa se recoge en el Decreto Ley $2 / 2014$, donde el AFE de León ${ }^{97}$ está formada por la capital y San Andrés del Rabanedo (ambas mayores de 20.000 habitantes), los municipios limítrofes de Sariegos, Villaquilambre, Valdefresno, Villaturiel, Onzonilla, Santovenia de la Valdoncina y Valverde de la

\footnotetext{
97 Véase el plano en la Figura 1.
} 
Virgen, y los exteriores de Cuadros, Garrafe de Torío, Villasabariego, Mansilla Mayor, Vega de Infanzones y Chozas de Abajo.

Por tanto, en teoría, ya existe un órgano supramunicipal de coordinación, que, además, legalmente tiene entre sus funciones "la aplicación de los instrumentos y herramientas de ordenación territorial de escala intermedia"98. Existiendo en la teoría tanto el instrumento como el órgano, lo que se echa en falta es la voluntad política para ponerlos en práctica.

Pasamos ahora a los contenidos que deberían incluirse en el correspondiente instrumento de ordenación territorial:

- El primero sería un diagnóstico de la situación actual, comprendiendo un análisis y cuantificación del grado de desarrollo de los suelos clasificados ${ }^{99}$, de acuerdo con las diferentes situaciones enunciadas, y de su capacidad residual. En paralelo, debería también abordarse un estudio de la demanda retenida durante los últimos años, como consecuencia del estallido de la burbuja y la crisis del Covid-19.

- El cruce de estas estimaciones de demanda de vivienda y suelo con la oferta de suelo existente, debería permitir abrir una reflexión sobre la viabilidad de las piezas de suelo clasificado por todo el tablero del alfoz. A partir de aquí sería necesario un debate sobre la priorización, secuenciación y programación de estas piezas.

En este sentido, y dado que ya existe un calendario legal para la desclasificación, habría que comenzar revisando la pertinencia del apartado c) de la Disposición Transitoria Tercera de la Ley 7/2014, según el cual el 19 de octubre de 2022 quedarán desclasificados los Suelos Urbanizables Delimitados que no tengan aprobada su ordenación pormenorizada. A pesar de los reclamos (y presiones) a la Junta, por parte de algunos promotores y propietarios de suelo, para "indultar" estos sectores ${ }^{100}$, y de los intentos desesperados de otros por aprobar a toda costa el planeamiento de desarrollo como salvoconducto para sostener la esperanza del negocio urbanístico en el futuro ${ }^{101}$, no cabe duda

\footnotetext{
98 Existe también la Mancomunidad de Interés General Urbana de León y Alfoz (declarada de interés general y publicados sus estatutos el 30 de noviembre de 2020, dando continuidad a la mancomunidad inicialmente creada para la recogida y tratamiento de RSU), conformada por los municipios de León, San Andrés del Rabanedo, Villaquilambre, Santovenia de la Valdoncina, Cuadros, Chozas de Abajo, Sariegos y Valverde de la Virgen. Sus órganos de gobierno son: la Asamblea de Concejales, el Consejo Directivo, el Presidente y la Comisión Especial de Cuentas. Entre sus competencias y funciones se encuentran la prestación de servicios públicos básicos; actuaciones de protección y promoción social; producción de servicios públicos de carácter preferente; actuaciones de carácter económico; y servicio de taxis en zona de prestación conjunta.

99 Deberían incluirse no sólo los Suelos Urbanizables y Urbanos No Consolidados, sino también los Urbanos Consolidados, pues existen casos - como el de Estrella de Izar- en que, a pesar de su clasificación como Urbano, la urbanización está sin ejecutar.

100 Como señala A. Marinero (2018): "En sentido contrario, desde sectores empresariales o asociaciones de propietarios se reclama un cambio en la legislación urbanística mediante el cual se "indulten" definitivamente estos sectores que aún conservan su condición de urbanizables, sabiendo que hay tiempo suficiente para ello en el marco de la legislatura 2019-2023, y que se dé por cerrado el proceso de desclasificación. Se aduce en favor de esta opción que la crisis quedó atrás, y que es necesario de nuevo disponer de una provisión suficiente de suelo urbanizable para encauzar el crecimiento urbano." En fin, los argumentos expansionistas siempre terminan regresando...

101 Ante la cercanía del plazo, algunos propietarios de suelo están comenzando a mostrar interés por aprobar los planes de desarrollo o a remover proyectos a medio tramitar que estaban paralizados. El caso más mediático es el
} 
de que lo suyo sería incluso repensar la viabilidad de todos los sectores que no se hayan comenzado a urbanizar todavía, tengan o no su ordenación aprobada, pues este hecho no es garantía de una mayor conveniencia para su desarrollo desde el punto de vista territorial.

- Además, habría que incluir también en esta reflexión sobre viabilidad -lo cual no quiere decir que finalmente se propusiese su desclasificación- otras situaciones más complejas que hemos visto: algunas áreas de suelo clasificado como urbano que en realidad no han completado la urbanización (caso de Estrella de Izar, en Garrafe); otras que, habiéndola completado, no han comenzado la edificación y tienen un escaso atractivo para el mercado (caso de la urbanización fantasma de Villatoldanos); u otras que, habiendo incluso comenzado la edificación, tienen difícil su completa consolidación a medio plazo (caso del sector El Cueto junto al Campo de Golf).

Pero la desclasificación por sí misma tampoco será la panacea. No sólo porque como se acaba de comentar- sea dudosa la efectividad de su aplicación automática en el contexto actual, sino porque devolver el suelo a su situación original sólo significaría volver a la casilla de salida. Los problemas urbanísticos que tenían originalmente los municipios antes de aprobar su planeamiento van a quedar igualmente sin resolver. Es más, hemos visto cómo varios planes urbanísticos apostaron por el crecimiento como mecanismo reparador, asignando a los sectores de Suelo Urbanizable el papel de tejidos de sutura, articulando los vacíos y discontinuidades provocados por el desorden anterior. En todos los casos, el crecimiento conllevaba nuevos Sistemas Generales de infraestructuras y equipamientos para todo el municipio cuya obtención o ejecución ahora se tornan inviables.

La desclasificación tampoco va a devolver la coherencia al planeamiento urbanístico de cada municipio, que -además- quedará "recortado". Y será necesario revisar con una nueva perspectiva estos "planes municipales recortados" en virtud de la Disposición Transitoria Tercera de la Ley $7 / 2014$, porque se hicieron con una idea -buena o mala, pero unitaria, de conjunto- que una desclasificación automática, parcial y sin otro criterio que la ausencia de planeamiento de desarrollo va a desbaratar.

En cualquier caso, como señalaba Gaja (2015, p.22) la solución debe pasar "por una revisión generalizada del planeamiento para adaptarlo a un horizonte de no crecimiento, de contención urbana, de ajuste a las verdaderas necesidades, con una demografía a la baja, y con un parque acumulado de vivienda, que excede de las demandas previsibles en el más expansivo de los escenarios".

sector SUR-D04 Cerro de los Moros, en Soria. Véase "El Ayuntamiento abandona el Cerro de los Moros" en Soria Noticias.com 24 de enero de 2021. https://sorianoticias.com/noticia/2021-01-24-opinion-el-ayuntamientoabandona-el-cerro-de-los-moros-74823_"Cemento sobre las orillas del Duero de Machado" en El País, 29 de enero de 2021. https://elpais.com/cultura/2021-01-28/cemento-sobre-las-orillas-del-duero-de-machado.html 
En conclusión, un urbanismo reparador y corrector de los excesos cometidos durante la burbuja inmobiliaria debe tener la "goma de borrar" como una herramienta imprescindible, pero no debe olvidarse de abordar también los grandes retos pendientes del territorio del alfoz: la organización de la movilidad en la escala conjunta del área urbana, la integración del ferrocarril, la articulación de los espacios naturales y los cauces de los ríos como grandes "infraestructuras verdes", la recualificación y densificación de los tejidos dispersos de baja densidad construidos en los últimos años, la regeneración urbana de los barrios consolidados y la rehabilitación edificatoria, etc.

La recomposición de la coherencia del mosaico fragmentado de planeamiento actual y, en futuro próximo, del mosaico de "planes recortados", va a ser necesaria desde la lógica municipal y desde la supramunicipal. Para reconducir la dolorosa herencia recibida de los años de la burbuja, habrá que diseñar los instrumentos adecuados y poner en marcha los correspondientes órganos de gestión.

\section{AGRADECIMIENTOS}

Los autores agradecen los comentarios, la información y documentación facilitada por Begoña Gonzalo Orden y Javier García Argüello, del Ayuntamiento de León.

También agradecen el carácter constructivo y los comentarios y sugerencias de los evaluadores, que han contribuido a mejorar el texto original. 


\section{BIBLIOGRAFÍA}

Burriel de Orueta, Eugenio L. (2008). "La "década prodigiosa" del urbanismo español (1997-2006)". En Diez años de cambios en el Mundo, en la Geografía y en las Ciencias Sociales, 1999-2008. Actas del X Coloquio Internacional de Geocrítica, Universidad de Barcelona, 26-30 de mayo de 2008.

Calderón Calderón, Basilio; García Cuesta, José Luis. (2017) "Legislación urbanística y planeamiento urbano en España, 1998-2015. Del despilfarro a la sostenibilidad". Scripta Nova: Revista electrónica de geografía y ciencias sociales, n 21 , págs. $560-$ 580.

Cardoso Delso, Juan Carlos (2020). "Clasificación del Suelo Urbanizable: el preciso, interpretación judicial". En Castelao, Julio; Criado, Alejandro; Jalvo, Joaquín (Coords.). La crisis del modelo urbanístico actual. Hacia el urbanismo del siglo XXI. Ed. Wolter Kluwers. El Consultor de los Ayuntamientos.

De Santiago Rodríguez, Eduardo (2012). "Una lectura de las políticas de suelo y los modelos urbanísticos madrileños desde mediados de los años 1990: de la liberalización a la resaca inmobiliaria". Geopolítica (s), vol. 3, no 1, págs. 83-116. https://doi.org/10.5209/rev_GEOP.2012.v3.n1.39303

Fariña, José; Naredo, José Manuel (Dirs.) (2010): "Libro Blanco de la Sostenibilidad en el Planeamiento Urbanístico Español", Madrid: Ministerio de la Vivienda.

Gaja, Fernando (2015). "Reparar los impactos de la burbuja constructora". Scripta Nova. Revista Electrónica de Geografía y Ciencias Sociales, vol. XIX, n 517. Accesible en: http://www.ub.es/ geocrit/sn/sn-517.pdf

García Argüello, Javier (2016). "Evolución de la planificación urbanística en los municipios del área urbana de León". Tesis doctoral leída en Universidad de León, María Jesús González González (Directora de Tesis doctoral). Accesible en: https://dialnet.unirioja.es/servlet/tesis?codigo $=67383$

García Montalvo, José (2008). De la quimera inmobiliaria al colapso financiero. Crónica de un desenlace anunciado. Barcelona: Antoni Bosch.

Górgolas, Pedro. (2019): "Del «urbanismo expansivo» al «urbanismo regenerativo»: directrices y recomendaciones para reconducir la herencia territorial de la década prodigiosa del urbanismo español". Ciudad y Territorio: Estudios Territoriales, no 199, págs. 81-100.

Jáuregui, Gurutz (1997). "Liberalismo versus neoliberalismo". El País, 26 de mayo de 1997.

Latouche, Serge (2009). Pequeño tratado del decrecimiento sereno. Barcelona: Icaria. 
López Trigal, Lorenzo; Relea Fernández, Carlos Emilio (2010): Ciudad y territorio de León: revisión y escenarios. León: Pensar la ciudad, págs. 51-65

Marinero Peral, Ángel María (2018): "Desclasificando suelo urbanizable: La experiencia de Castilla y León". Planur-e: Territorio, Urbanismo, Paisaje, Sostenibilidad y Diseño Urbano, nº 12.

MITMA (2014). Estudio sobre la situación actual de ámbitos o sectores con especial potencialidad edificatoria incluidos en el Sistema de Información Urbana (SIU). Accesible en: https://www.mitma.gob.es/arquitectura-vivienda-y-suelo/urbanismoy-politica-de-suelo/estudios-y-publicaciones/sectores-residenciales-en-espana-2014

MITMA (2020a). "SIU Sistema de Información Urbana". Accesible en: https://www.mitma.gob.es/portal-del-suelo-y-politicas-urbanas/sistema-deinformacion-urbana/sistema-de-informacion-urbana-siu

MITMA (2020b). "Áreas Urbanas en España 2020". Accesible en: https://apps.fomento.gob.es/CVP/handlers/pdfhandler.ashx?idpub=BAW080

Naredo, José Manuel (1996). La burbuja inmobiliario-financiera en la coyuntura económica reciente: (1985-1995). Madrid: Siglo XXI Editores.

Naredo, José Manuel (2006). Raíces económicas del deterioro ecológico y social. Más allá de los dogmas. Madrid: Siglo XXI Editores.

Naredo, José Manuel; y Montiel, Antonio. (2011). El Modelo Inmobiliario Español y su Culminación en el Caso Valenciano. Barcelona: Icaria Editorial.

Nel.lo, Oriol (2012). "Herencias territoriales, exploraciones geográficas y designios políticos", en Schulz-Dornburg, J., Ruinas modernas. Una topografía del lucro. Barcelona: Ambit. Servicios Editoriales. Colección Palabra y Paisaje.

Reguera Rodríguez, Antonio T. (1987). La ciudad de León en el siglo XX: teoría y práctica en el urbanismo local. León: Colegio Oficial de Arquitectos.

Reguera Rodríguez, Antonio T. (1987): La ciudad de León: análisis dialéctico de su construcción y de la política de planeamiento local. Tesis doctoral leída en Universidad de León, Emilio Murcia Navarro (Director).

Reguera Rodríguez, Antonio T. (1987): "Construcción Urbana y modelos de planificación: La ciudad de León como ejemplo". REALA Revista de Estudios de la Administración Local y Autonómica, no 234, págs. 317-354.

Rullán Salamanca, Onofre (1999). "La nueva Ley del Suelo de 1998 en el contexto del neoliberalismo postmoderno". Revista Investigaciones Geográficas, no 22, pp. 522. 
Tomé Fernández, Sergio (2019): "Shrinking cities de tamaño medio: la ciudad de León, ¿Detroit española?". En Crisis y espacios de oportunidad: retos para la Geografía: Libro de Actas, págs. 837-851.

Tribunal de Defensa de la Competencia (2005). La competencia en España: Balance y Nuevas propuestas. Madrid: Ed. Tribunal de Defensa de la Competencia.

VV. AA. (2007): Mesa Redonda posterior a la Conferencia "León en escorzo", 27 de noviembre de 2007 en el Colegio de Arquitectos de León. Accesible en Blog de Manuel Saravia:

http://urblog.org/index.php/Mundos/2008/01/10/sin_vision_de_como_quiere_ser_1 
LOS CUADERNOS DE INVESTIGACIÓN URBANÍSTICA. El Departamento de Urbanística y Ordenación del Territorio de la Escuela Técnica Superior de Arquitectura de Madrid, lleva publicando desde el año 1993 la revista Cuadernos Investigación Urbanística, (Ci[ur]), para dar a conocer trabajos de investigación realizados en el área del Urbanismo, la Ordenación Territorial, el Medio Ambiente, la Planificación Sostenible y el Paisaje. Su objetivo es la difusión de estos trabajos. La lengua preferente utilizada es el español, aunque se admiten artículos en inglés, francés, italiano y portugués.

La publicación presenta un carácter monográfico. Se trata de amplios informes de la investigación realizada que ocupan la totalidad de cada número sobre todo a aquellos investigadores que se inician, y que permite tener accesibles los aspectos más relevantes de los trabajos y conocer con bastante precisión el proceso de elaboración de los mismos. Los artículos constituyen amplios informes de una investigación realizada que tiene como objeto preferente las tesis doctorales leídas relacionadas con las temáticas del Urbanismo, la Ordenación Territorial, el Medio Ambiente, la Planificación Sostenible y el Paisaje en las condiciones que se detallan en el apartado "Publicar un trabajo".

La realización material de los Cuadernos de Investigación Urbanística está a cargo del Departamento de Urbanística y Ordenación del Territorio de la Escuela Técnica Superior de Arquitectura de Madrid. El respeto de la propiedad intelectual está garantizado, ya que el registro es siempre en su totalidad propiedad del autor $y$, en todo caso, con autorización de la entidad pública o privada que ha subvencionado la investigación. Está permitida su reproducción parcial en las condiciones establecidas por la legislación sobre propiedad intelectual citando autor, previa petición de permiso al mismo, y procedencia.

Con objeto de verificar la calidad de los trabajos publicados los originales serán sometidos a un proceso de revisión por pares de expertos pertenecientes al Comité Científico de la Red de Cuadernos de Investigación Urbanística (RCi[ur]). Cualquier universidad que lo solicite y sea admitida por el Departamento de Urbanística y Ordenación del Territorio de la Universidad Politécnica de Madrid (DUYOT) puede pertenecer a esta red. Su único compromiso es el nombramiento, como mínimo, de un miembro de esa universidad experto en el área de conocimiento del Urbanismo, la Ordenación Territorial, el Medio Ambiente, la Planificación Sostenible y el Paisaje para que forme parte del Comité Científico de la revista y cuya obligación es evaluar los trabajos que se le remitan para verificar su calidad.

A juicio del Consejo de Redacción los resúmenes de tesis o partes de tesis doctorales leídas ante el tribunal correspondiente podrán ser exceptuados de esta revisión por pares. Sin embargo, dicho Consejo tendrá que manifestarse sobre si el resumen o parte de tesis doctoral responde efectivamente a la aportación científica de la misma.

\section{NORMAS DE PUBLICACIÓN / SUBMISSION GUIDELINES}

Las condiciones para el envío de originales se pueden consultar en la página web: Manuscript Submission Guidelines:

http://polired.upm.es/index.php/ciur 


\section{CONSULTA DE NÚMEROS ANTERIORES/ACCESS TO PREVIOUS ISSUES}

La colección completa se puede consultar en siguiente página web:

The entire publication is available in the following web page:

http://polired.upm.es/index.php/ciur

\section{ÚLTIMOS NÚMEROS PUBLICADOS:}

137 Javier Zulategui Beñarán: "Hacia un diálogo entre ciudad y naturaleza. Una revisión histórica para fundamentar un futuro ambiental menos incierto", 137, 58 páginas, agosto, 2021.

136 Augusto Tovar Numpaque: "Red de autopistas urbanas. Estimación de los efectos territoriales en la Ciudad de Buenos Aires", 104 páginas, junio, 2021.

135 María Teresa Baquero Larriva: "Salud urbana, confort térmico y acústico en espacios públicos exteriores, en el marco de las ciudades amigables con los mayores", 92 páginas, abril, 2021.

134 Sonia De Gregorio Hurtado, Virginia Do Santos Coelho y Amina Baatti Boulahia: "La europeización de la política urbana en España en el periodo 2014-2020. análisis de las estrategias de desarrollo urbano sostenible integrado (EDUSI)", 100 páginas, febrero,2021.

133 Eduardo De Santiago Rodríguez y Isabel González García: "Planes urbanísticos y asentamientos tradicionales en el medio rural: el tratamiento del suelo de núcleo rural en Asturias", 102 páginas, diciembre 2020.

132 Carlos Bustamante Oleart: "La historia del viento en las ciudades", 63 páginas, octubre 2020.

131 José Jorge Peralta Arias: "Sostenibilidad urbana en el contexto latinoamericano y en el europeo", 128 páginas, agosto 2020.

130 Álvaro Cerezo Ibarrondo: "La actuación sobre el medio urbano de regeneración y renovación integrada. El nuevo paradigma de la gestión urbanística en suelo urbanizado" 95 páginas, junio 2020.

129 Emilia Román López (editora): "Seminario Internacional. Paisajes culturales de la sal artesanal en España e Iberoamérica. Estrategias e instrumentos para la planificación y gestión del patrimonio cultural [I/II]. II. Sal y cultura", 109 páginas, abril 2020.

128 Ester Higueras García (editora): "Seminario Internacional. Paisajes culturales de la sal artesanal en España e Iberoamérica. Estrategias e instrumentos para la planificación y gestión del patrimonio cultural [I/II]. I. Sal y cultura", 86 páginas, febrero 2020.

127 Eduardo de Santiago Rodríguez e Isabel González García: "El estado del planeamiento urbanístico municipal en España: Análisis de los instrumentos vigentes y de los municipios sin planeamiento", 82 páginas, diciembre 2019.

126 Maria do Carmo: "Cidade e água: Relações entre tipologías de ocupação urbana e recarga de aquíferos", 74 páginas, octubre 2019. 

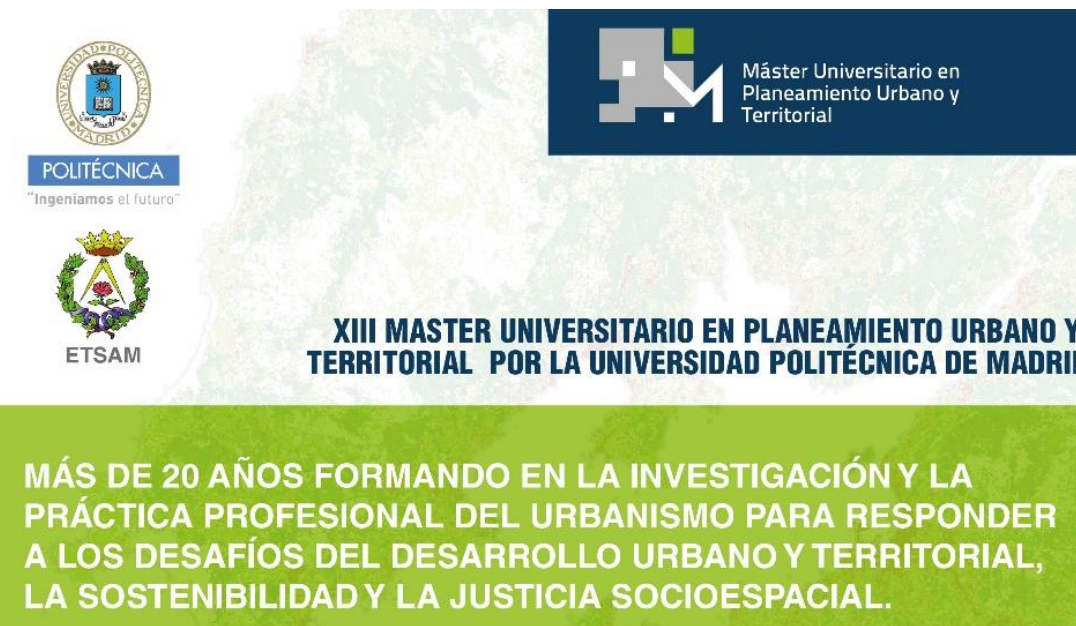

Nuestras ciudades están cambiando a un ritmo acelerado ante los retos cada vez más apremiantes de la crisis climática, la desigualdad social, la reestructuración económica y el desarrollo de nuevas tecnologias. Junto a estos desafíos, estrategias emergentes como la Agenda 2030, la Agenda Urbana Mundial o la reconstrucción post-COVID demandan una respuesta urgente por parte de los agentes implicados en la producción y ordenación del territorio. EI MUPUT prepara al alumnado para enfrentarse a estas transformaciones con un programa que combina una mirada interdisciplinar con la especialización técnica y una larga experiencia en la incorporación de enfoques innovadores, adaptados a las nuevas demandas sociales, dando también respuesta a los conflictos y oportunidades derivados de la actual pandemia.

El máster se apoya en las fortalezas del DUyOT, la ETSAM, y la UPM para ofrecer la formación de postgrado en urbanismo con mayor trayectoria en España. Durante más de 20 años el Departamento de Urbanística y Ordenación del Territorio ha formado en la investigación y la práctica profesional a un alumnado de más de 30 países, procedentes de las diversas áreas de conocimiento que se articulan en nuestra visión multidisciplinar del urbanismo. El MUPUT cuenta con certificados de calidad de AESOP (Association of European Schools of Planning) y la Fundación para el Conocimiento MADRI+D, es reconocido por la AETU (Asociación Española de Técnicos Urbanistas) y colabora con numerosas administraciones públicas y empresas para el desarrollo de sus prácticas de formación. La plantilla docente incluye a urbanistas e investigadores/as de reconocido prestigio y una prolongada experiencia a nivel nacional e internacional.

\begin{tabular}{|c|c|}
\hline 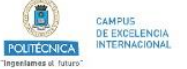 & DUyOT \\
\hline FIU & \\
\hline tuntasibriried & AETU \\
\hline 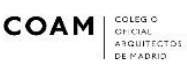 & \\
\hline
\end{tabular}

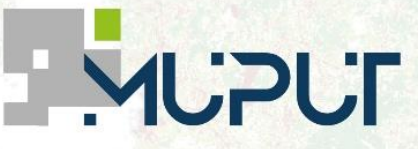

Máster Universitario en Planeamiento Urbano y Territorial

\section{Especialidad en Planeamiento Urbanístico}

Este itinerario tiene una orientación profesional y capacita al alumnado en el uso de instrumentos de análisis, nuevas tecnologías y criterios de planificación y diseño para ejercer el oficio de urbanista en organismos públicos y empresas de consultoría.

Se ofrece la oportunidad de desarrollar prácticas de formación en empresas y administraciones públicas como parte del programa lectivo. El título del MUPUT es reconocido para la admisión como miembro de AETU.

\section{Especialidad en Estudios Urbanos}

Este itinerario está orientado a la formación de investigadores/as, dotándoles de destrezas para examinar críticamente y dar respuesta a los principales retos urbanos contemporáneos a través de metodologías y marcos conceptuales avanzados.

La titulación da accese al programa de doctorado del DUyOT. El alumnado tiene la oportunidad de continuar sus carreras en el mundo académico, en observatorios urbanos y en departamentos de investigación de organismos públicos.

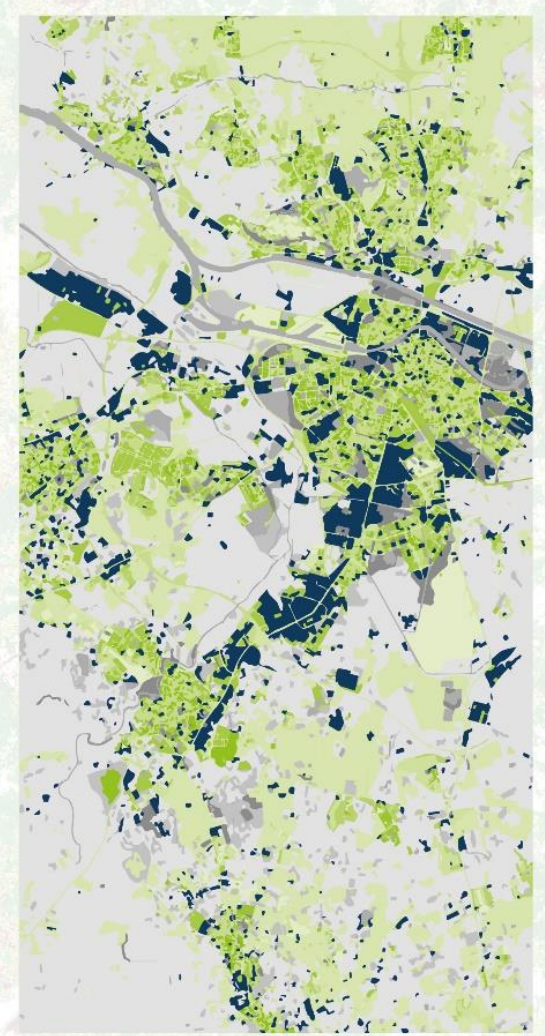

Créditos: 60 ECTS

Equipo de dirección: Director Subdirector: José Miguel Fernandez Guell Secretaria académica: Maria Cristina García González Responsable en marketing y comunicación: Inmaculada Mohrno Sanz

Profesorado: Agustin Hernández: José Miguel Fernández-Güell; José Maria Ezquiaga; Ester Higueras; Javier Ruiz; Inés Sánchez de Madariaga; Álvaro Sevilla; Andrea Alonso: Eva Alvarez; Cristina Garcia: Isabel Gonzáler; Sania De Gregorio: Francisco Lamíquiz: Emilia Román. Carmen Andrés; Llanos Masiá Lugar de impartición:
Escuela Ténica Superior de Arquitectura de Madrid

Tipo de enseñanza: Presencial

Calendario: Malriculación $1^{\circ}$ semestre / Periodo de desmatriculación: consullar web Inicio de las clases: 13 de septiembre de 2021 Presentación Trabajos Fin de Máster julio de 2022

Web oficial: hitps://duyot.zq.upmes/master/muput Contacto: masterplaneamiento arcuitecturempes

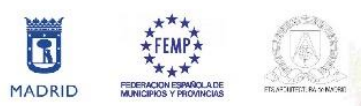


Otros medios divulgativos del Departamento de Urbanística y Ordenación del Territorio:

https://duyot.aq.upm.es/, donde figuran todas las actividades docentes, divulgativas y de investigación que se realizan en el Departamento con una actualización permanente de sus contenidos.

\section{urbain}

\section{REVISTA del DEPARTAMENTO de URBANÍSTICA Y ORDENACIÓN del TERRITORIO}

ESCUELA TÉCNICA SUPERIOR DE ARQUITECTURA

\section{Presentación Segunda ÉPOCA}

DESDE el año 1997, URBAN ha sido vehículo de expresión de la reflexión urbanística más innovadora en España y lugar de encuentro entre profesionales y académicos de todo el mundo. Durante su primera época la revista ha combinado el interés por los resultados de la investigación con la atención a la práctica profesional, especialmente en el ámbito español y la región madrileña. Sin abandonar dicha vocación de saber aplicado y localizado, la segunda época se centra en el progreso de las políticas urbanas y territoriales y la investigación científica a nivel internacional.

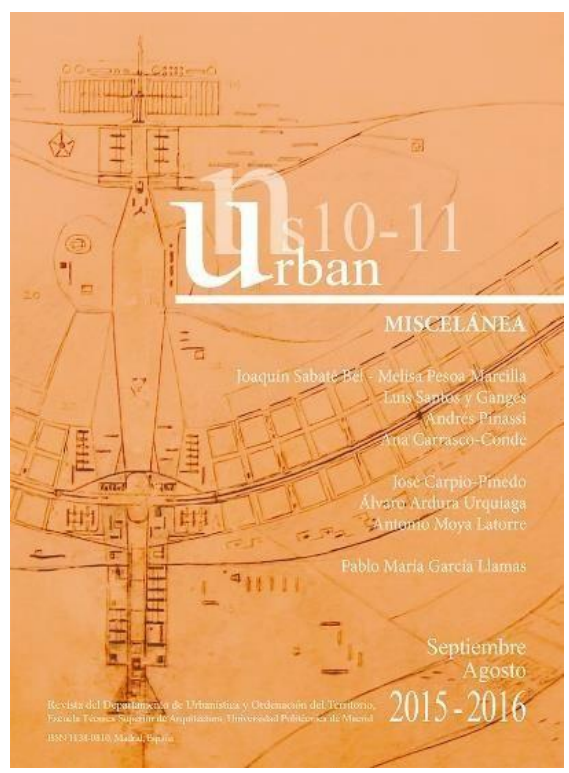




\section{lemilorios}

\section{en formación}

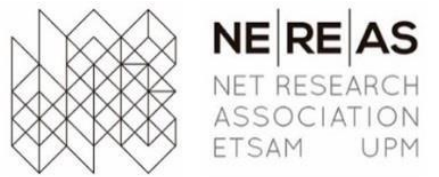

\section{ESCUELA TÉCNICA SUPERIOR DE ARQUITECTURA}

Territorios en formación constituye una plataforma de divulgación de la producción académica relacionada con los programas de postgrado del Departamento de Urbanística y Ordenación del Territorio de la ETSAM-UPM proporcionando una vía para la publicación de los artículos científicos y los trabajos de investigación del alumnado y garantizando su excelencia gracias a la constatación de que los mismos han tenido que superar un tribunal fin de máster o de los programas de doctorado del DUyOT.

Así, la publicación persigue dos objetivos: por un lado, pretende abordar la investigación dentro del ámbito de conocimiento de la Urbanística y la Ordenación del Territorio, así como la producción técnica de los programas profesionales relacionados con ellas; por otro, promueve la difusión de investigaciones o ejercicios técnicos que hayan sido planteados desde el ámbito de la formación de postgrado. En este caso es, principalmente, el Departamento de Urbanística y Ordenación del Territorio el que genera esta producción, gracias a la colaboración con la asociación Ne.Re.As. (Net Research Association / Asociación Red Investiga, asociación de investigadores de urbanismo y del territorio de la UPM), que, por acuerdo del Consejo de Departamento del DUyOT, es la encargada de la edición de la revista electrónica.

\section{DATOS DE CONTACTO}

http://polired.upm.es/index.php/territoriosenformacion
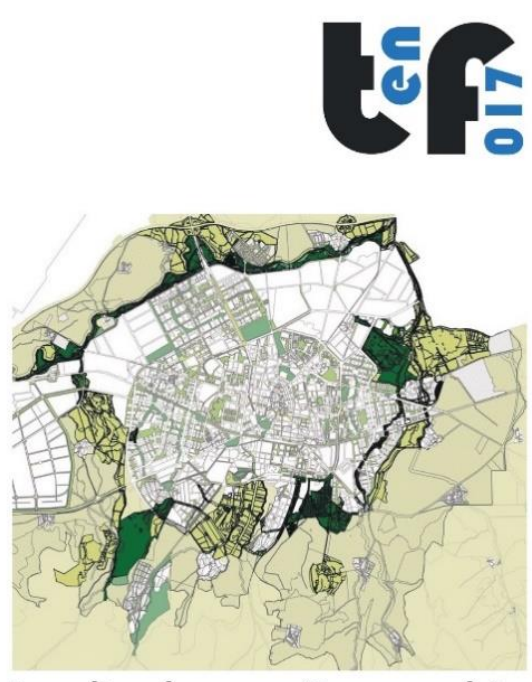

territorios en formación 